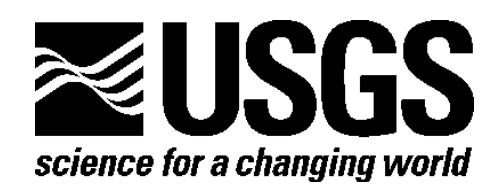

\title{
Site-Specific Seismic-Hazard Maps and Deaggregation in the Western United States Using the NGA Models for Ground-Motion Prediction
}

By Stephen Harmsen

Open-File Report 2011-1218

U.S. Department of the Interior U.S. Geological Survey 


\section{U.S. Department of the Interior \\ KEN SALAZAR, Secretary}

\section{U.S. Geological Survey \\ Marcia K. McNutt, Director}

U.S. Geological Survey, Reston, Virginia: 2011

For product and ordering information:

World Wide Web: http://www.usgs.gov/pubprod

Telephone: 1-888-ASK-USGS

For more information on the USGS—-the Federal source for science about the Earth, its natural and living resources, natural hazards, and the environment:

World Wide Web: http://www.usgs.gov

Telephone: 1-888-ASK-USGS

Any use of trade, product, or firm names is for descriptive purposes only and does not imply endorsement by the U.S. Government.

Although this report is in the public domain, permission must be secured from the individual copyright owners to reproduce any copyrighted materials contained within this report.

Suggested citation:

Harmsen, Stephen, 2011, Site-specific seismic-hazard maps and deaggregation in the western United States using the NGA models for ground-motion prediction: U.S. Geological Survey Open-File Report 2011-1218, $67 \mathrm{p}$. 


\section{Contents}

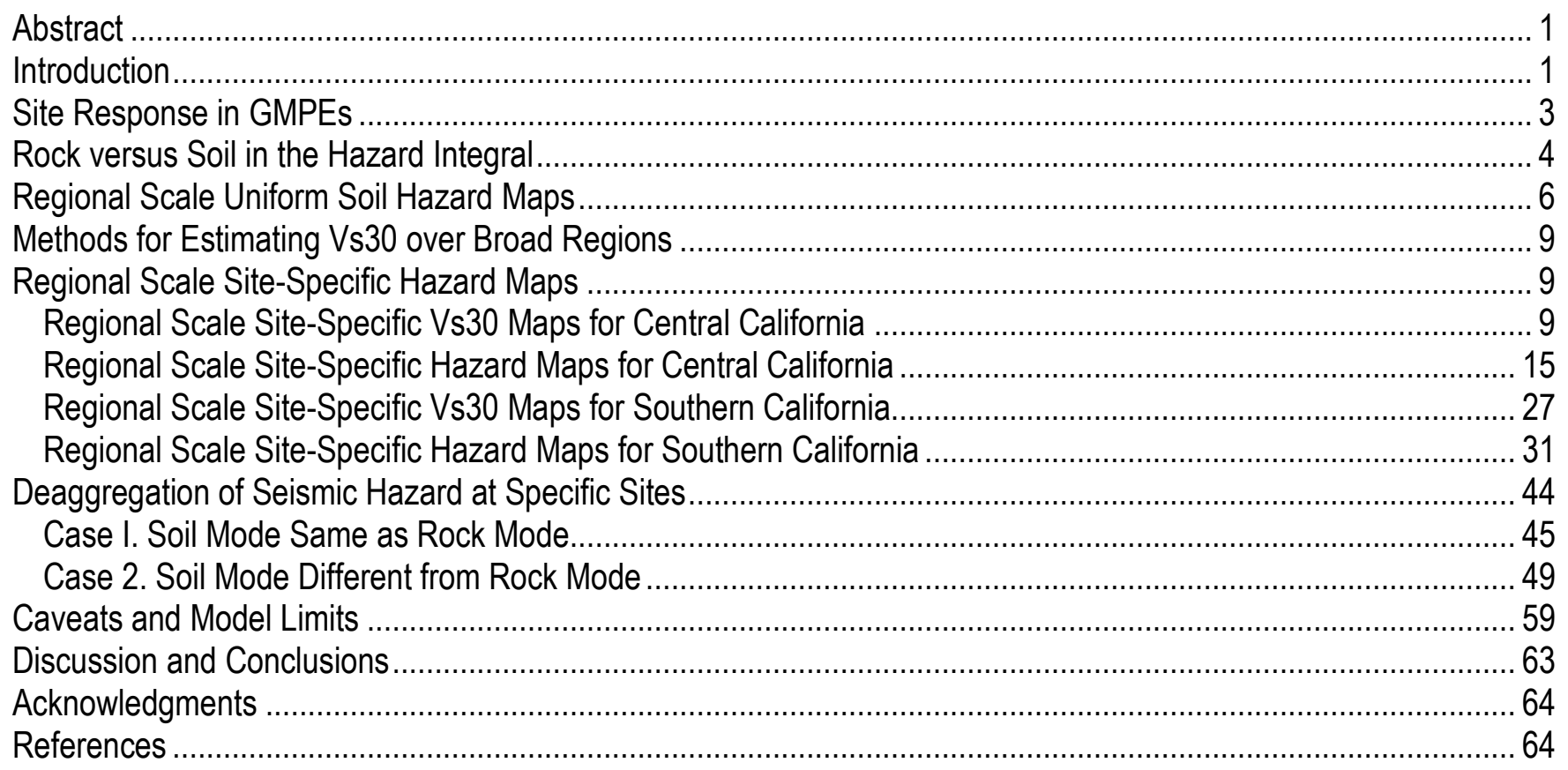

\section{Figures}

Figure 1. Schematic diagram of spectral acceleration distribution from two types of sources recorded on

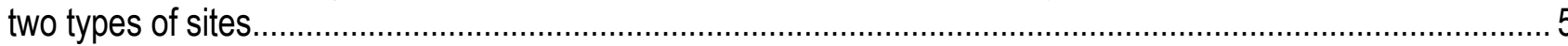

Figure 2. Spectral acceleration ratio for sites in the western United States, using the new Next Generation of Attenuation ground-motion prediction equations .................................................................

Figure 3. Regional scale site-specific Vs30 maps for central California using three methods to

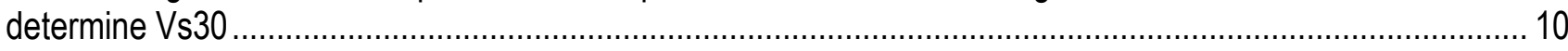

Figure 4. Regional scale site-specific hazard maps for central California, 5-hertz spectral acceleration .............. 16

Figure 5. Regional scale site-specific hazard maps for central California, 3-second spectral acceleration.......... 22

Figure 6. Regional scale site-specific Vs30 maps for southern California using three methods to

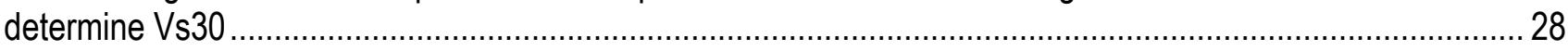

Figure 7. Regional scale site-specific hazard maps for southern California, 5-hertz spectral acceleration ........... 32

Figure 8. Regional scale site-specific hazard maps for central California, 3-second spectral acceleration........... 38

Figure 9. Map showing principal faults in the vicinity of the Los Angeles site over a base map showing the site-specific 1 -second spectral acceleration at 2 percent in 50 years probability of exceedance, using method 1 to estimate Vs30.

Figure 10. Map showing principal faults in the vicinity of a site in San Jose, California, over a contour map showing site-specific 1-second spectral acceleration with 2 percent in 50 years probability of exceedance using method 1 to estimate Vs30.

Figure 11. Rock-site hazard near San Rafael: 5-hertz spectral acceleration with 2 percent in 50 years probability of exceedance for a site with Vs 30 of 760 meters per second.

Figure 12. Soil-site hazard near San Rafael: 5 -hertz spectral acceleration with 2 percent in 50 years probability of exceedance for a site with Vs30 of 180 meters per second .....................................................5 52

Figure 13. Harbor Island 5-hertz hazard deaggregation assuming rock site condition......................................54 
Figure 14. Harbor Island 5-hertz hazard deaggregation assuming soil site condition ..................................55

Figure 15. Harbor Island 1-second spectral acceleration assuming rock site condition .................................57

Figure 16. Harbor Island 1-second spectral acceleration assuming soil site condition ..................................58

Figure 17. Scattergram of Vs100 versus Vs30 at or near 50 southern California strong-motion sites ..............6 62

\section{Tables}

Table 1. Important future earthquake sources in Los Angeles, California................................................. 45

Table 2. Seismic hazard at San Jose, California. ................................................................................. 49

Table 3. Comparison of Vs30 values measured by one of three methods (borehole, spectral analysis of surface waves, or refraction microtremor) and $\mathrm{Vs} 30$ values from three regional model values.

\section{List of Abbreviations Used in This Report}

\begin{tabular}{|c|c|}
\hline$\mu$ and $\sigma$ & $\begin{array}{l}\text { median and logarithmic standard deviation, respectively, of ground-motion prediction equation } \\
\text { gravitational acceleration at Earth surface, approximately equal to } 9.8 \mathrm{~m} / \mathrm{s}^{2}\end{array}$ \\
\hline MPE & ground-motion prediction equation, also known as attenuation equation \\
\hline $\mathrm{Hz}$ & hertz (frequency in cycles per second of seismic waves or building oscillations) \\
\hline IMW & $\begin{array}{l}\text { Intermountain West; a boundary that separates the central and western United States based on differences in } \\
\text { attenuation of seismic waves in the Earth's continental crust }\end{array}$ \\
\hline IP & Intermediate-period; generally in the range 0.5 to 2.0 seconds \\
\hline km & kilometer \\
\hline LP & long-period; generally in the range 2.5 seconds or greater \\
\hline & meter \\
\hline NEHRP & National Earthquake Hazard Reduction Program \\
\hline VGA & Next Generation of Attenuation models (developed for tectonically active regions) \\
\hline $\begin{array}{l}\text { NSHMP } \\
\text { PE }\end{array}$ & $\begin{array}{l}\text { National Seismic Hazards Mapping Project (Golden, Colorado) } \\
\text { probability of exceedence; probability that a specified ground acceleration or other intensity measure will be } \\
\text { exceeded in a specified time, such as } 50 \text { years. Typically, PE values like } 2 \% \text { in } 50 \text { years or } 10 \% \text { in } 50 \text { years are } \\
\text { considered. (Term coined for use in PSHA.) }\end{array}$ \\
\hline $\begin{array}{l}\text { PGA } \\
\text { PGV }\end{array}$ & $\begin{array}{l}\text { peak (horizontal) ground acceleration; generally, PGA is the geometric mean of the two horizontal components } \\
\text { peak (horizontal) ground velocity }\end{array}$ \\
\hline SHA & obabilistic seismic hazard analysis \\
\hline & damped pseudo spectral acceleration \\
\hline & ctral analysis of surface waves \\
\hline & ort-period; generally in the range 0.01 to 0.4 seconds \\
\hline & \\
\hline
\end{tabular}




\title{
Site-Specific Seismic-Hazard Maps and Deaggregation in the Western United States Using the NGA Models for Ground-Motion Prediction
}

\author{
By Stephen Harmsen
}

\begin{abstract}
The 2008 National Seismic Hazard Mapping Project (NSHMP) update for the conterminous United States employs several new ground-motion prediction equations which include modern empirical models of linear and nonlinear site response to local and regional earthquakes. The recent availability of attenuation functions incorporating site conditions via Vs30 values permits the calculation of site-specific hazard maps for a wide range of spectral accelerations. I compare alternative site specific hazard maps using Vs30 values estimated according to the methods of Wills and Clahan (2006), Wald and Allen (2007), and Yong and others (in press). These maps are presented for 5-hertz (Hz) and 3-second spectral accelerations having 2 percent probability of exceedance in 50 years for central California and the western part of southern California.

Because these attenuations incorporate nonlinear site response for the larger ground motions, the site-specific probabilistic ground motions for the western United States can show either increases or decreases with respect to the firm-rock site condition. Furthermore, the ground motions on soil can be different from those that are predicted by applying National Earthquake Hazard Reduction Program recommendations for adjusting rock values to account for the soil column. One finding of this investigation is that at high spectral frequencies, strong differences in the site's Vs30 estimates often result in relatively small differences in probabilistic ground motion in western California or other tectonically active regions.

In addition, this report shows how incorporating geologic site condition information alters the values of the dominating magnitudes and distances in deaggregation $-5-\mathrm{Hz}$ values for a site near San Quentin, Calif., and 5-Hz and 1-Hz values for Harbor Island near Seattle, Wash. These deaggregations show that the modal event can shift from a larger closer source to a more distant, perhaps smaller source when nonlinear soil behavior is explicitly included in the hazard integral. The potential shift in the mode when considering the soil column's effect ought to be carefully considered by engineers who select scenario events based in part on the distribution in magnitude, distance, and epsilon space.
\end{abstract}

\section{Introduction}

Seismic hazard analysis and seismic risk analysis have always been applied to sites with specific local site conditions, such as nearness to active faults, soil column properties, topography, and much more. The National Seismic Hazard Mapping Project (NSHMP) has traditionally focused its modeling effort on the estimation of probabilistic motion for a specific, albeit generic, site condition, namely, rock having average shear-wave velocity of 760 meters per second $(\mathrm{m} / \mathrm{s})$ in the upper $30 \mathrm{~m}$. Procedures for modifying probabilistic rock motion to account 
for local site conditions have been traditionally left to other agencies, such as the National Earthquake Hazard Reduction Program (NEHRP) and the Federal Emergency Planning Agency, and to members of the geotechnical consulting industry.

The NEHRP recommended provisions for seismic regulations include the standard guide for converting rock motions to soil motions, for example, table 4.1.2.4ab in Building Seismic Safety Council (BSSC) (1997). These tables list factors to apply to sites within NEHRP site classes when converting probabilistic rock motion (presumed to be associated with class B rock) to soil motion. There are two sets of factors: one for intermediate-period (IP) ground motion and one for short-period (SP) ground motion. These factors begin to address variability of response with Vs30 (through site classes) and spectral period (two-state period classification). The SP soil factors in that standard reference (Building Seismic Safety Council, 1997, table 4.1.2.4a) do not go below 0.9, that is, substantial damping of the input rock motion is not recognized. All IP soil factors (Building Seismic Safety Council, 1997, table 4.1.2.4b) are $\geq 1.3$. The basic underlying idea of the BSSC tables is that Vs30 in broad classes (A, B, C, D, and E) controls site response and that the response generally goes up with NEHRP site class.

This report performs site-specific hazard analysis using the NSHMP 2008 source model and NGA (Next Generation of Attenuation) ground-motion equations for sites in parts of California and other western United States locations. Three new NGA equations are used to perform site-specific seismic hazard deaggregation. The first equation is the Boore and Atkinson (2008) NGA model, hereafter designated BA08. A modified version of the Choi and Stewart (2005) site-response model is used in BA08. The second equation is from Chiou and Youngs (2008), designated CY08. The CY08 equation incorporates a new site-response model that at each input period $T$ captures many salient features of site amplification on soft and firm soil. The third equation is from Campbell and Bozorgnia (2008), designated CB08. The CB08 models site response using a functional form developed by Walling and others (2008). In contrast to the tables in BSSC (1997), $\mu$ and $\sigma$ in the NGA ground-motion prediction equations (GMPEs) exhibit continuous variation with Vs30, ground-motion input, and other factors. Next Generation of Attenuation GMPEs attempt to capture a broad range of observed soil response and in this way may be superior to earlier simplified models. In several NGA site-response models, IP soil amplification can be unity or less, and SP signal deamplification through the soil column can be substantial, in some instances reducing the probabilistic motion to half the input rock motion. To perform site-specific hazard analysis, several models of the local site condition, parameterized by Vs30, are considered and compared. Some caveats regarding the adequacy of this parameterization are discussed in a later section.

Many regional Probabilistic Seismic Hazard Analysis (PSHA) studies have incorporated soil response in various ways. Engineers have long requested more sophisticated soil-response models than those used in GMPEs predating the NGA. Earlier GMPEs, such as Boore and others (1997), explicitly model site response as a monotonically increasing amplification with decreasing Vs30 but without the nonlinear damping feature. Other earlier GMPEs, such as Sadigh and others (1997) and McGuire (2004), include soil-damping features but categorize sites broadly (rock or soil) and are not sensitive to the degree of soil firmness or thickness, which are often important for assessing variation in soil amplification and damping. To add realism to site response modeling, many geotechnical analyses perform exhaustive scenario development, where the scenarios vary the soil column properties - for example, shear-wave modulus reduction and damping - over their ranges of uncertainty. Such studies tend to entail considerable expense and result in amplification factors that are applied to input rock motion. 
While the approach taken in this study is not designed to replace comprehensive soil-column analysis, it exercises the most recently developed capabilities of the NGA equations. In particular, this analysis computes probabilistic ground motions "inside the hazard integral," which in some ways is a superior method to subsequent modification of the rock probabilistic motion to account for local site conditions (Bazzurro and Cornell, 2004).

\section{Site Response in GMPEs}

Seismological investigators have long recognized that local geology underlying the site and vicinity often strongly affects the character (amplitude, phase, duration) of ground motion recorded from near and distant earthquakes. The Loma Prieta earthquake of 1989 provided evidence that soft soils - for example, those at the man-made Treasure Island in San Francisco Bay - could behave in dramatically nonlinear ways, initially amplifying the seismic signal, then liquefying and deamplifying the signal (Chin and Aki, 1991; Hanks and Brady, 1991). A consensus view is that much of local geology's influence may be captured by a few parameters such as Vs30, the average shear-wave velocity in the top $30 \mathrm{~m}$, and depth to basement or bedrock, variously defined as the depth where $1,000-2,500 \mathrm{~m} / \mathrm{s}$ sustained shear-wave velocity is found (Power and others, 2008). Decades of study of seismic response of many soil columns, in both in situ and laboratory settings, has resulted in the development of empirical soil-response models, such as Choi and Stewart (2005), whose purpose is to predict peak ground acceleration (PGA) and spectral acceleration (SA) given the rock PGA at the base of the soil column, accounting for both damping dependent on ground motion and shear modulus reduction in the soil column.

The most recent NSHMP U.S. seismic-hazard update (Petersen and others, 2008) uses three NGA models to model ground vibration from sources in the western United States: BA08, CB08, and CY08. The soil-response parts of these three models (briefly outlined above), along with other features, are discussed by the respective authors. All of the NGA soil-response models contain nonlinear damping features. The BA08 model assumes that only the median ground motion is affected by local geology, but the CB08 and CY08 models, however, indicate that damping mechanisms in the soil column also reduce $\sigma_{\mathrm{T}}$, the total aleatory uncertainty in ground motion. Heuristically, larger-than-median input motions at the base of the soil column dampen more, and smaller-than-median ground motions dampen less as they traverse the soil column. A fourth NGA relation, that of Abrahamson and Silva (2008), also develops a new model of nonlinear soil response, but their GMPE was not used in the NSHMP 2008 update (due to time constraints) nor is it used in this report.

Nonlinear soil behavior in the NGA models includes a limited degree of ground-vibration damping at intermediate spectral periods (IP, 0.5-2 s, and peak ground velocity [PGV]) and significant damping at short periods (SP, 0.01-0.3 s, and PGA). For motions in the IP band, soil amplification (that is, amplification of the seismic shear-wave input at the base of the soil column) is not as strong for high ground-motion input as for low ground-motion input, whereas for SP motions, soil de-amplification is significant (reduction of a factor of 2, for example). A summary of these effects is graphed in Campbell and Bozorgnia (2008, fig. 13). 


\section{Rock versus Soil in the Hazard Integral}

The basic seismic-hazard equation associated with a specific GMPE may be written

$$
v\left[S A>s a_{0}\right]=\sum_{i=1}^{n} w_{i} \lambda_{i} \int_{s a_{0}}^{s a_{3}} \operatorname{Pr}\left[s \mid \mathrm{S}_{i}, R_{v}\right] d s
$$

where $n$ is the number of sources, indexed $S_{i}$, and $R_{v}$ is the receiver's local site condition, parameterized as Vs30, depth to bedrock, and perhaps other variables.

Further, $v$ is the mean annual rate of ground-motion exceedances from the set of sources $\left\{S_{i}\right\}$ in the model. The integral factor is the probability of exceedance of a specific logged ground-motion value, here specified as $s a_{0}$, and is fully computable for each GMPE. Spectral acceleration, $S A$ in equation 1, refers in this report to pseudo-spectral acceleration with 5 percent damping, but more generally it may refer to PGA, PGV, or PGD (peak ground displacement), along with other measures of motion. The integral's upper bound is the maximum considered ground motion as a function of ground-motion uncertainty, here $s a_{3}=\mu+3 \sigma$, and $\lambda_{i}$ is an estimate of the rate of occurrence of $S_{i}$, either the mean annual rate or an adjusted rate based on recent history of $S_{i}$. The basic equation above is in practice made more elaborate by considering alternative models of sources that sample the range of informed belief about future hazardous earthquakes and their distribution (of magnitude, frequency, etc.), as well as multiple GMPEs and their weights. In the above representation, a given fault or fault segment may host many ruptures, and each rupture is considered a specific source with known magnitude, sense of slip, fault geometry, and distance to site and with weight $w_{i}$ relative to other sources in the model. The need to separate weights and frequencies results from multiple scenarios of a given magnitude earthquake on a fault segment - for example, weights to apply to the set of magnitude (M) 6.5 earthquakes on fault segment F. Alternatively, equation 1 may be written as a multiple integral with $d M$ and $d r$ components, where $r$ is source-to-site distance. The left-side $v$ is a Poisson rate of exceedance and is converted to probability of one or more exceedances of $s a_{0}$ in $T$ years through the standard Poisson formula:

$$
\operatorname{Pr}\left[S A>s a_{0}\right]=1-\exp (-v T) .
$$

The influence of the recurrence model on this probability is in the event-rate parameter $\lambda_{i}$, a linear factor. The influence of site geology is contained in the conditional probability, which is computed for the joint occurrence of $S_{i}$ and $R_{v}$. Nonlinearity occurs in the determination of the mean response on soil, which is a function of strength of shaking in bedrock at the base of the soil column. The NGA GMPEs all model the conditional probability as a normal density function, whose parameters depend on source geometry and distance, as well as on site properties. As mentioned before, $\sigma$ is site- as well as source-dependent in most NGA GMPEs (exception, BA08).

There is no dynamic or time-varying element to site-response dependencies (for example, no potential for modeling degradation of shear strength of the soil column) in the PSHA model. For engineering applications that require such dynamic analysis, further geotechnical investigation is indicated.

Figure 1 schematically illustrates the joint influence of site and source on the probability of exceedance integral. On the left side $(A)$, the bell curves correspond to short-period ground motion from a hypothetical close, large, reverse-slip source. The rock curve has $\ln (\mu)$ and $\sigma$ of 0 and 0.6 , and the soil curve has $\ln (\mu)$ and $\sigma$ of -0.693 and 0.5 , respectively. That is, the soil mean is half the rock mean, resulting from significant nonlinear soil de-amplification. This graph 
approximately corresponds to the upper tail of probabilistic 10-Hz SA from an M6.5 earthquake at 1-kilometer $(\mathrm{km})$ distance, according to BA08. On the right side $(B)$, the curves correspond to motion from a more distant, smaller source. The rock curve has $\ln (\mu)$ and $\sigma$ of -1.693 and 0.6 , and the soil curve has $\ln (\mu)$ and $\sigma$ of -1.0 and 0.5 , respectively. That is, the soil median is double the rock median. Figure $1 B$ illustrates typical linear soil amplification and approximately corresponds to the upper tail of 10-Hz SA from an M5.5 earthquake at 10-km distance, according to BA08. The soil-site standard deviation $\sigma_{\mathrm{T}}$ is 20 percent lower than the rock-site $\sigma_{\mathrm{T}}$ in both cases, as in CY08.
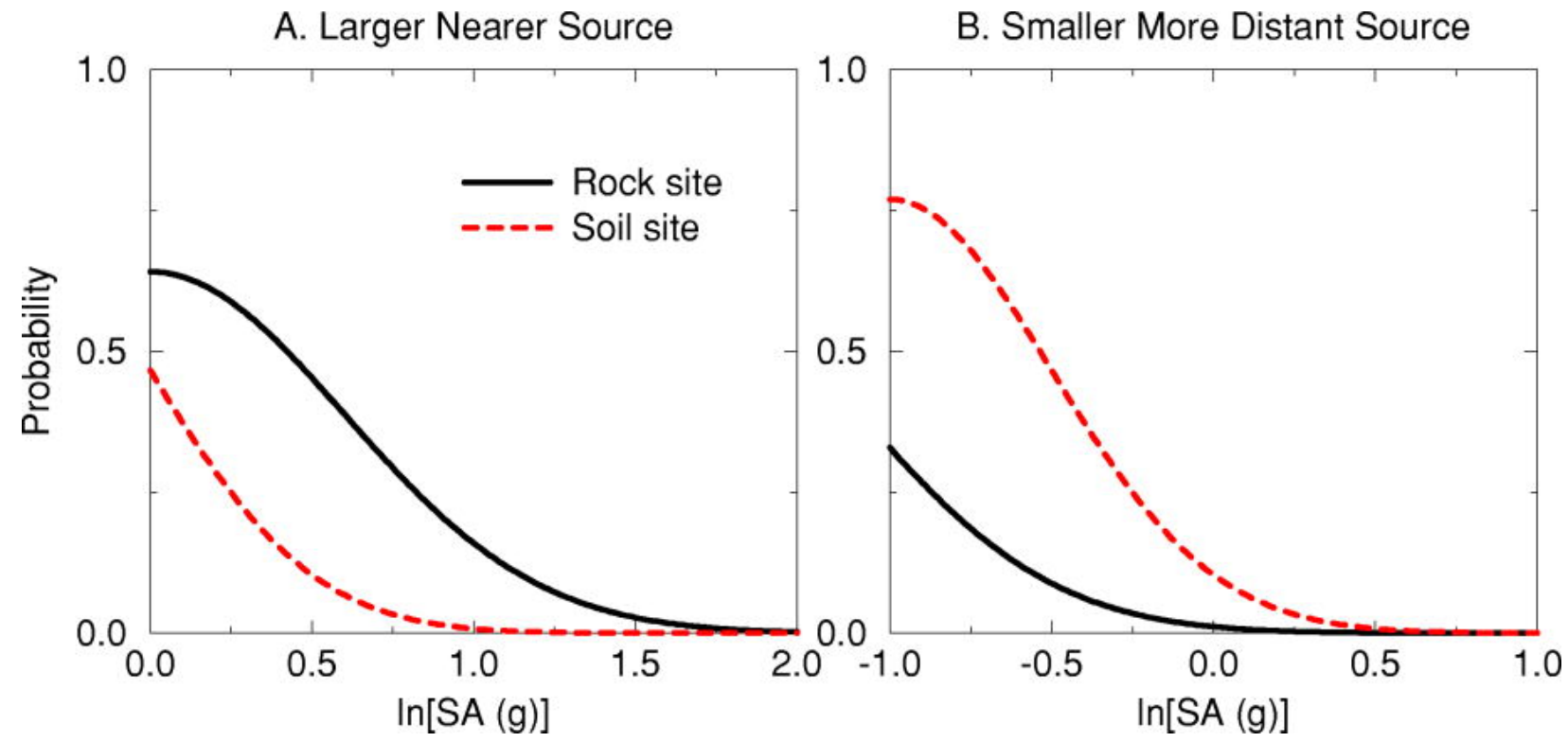

Figure 1. Schematic diagram of spectral acceleration (SA) distribution from two types of sources recorded on two types of sites. $A$, Upper-tail distribution of short-period (SP) ground-motion from a relatively large, nearby source and firm-rock or soft-soil site condition. $B$, Upper-tail distribution of SP groundmotion from a relatively distant small source and same pair of site conditions. Text gives more concrete examples of earthquake size, distance, and spectral period where these distributions may approximately occur in nature (or ground-motion prediction equations that describe nature).

The site-response models embedded in the NGA equations are believed to be reasonably appropriate for application to crustal sources originating in the western United States. For plate subduction or interface sources and deep intraplate sources, earlier source-specific GMPEs are used in the NSHMP 2008 PSHA update (Petersen and others, 2008). Interface GMPEs invariably use less sophisticated equations for modeling soil nonlinear response than those used in the NGA equations. For this article, and at the 2008 deaggregation Web site, we apply the Geomatrix interface and intraplate equations (Youngs and others, 1997) at reference Vs30, but we modify site response to correspond to the model of BA08 for nonreference Vs30. Other interface GMPEs were left as originally written. Several interface GMPEs have site-class sensitivity (for example, NEHRP D, CD, C, BC, and B site classes) but not continuous variation with respect to Vs30. Where different types of sources, such as crustal versus interface, make comparable contributions to the hazard, readers should keep in mind that these different levels of sophistication in GMPE site-response estimation may influence the relative contributions of 
different classes of sources (crustal, interface, intraplate). In a more ideal modeling environment, all GMPEs would display comparable nonlinear site response behavior.

\section{Regional Scale Uniform Soil Hazard Maps}

The third revision to the 2008 U.S. National Seismic Hazard Map (http://earthquake.usgs.gov/hazards/products/conterminous/2008/update_201001/), maintained and hosted online by the U.S. Geological Survey (USGS), provides to the public hazard curves and hazard values at specific probabilities of exceedance. These PSHA data all utilize source and ground-motion models of the most recent NSHMP update (Petersen and others, 2008). For sites in the western United States, they are computed for a variety of uniform soil conditions, with Vs30 of 180, 259, 360, 537, 760, and 1,150 m/s, using the NGA-West GMPEs and other modern GMPEs for noncrustal earthquakes. These Vs30 values were chosen to sample NEHRP site class central values and site class boundaries. Besides variation in Vs30, deep-basin information helps to define the site response in several of the NGA GMPEs, but this information was not available for most sites. The Chiou-Youngs equation requires the depth at which Vs becomes greater than $1 \mathrm{~km} / \mathrm{s}$. This depth is denoted Z1 and is, at best, approximately known at most locations. This report adopts a recommended default value, which is a function of Vs30, given in equation 1 of CY08 (Chiou and Youngs, 2008). The Campbell-Bozorgnia GMPE requires the depth at which $\mathrm{Vs}$ becomes greater than $2.5 \mathrm{~km} / \mathrm{s}$, called Z2.5. For these calculations, we use neutral values (Z2.5 of 1-2 km) in the absence of comprehensive knowledge of this depth. These neutral values are those which yield 0 additional basin effect (CB08; Campbell and Bozorgnia, 2008, equation 12).

Using the new NGA GMPEs, we compute ratios of probabilistic motion at a given site, where the numerator and denominator values result from different Vs30, show the effect of soil nonlinear damping, and provide information on differences between NGA predictions and, for example, 1997 NEHRP Recommended Provisions for Seismic-Resistant Design. Figure $2 A$ below is a map showing the ratio of probabilisitic 5-Hz SA with 2 percent in 50-year probability of exceedence (PE), where the numerator model assumes a uniform $259 \mathrm{~m} / \mathrm{s}$ Vs30 and the denominator model assumes a uniform $760 \mathrm{~m} / \mathrm{s}$ Vs30. Figure $2 B$ below shows the corresponding ratio of 3.0-s SA. Hazard calculations used in these maps stop at the Intermountain West (IMW), because Central and Eastern U.S. (CEUS) earthquake sources are important east of this boundary and no widely accepted GMPEs are currently available for modeling soil ground motion from these sources. Figure $2 A$ shows that sites near the most active faults of California, where predicted probabilistic ground motion is largest, have the greatest amount of high-frequency ground-motion damping. At such sites, the soil probabilistic motion is about 70 percent to 75 percent of the rock value. On the other hand, the soil column typically amplifies the rock motion by 1.5 times or more at sites with lower expected rock ground motion, that is, away from the most active faults. Figure $2 B$ shows that even when considering long-period motion, less soil site amplification is expected to occur near the most seismically active locations than elsewhere. Numerous maps available at the 2008 U.S. National Seismic Hazard Map Web site (http://earthquake.usgs.gov/hazards/products/conterminous/2008/update_201001/) consider other spectral periods and soil-to-soil comparisons. 


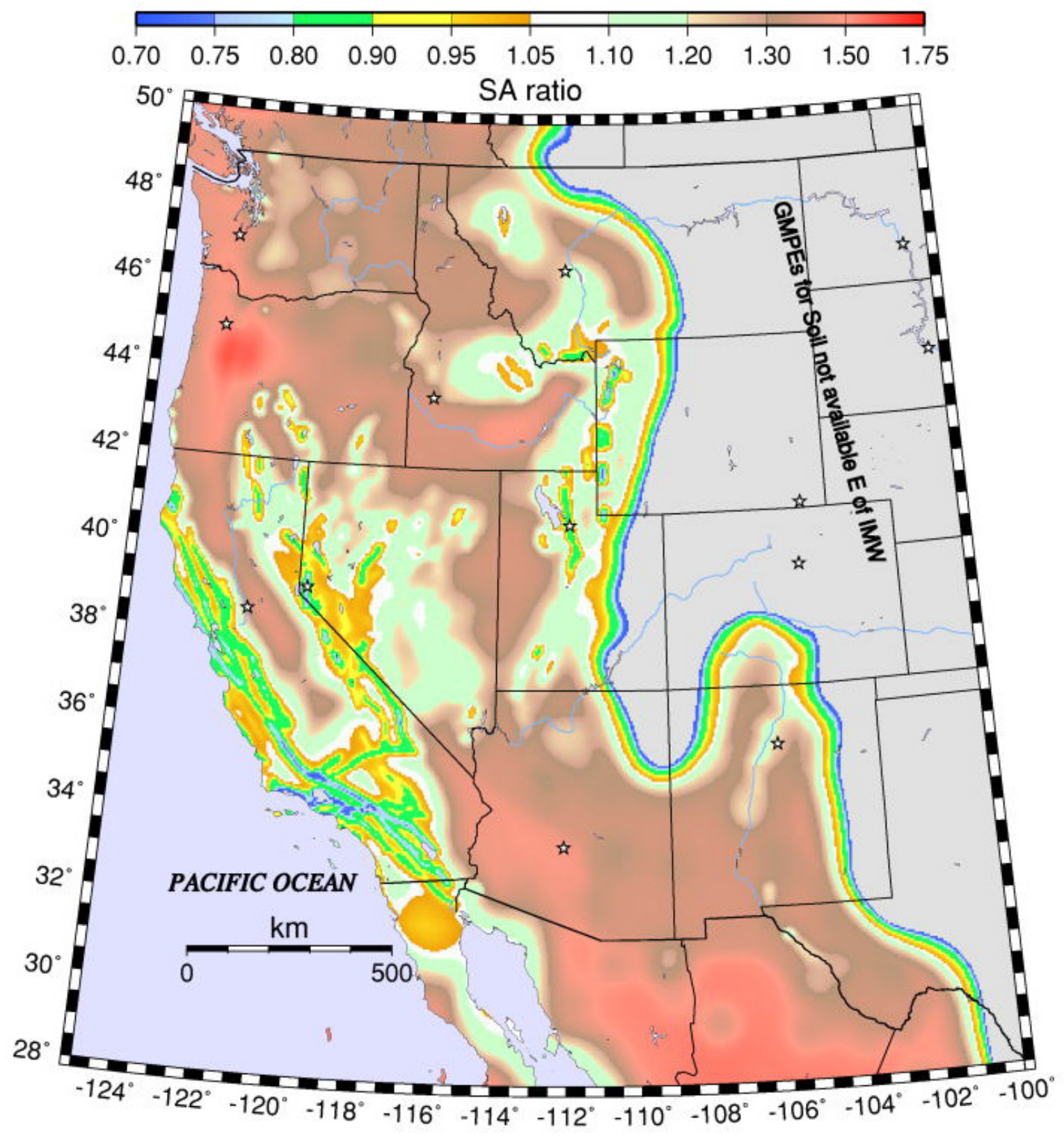

Figure 2. Spectral acceleration (SA) ratio for sites in the western United States, using recently developed ground-motion prediction equations. The numerator model has uniform Vs30 of $259 \mathrm{~m} / \mathrm{s}$ and denominator has uniform Vs 30 of $760 \mathrm{~m} / \mathrm{s}$. Ground motions are computed for the 2 percent in 50 year probability of exceedance, from the seismic-hazard model of Petersen and others (2008). (IMW, Intermountain West; east of the IMW boundary, hazard at soil sites is not computed)

A, 5-Hertz or 0.2-second SA ratio. 


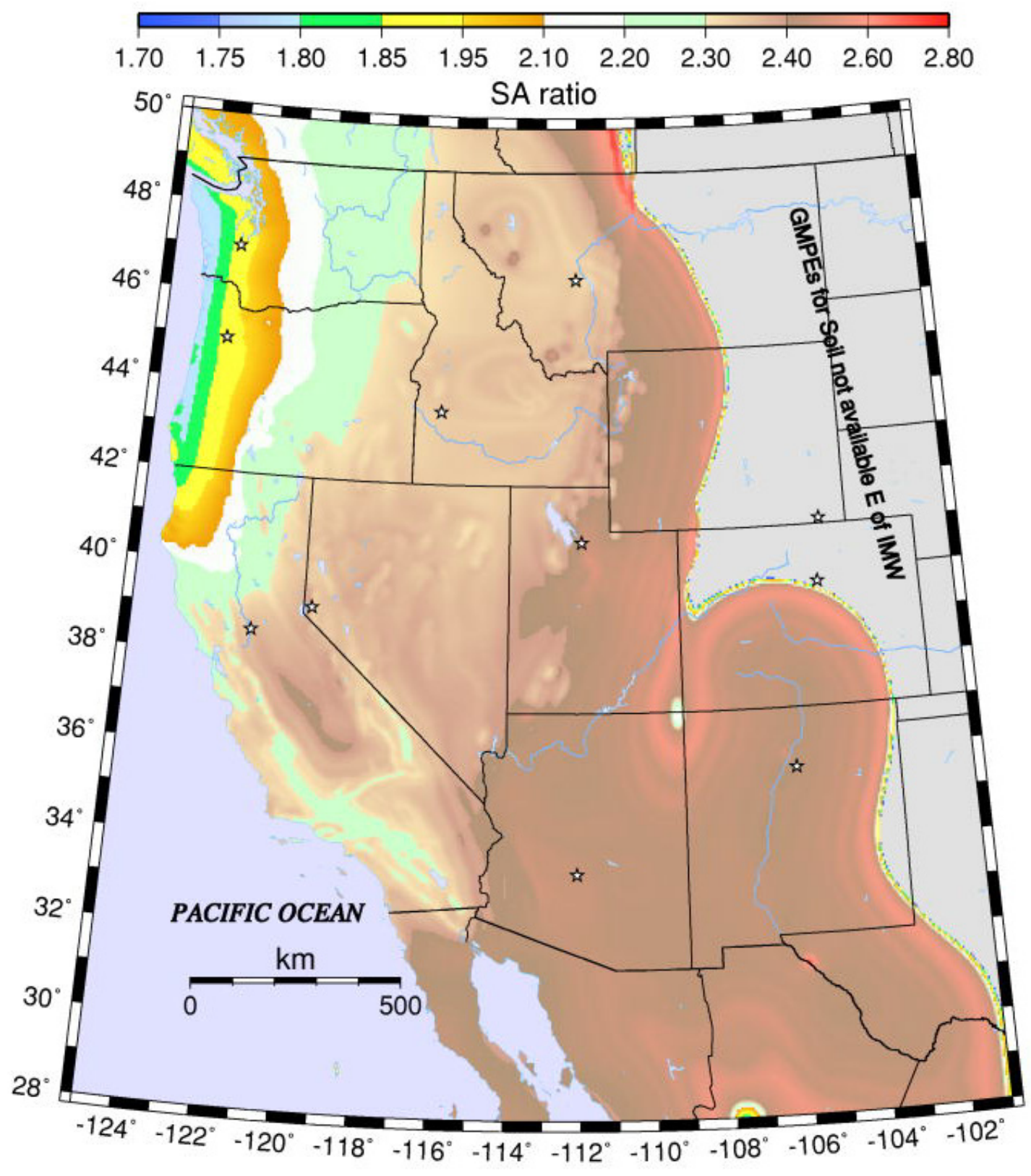

Figure 2. Spectral acceleration (SA) ratio for sites in the western United States, using recently developed ground-motion prediction equations. The numerator model has uniform Vs30 of $259 \mathrm{~m} / \mathrm{s}$ and denominator has uniform Vs 30 of $760 \mathrm{~m} / \mathrm{s}$. Ground motions are computed for the 2 percent in 50 year probability of exceedance, from the seismic-hazard model of Petersen and others (2008). (IMW, Intermountain West; east of the IMW boundary, hazard at soil sites is not computed)—Continued

$B, 3.0$-second, or 0.33 -Hertz SA ratio. Note: although the color tiles are the same as those of figure $2 A$, their meanings are different. 


\section{Methods for Estimating Vs30 over Broad Regions}

In the United States, California leads the way in the development of statewide Vs30 maps, using geologically mapped units to estimate Vs30 (Wills and Clahan, 2006) and soil hazard probabilistic seismic hazard assessments (Kalkan and others, 2010). Investigators at the California Geological Survey continue to refine this model, and the latest available revision of the Wills and Clahan model as of April 2010 that is used in this report is a hybrid of the original geologic-unit and topographic-slope methods. This hybrid is referred to as "method 1" in this report. Wald and Allen (2007) developed a different method ("method 2") of estimating Vs30 based on topography and topographic slope, and their method is routinely applied globally, for example, in the production of near real-time shake maps following major earthquakes. Wald and Allen (2007) discuss differences and merits of method 2 versus the original method 1. Investigators at the USGS Pasadena office developed a terrain-based shear-wave velocity estimation method ("method 3") that is used to compute Vs30 in California (Yong and others, in press). Method 3 uses the average measured or inferred Vs30 in each of 16 terrain classes to predict Vs30 anywhere that the terrain class can be determined. In this report, no strong preference is attached to any of these regional Vs30 models, and seismic-hazard maps based on each of them are presented separately, along with ratio maps.

\section{Regional Scale Site-Specific Hazard Maps}

Using Vs30 maps derived from methods 1, 2, and 3, we compute the site-specific hazard in two regions: (1) central California, and (2) southern California. Similar site-specific hazard mapping is possible in other western U.S. States using method 2, where soil GMPEs are available. Locally, sometimes significant variations from the site-class and topographic slope model Vs30s are known from borehole and related studies, but these Vs30 renderings are believed to capture the primary features of sedimentary rock and soil Vs30 distribution in California, and their differences capture some of the uncertainty, given sparse data. One caveat is that Vs30 in these models has an upper limit of $760 \mathrm{~m} / \mathrm{s}$, whereas shallow crystalline rock in parts of the Sierra Nevada Mountains and elsewhere is known to have faster shear-wave velocity (see section on "Caveats and Model Limits").

\section{Regional Scale Site-Specific Vs30 Maps for Central California}

Figure $3 A-E$, below, exhibits Vs30 in central California at a $0.01^{\circ}$ (roughly $1-\mathrm{km}^{2}$ ) sampling. Figure $3 A$ corresponds to the method 1 (primarily geologic-unit) approach, (R. Chen, California Geological Survey, written commun., 2010). Figure $3 B$ corresponds to method 2 , the topographic-slope approach (Wald and Allen, 2007). Figure $3 C$ corresponds to method 3, the terrain-based approach (Yong and others, in press). In figure $3 A$, note the low Vs30 values at several locations, for example, Holocene bay mud in the South Bay area and north of San Pablo Bay, and the large patch of low-velocity soils in the floodplain of the Sacramento River, in the Great Valley south of Sacramento and northwest of Stockton. Several of these low-Vs regions are also seen in figure $3 B$, whereas figure $3 C$ has a higher minimum Vs30 and less correlation with figures $3 A$ and $3 B$. Several significant differences are apparent in figures $3 A$ and $3 B$, such as in the Great Valley, where there is little agreement on where the slowest sediments may be found, and in the western foothills of the Sierra Nevada Mountains, where method 2 predicts considerably slower media. 
In general, method 2 finds far less extensive area of rock at or near the NEHRP B/C (Vs30 $>680 \mathrm{~m} / \mathrm{s}$ ) boundary than method 1 . While there may be more soil in the foothills of the Sierra Nevada Mountains than is suggested by figure $3 A$, it is likely to be thin at most locations, incapable of amplifying IP to long-period (LP) seismic vibrations. In mountains and hills with relatively thin Quaternary soil cover, method 1 for estimating Vs30 may be more appropriate for LP amplification, while the USGS method 2 may be more appropriate for SP amplification, although it may be that the soil column is too thin to amplify even the SP signal at some such locations. The upper limit of Vs 30 in method 3 is about $550 \mathrm{~m} / \mathrm{s}$, equivalent to a NEHRP middle$\mathrm{C}$ site class. Terrain-class Vs30 estimates are defined as the average measured Vs30 in that class (Yong and others, in press). The $550 \mathrm{~m} / \mathrm{s}$ upper limit is likely to be the result of sampling bias; geotechnical boreholes into harder rock are relatively infrequent. Method 3 is likely to underpredict Vs30 in many mountain environments, and therefore overpredict LP site response at those sites.

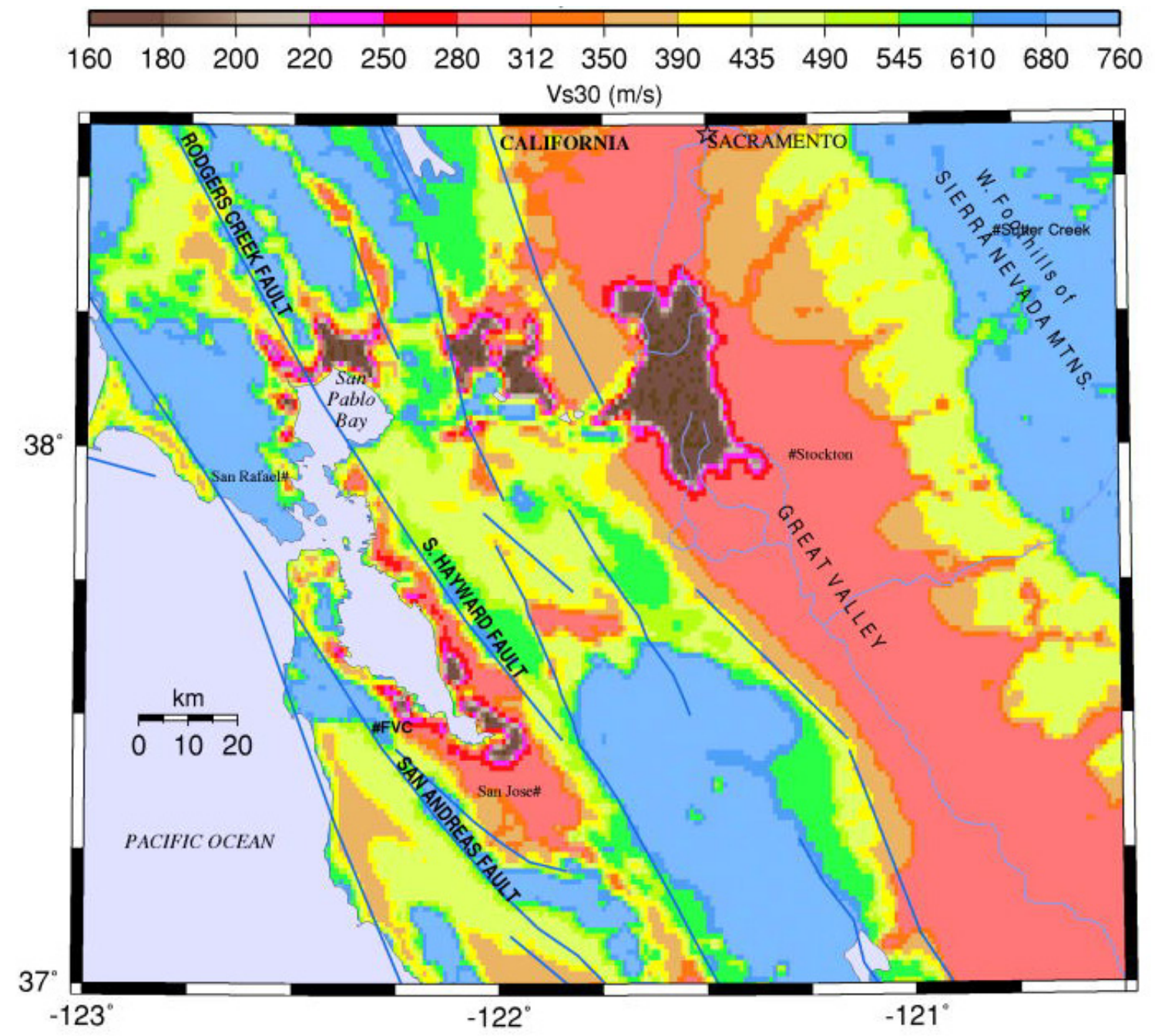

Figure 3. Regional scale site-specific Vs30 maps for central California. (km, kilometers; $\mathrm{m} / \mathrm{s}$, meters per second; FVC, Filoli Visitor Center, Woodside; MTNS, Mountains)

A, Vs30 map using method 1. 


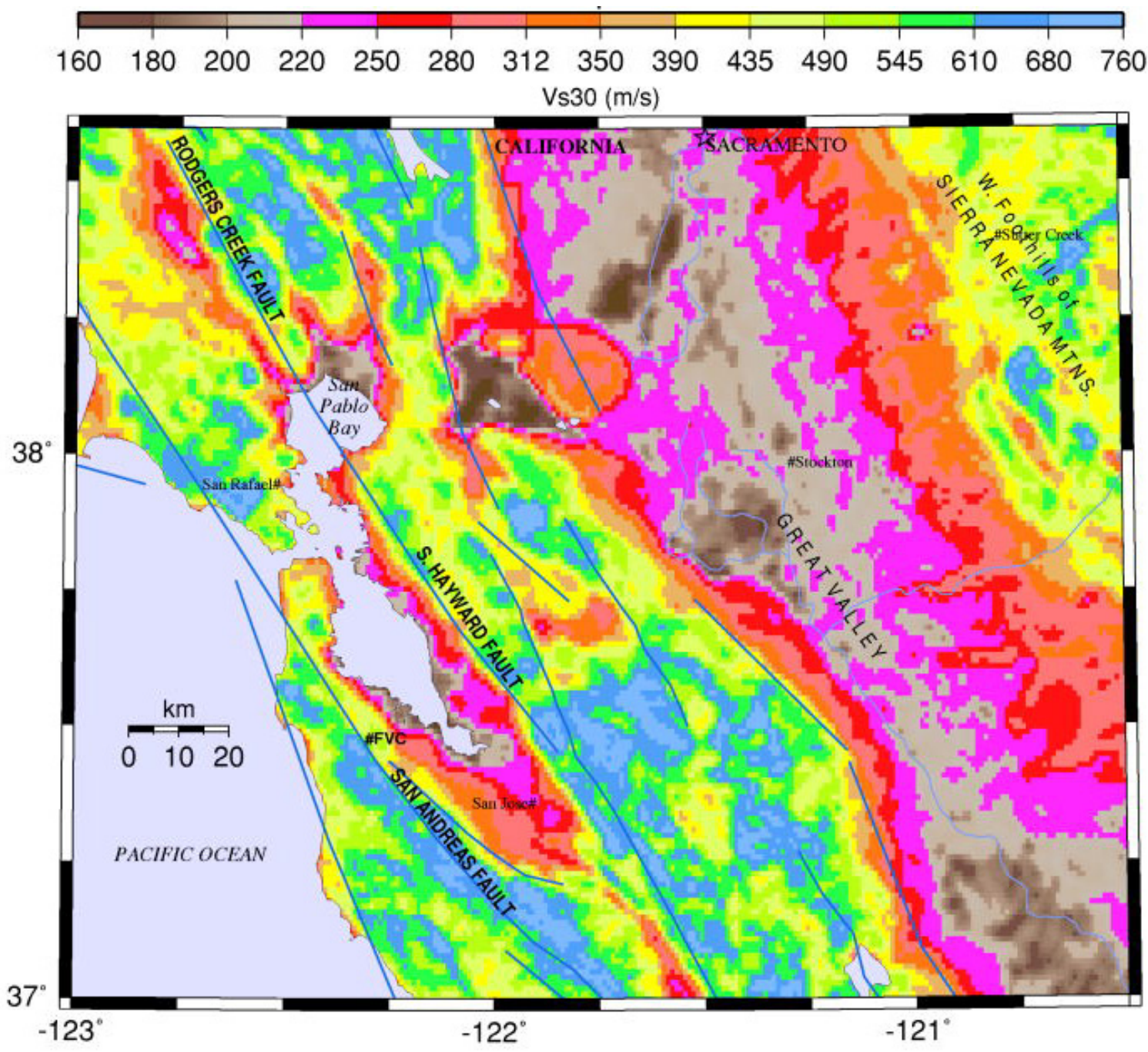

Figure 3. Regional scale site-specific Vs30 maps for central California. (km, kilometers; $\mathrm{m} / \mathrm{s}$, meters per second; FVC, Filoli Visitor Center, Woodside; MTNS, Mountains)—Continued

$B$, Vs30 map from topographic slope, method 2 . 


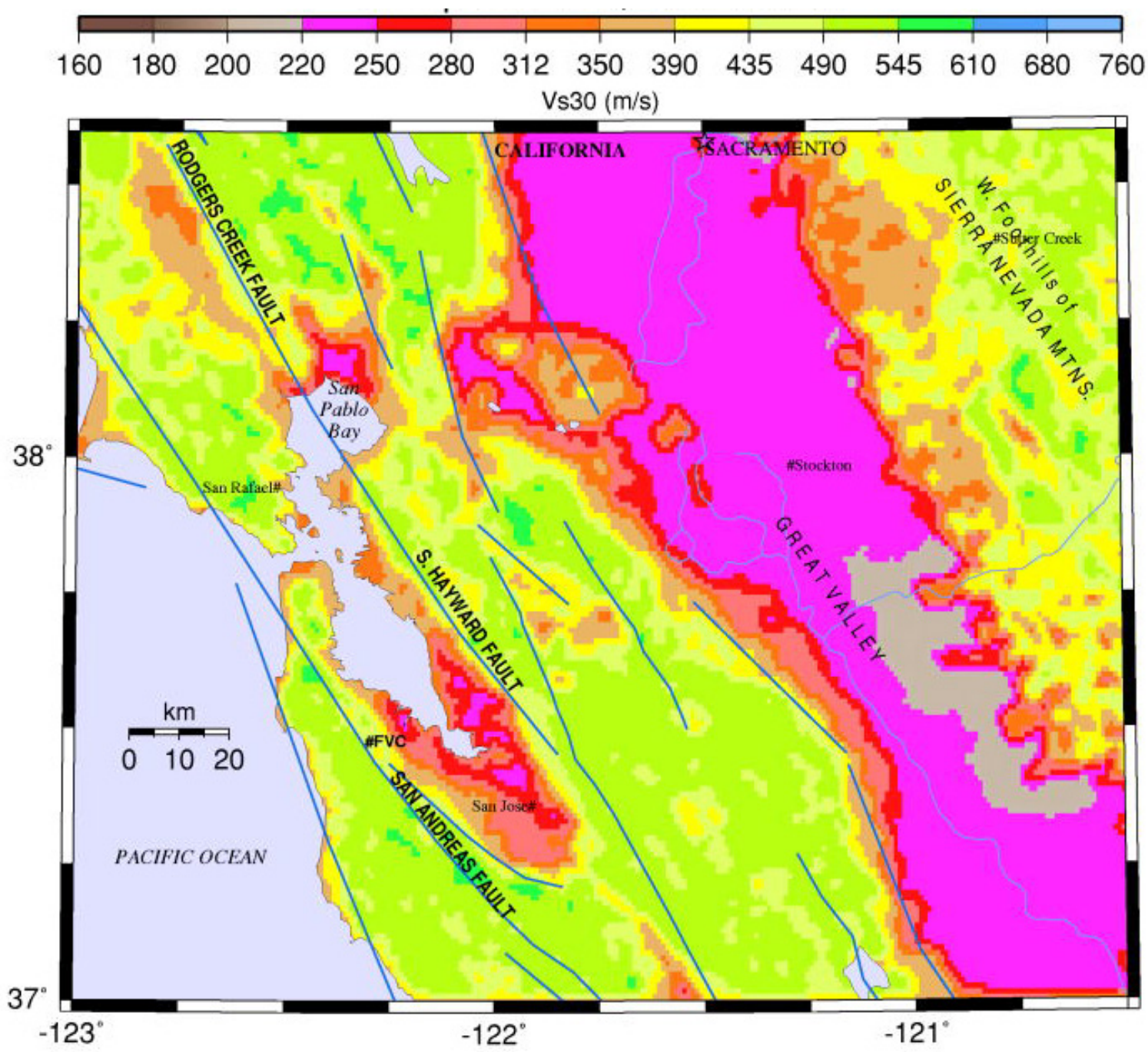

Figure 3. Regional scale site-specific Vs30 maps for central California. (km, kilometers; m/s, meters per second; FVC, Filoli Visitor Center, Woodside; MTNS, Mountains)—Continued

C, Vs30 map using method 3. 
Ratio maps of the estimated Vs30 for the region of figure 3 are shown in figures $3 D$ and $3 E$. Figure $3 D$ is the ratio Vs30_Wald / Vs30_Wills, and figure $3 E$ is the ratio Vs30_Wald / Vs30_Yong. In these figures, ratios that are off scale on the high side plot as dark brown, and ratios that are off scale on the low side plot as violet.

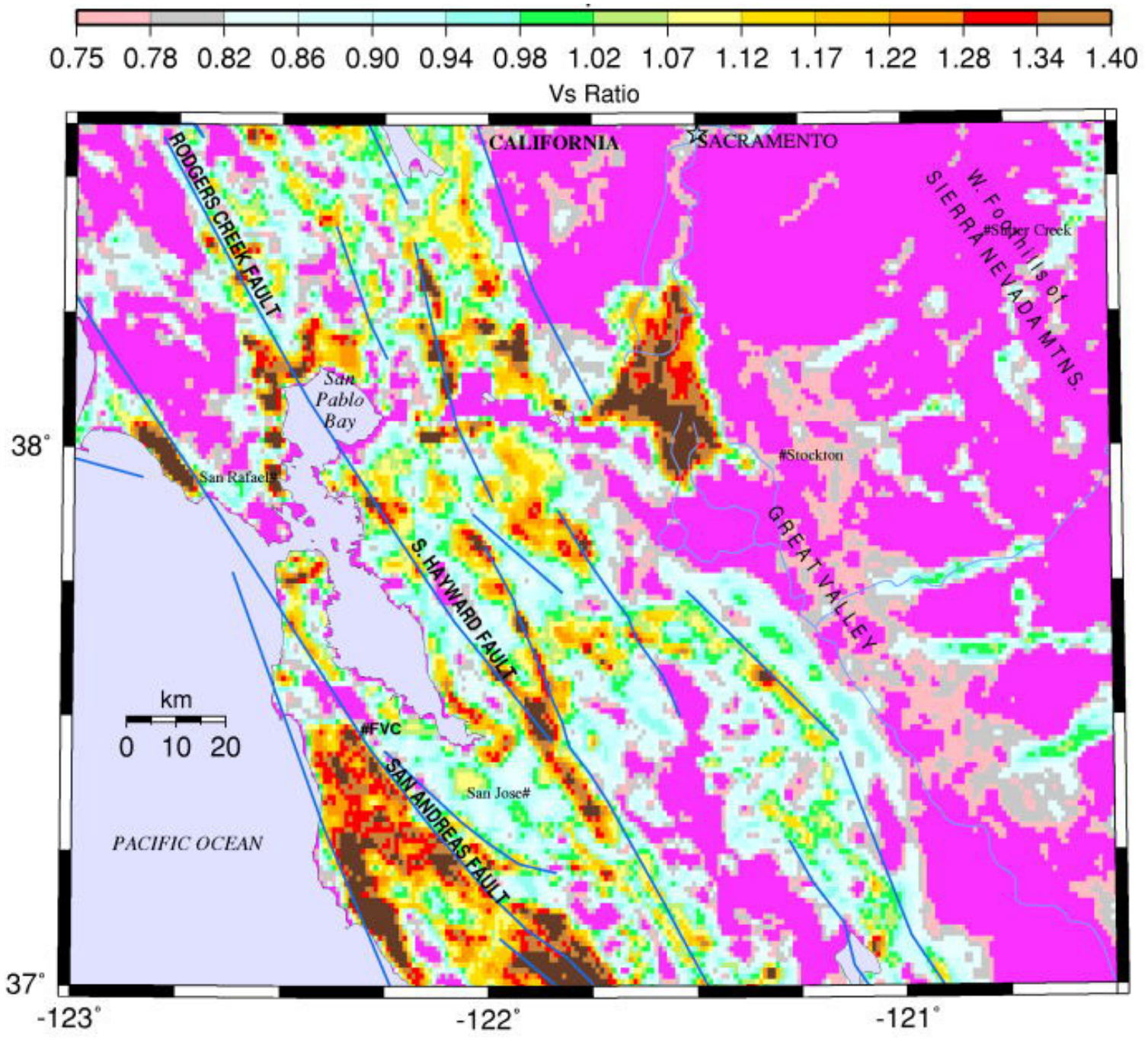

Figure 3. Regional scale site-specific Vs30 maps for central California. (km, kilometers; FVC, Filoli Visitor Center, Woodside; MTNS, Mountains)-Continued

$D$, Ratio of Vs30, method 2 divided by method 1, at each location. Violet zones are where the method 2 estimate is less than 75 percent of the method 1 estimate. Dark brown zones are where the method 2 estimate is more than 140 percent of the method 1 estimate. 


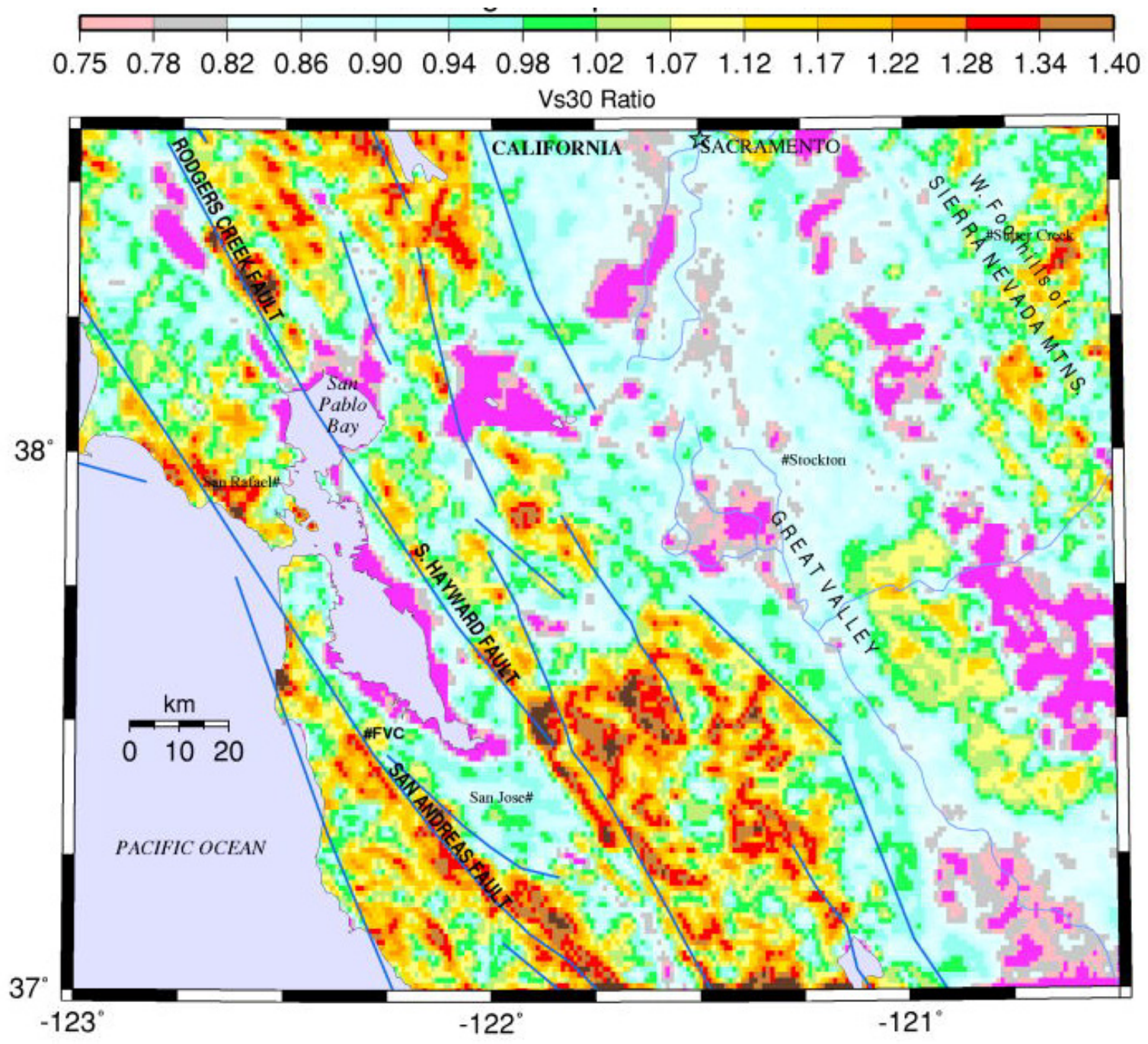

Figure 3. Regional scale site-specific Vs30 maps for central California. (km, kilometers; FVC, Filoli Visitor Center, Woodside; MTNS, Mountains)—Continued

$E$, Ratio of Vs30, method 2 model over method 3 model. Violet zones are where the method 2 estimate is less than 75 percent of the method 3 estimate. Dark brown zones are where the method 2 estimate is more than 140 percent of the method 3 estimate. 


\section{Regional Scale Site-Specific Hazard Maps for Central California}

The Vs30 values corresponding to the above maps are used in the hazard calculation according to equation 1 to produce the 2 percent in 50-year probability of exceedance (PE) maps for 5-Hz spectral acceleration (short-period example) and for 3-s spectral acceleration (longperiod example). Figure $4 A$ shows the $5-\mathrm{Hz}$ map corresponding to the $\mathrm{Vs} 30$ of figure $3 A$, and figure $4 B$ corresponds to figure $3 B$. Comparing figures $3 A$ and $4 A$, we see at best a weak correlation of probabilistic ground motion with Vs30 at most sites. For example, on the two sides of the San Andreas fault (SAF), the 5-Hz motion is similar, even though Vs30 can be quite different. Amplification effects of the very low Vs30 sediments in the Great Valley and near the shoreline of South San Francisco Bay are conspicuous for their absence (that is, predicted deamplification) in figures $4 A$ and $4 B$. In figure $3 C$, the very-low-velocity Holocene Bay muds are not modeled with lower Vs30 than surrounding sediments, and consequently, in figure $4 C$ those locations do not exhibit deamplified short-period strong ground motion. In high-hazard regions, the effect of relatively soft sediments on the 2 percent in 50-year SP motion is quite limited, even though the effect of these sediments on related hazards, such as liquefaction, is quite pronounced. One current concern is the safety of the levee system on the Sacramento River and tributaries and its ability to withstand seismic events. 


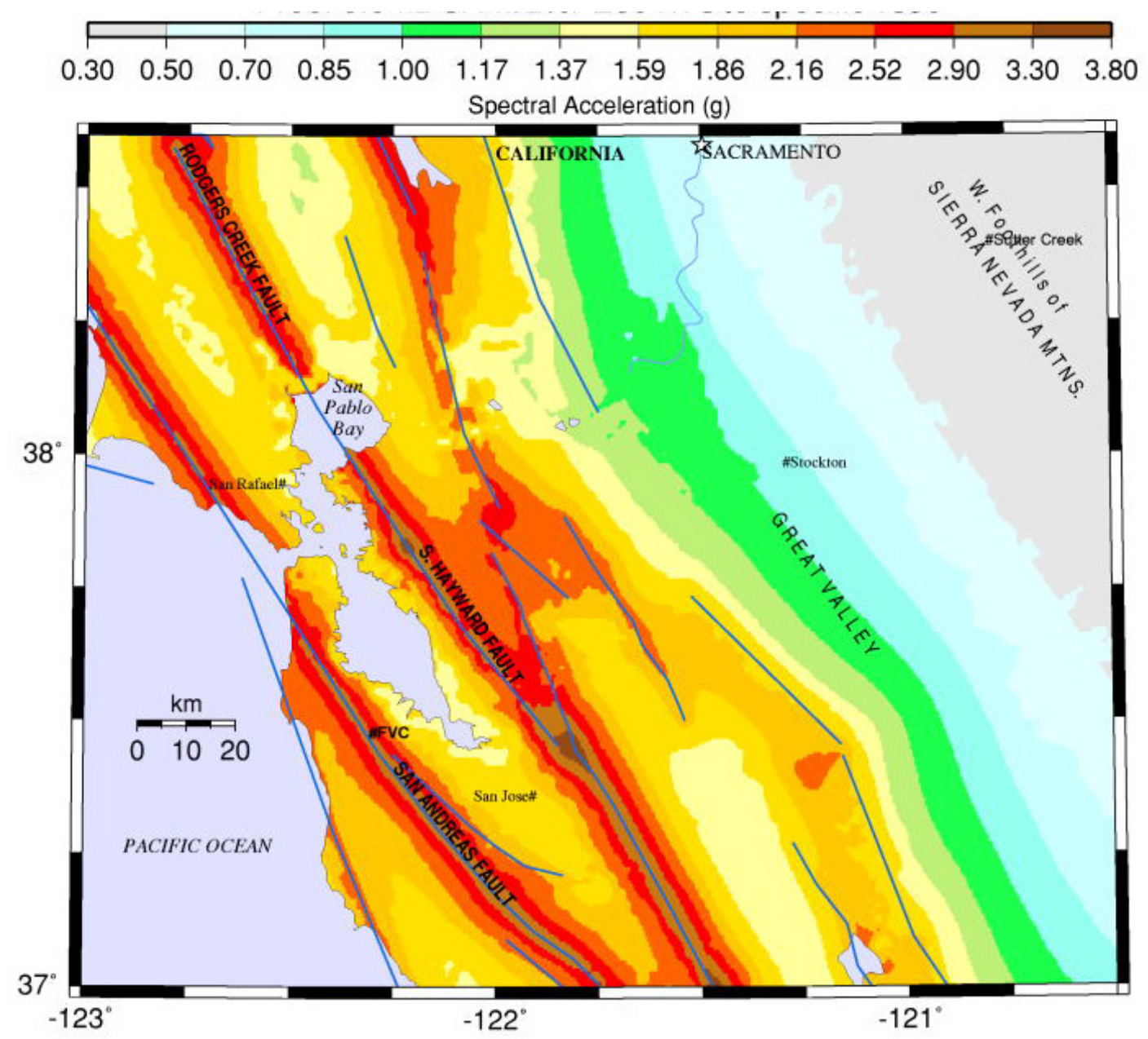

Figure 4. Regional scale site-specific hazard maps for central California, 5-hertz $(\mathrm{Hz})$ spectral acceleration (SA). (km, kilometers; $g$, acceleration of gravity, $9.8 \mathrm{~m} / \mathrm{s}^{2} ; \mathrm{FVC}$, Filoli Visitor Center, Woodside; MTNS, Mountains; SAF, San Andreas fault)

A, Site-specific 5-Hz SA for central California, using method 1 Vs30 model. 


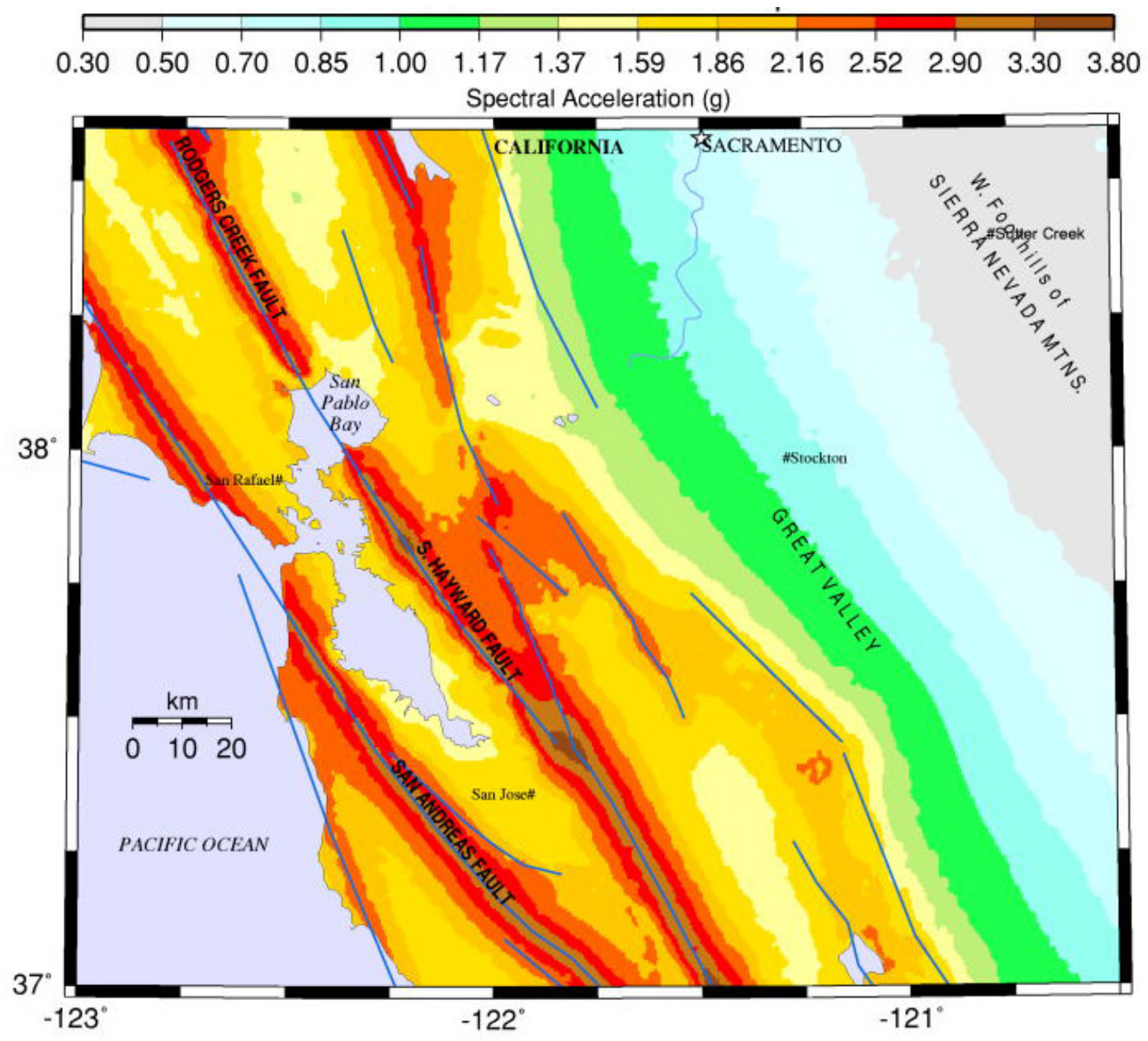

Figure 4. Regional scale site-specific hazard maps for central California, 5-hertz $(\mathrm{Hz})$ spectral acceleration (SA). (km, kilometers; g, acceleration of gravity, $9.8 \mathrm{~m} / \mathrm{s}^{2}$; MTNS, Mountains)-Continued $B$, Site-specific 5-Hz SA for central California, using method 2 Vs30 model. 


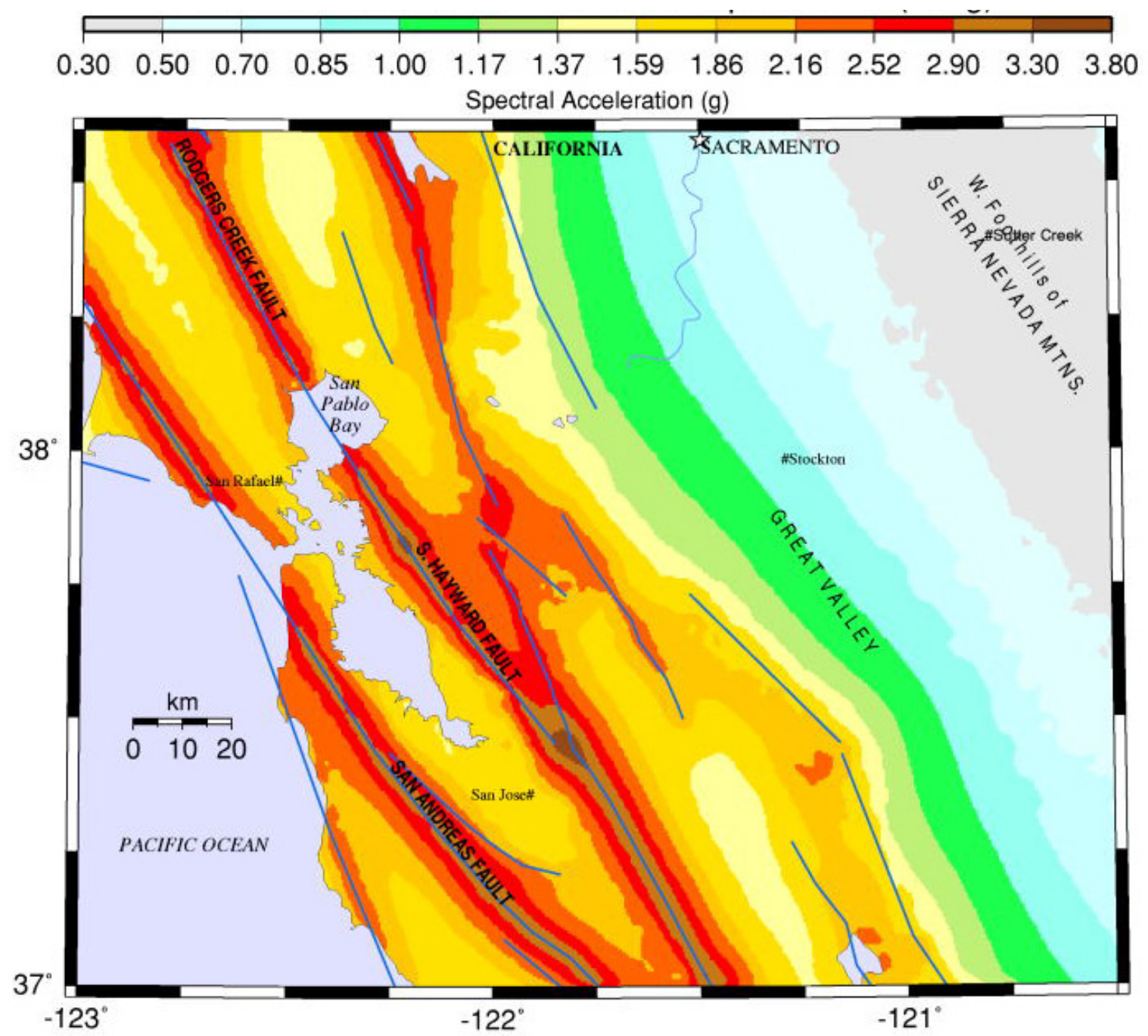

Figure 4. Regional scale site-specific hazard maps for central California, 5-hertz $(\mathrm{Hz})$ spectral acceleration (SA). (km, kilometers; g, acceleration of gravity, $9.8 \mathrm{~m} / \mathrm{s}^{2}$; MTNS, Mountains)—Continued C, Site-specific 5-hz SA for central California, using method 3 Vs30 model. 
Figure $4 D$ below is the $5-\mathrm{Hz}$ SA ratio, where the numerator results from using the Wald and Allen (2007) model of site-specific Vs30 and the denominator results from using the latest available revision of the Wills and Clahan (2006) model of Vs30 in the PSHA calculations. Figure $4 E$ has the same numerator, but the denominator is now the result of using the Yong and others (in press) Vs30 model in the PSHA calculations. Comparing figure $4 D$ with figure $3 D$ shows that at high frequencies and in high-SA regions, strong differences in the site's Vs30 estimates result in relatively small differences in probabilistic ground motion, but result in large differences in low-SA regions. These high- and low-SA regions depend strongly on the SA return time, here 2,500 years.

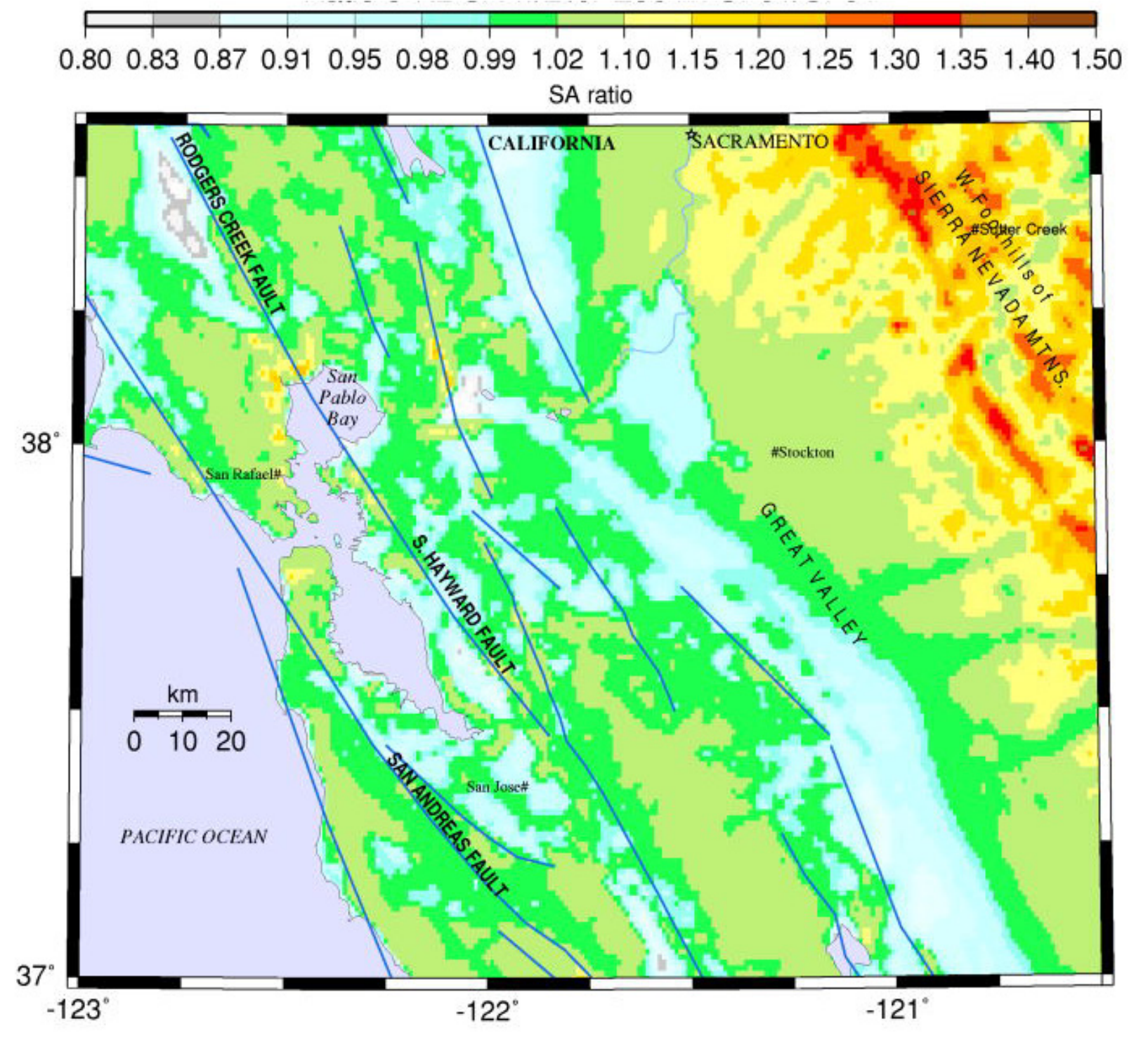

Figure 4. Regional scale site-specific hazard maps for central California, 5-hertz $(\mathrm{Hz})$ spectral acceleration (SA). (MTNS, Mountains)-Continued

$D$, Ratio of $V s 30$, method 2 divided by method 1 , at each location. 


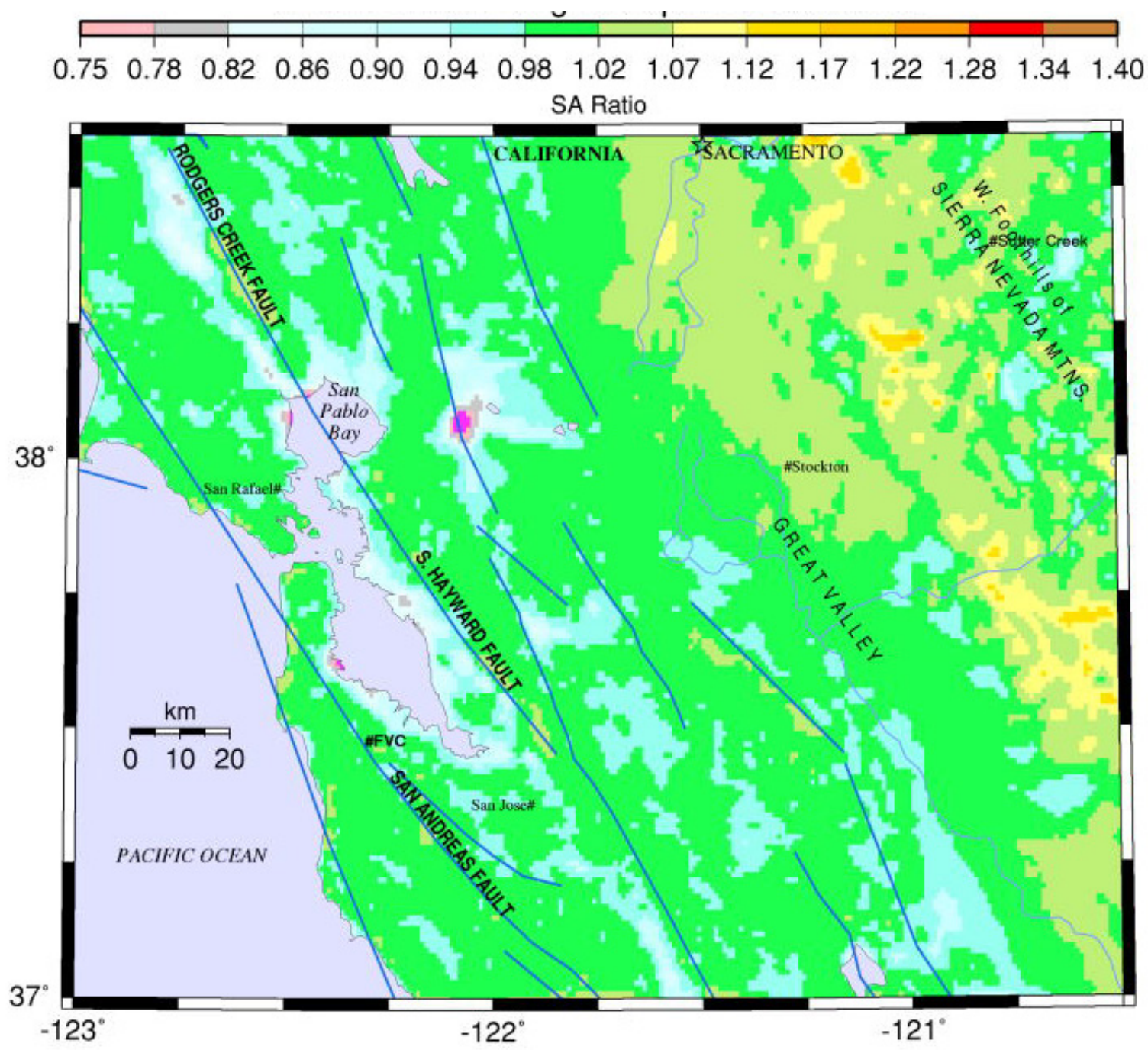

Figure 4. Regional scale site-specific hazard maps for central California, 5-hertz $(\mathrm{Hz})$ spectral acceleration (SA). (km, kilometers; MTNS, Mountains)-Continued

$E$, Ratio of $\mathrm{Vs} 30$, method 2 divided by method 3 , at each location. Violet zones are where the method 2 estimate is less than 75 percent of the method 3 estimate. 
Figures $5 A-C$ show the 3 -s maps corresponding to the Vs30 values of figures $3 A-C$, respectively. Three-second $\mathrm{SA}$ is a period that may roughly correspond to 30 -story-tall building resonance. Comparing figures $3 A$ and $5 A$, or figures $3 B$ and $5 B$, we see much stronger correlation of LP probabilistic ground motion with Vs30 at most sites, compared to SP ground motion and Vs30. For example, LP motion is now asymmetric on the two sides of the SAF where soil conditions differ markedly. In San Francisco, where tall, long-period buildings are not uncommon, there is a strong correlation of Vs30 with probabilistic LP motion. Alluvial valleys in the western foothills of the Sierra Nevada Mountains are prominently visible in figure $5 A$, as are the soil patches containing very low Vs30, less than $180 \mathrm{~m} / \mathrm{s}$ (NEHRP soil class E) in the Sacramento River floodplain and elsewhere. The floodplain region of the Sacramento River may have a few intermediate-to-long-period structures, such as bridges. Most of these soft-soil sites, however, are unlikely to have engineering infrastructure with long-period resonance because they are mostly farmland and riparian forest. Near San Francisco Bay, multi-use pressures such as ecosystem restoration may discourage such construction at many locations. The thickness of the very-low-Vs Holocene Bay mud may not be much greater than $30 \mathrm{~m}$ in most parts of the San Francisco Bay shoreline. For example, the bottom of Bay Mud at well-studied Treasure Island occurs at about $29 \mathrm{~m}$ depth (Darragh and Idriss, 1997). Intermediate-period SA, such as that at T $($ time $)=1.0 \mathrm{~s}$, exhibits stronger correlation with Vs30 than short-period SA but weaker correlation with Vs30 than long-period SA, such as the 3-s SA illustrated here. 


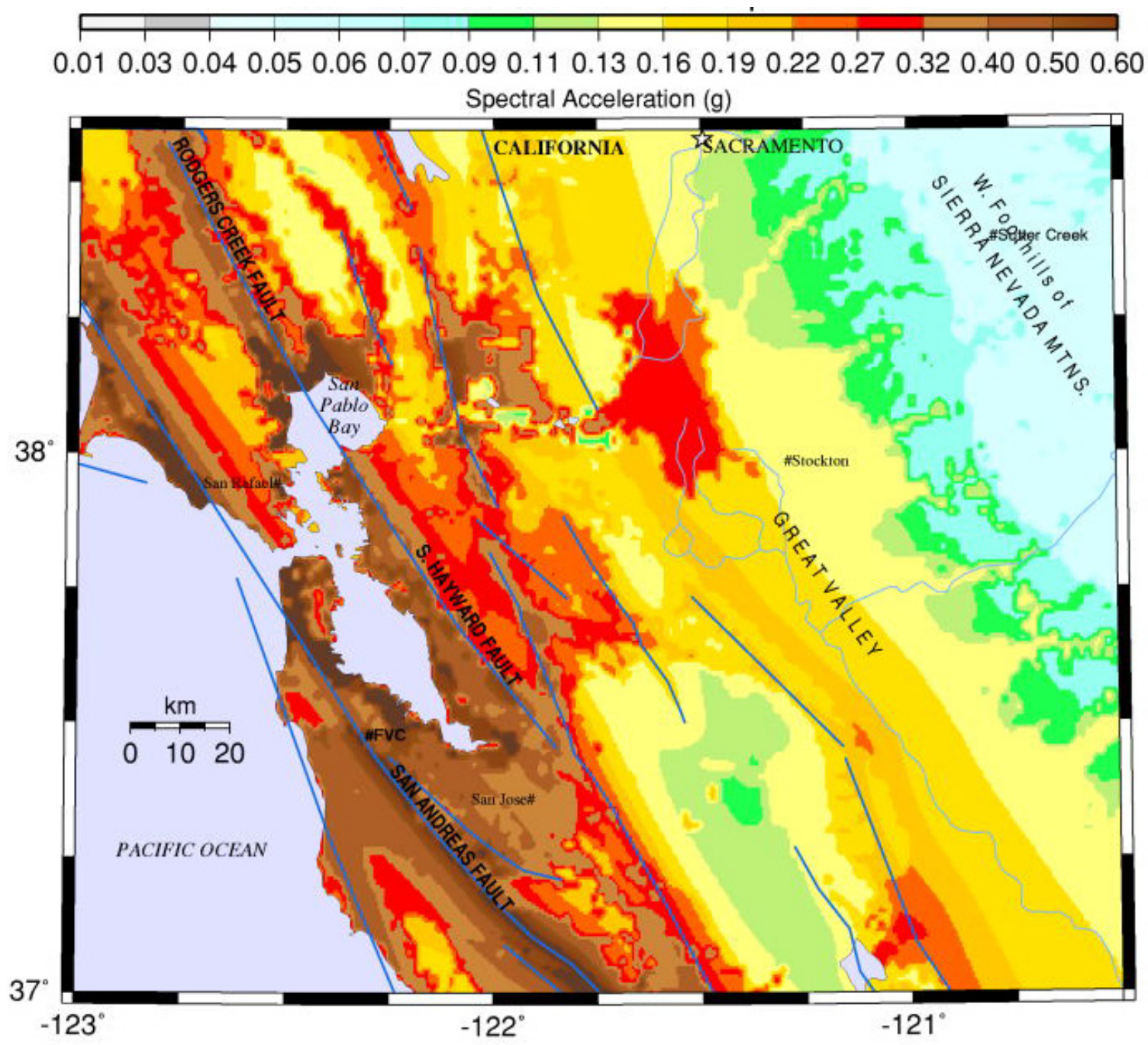

Figure 5. Regional scale site-specific hazard maps for central California, 3-second spectral acceleration $(\mathrm{SA})$. (km, kilometers; $\mathrm{g}$, acceleration of gravity, $9.8 \mathrm{~m} / \mathrm{s}^{2}$; MTNS, Mountains; darkest browns, in excess of $0.6 \mathrm{~g}$ )

A, Site-specific 3-second SA map for central California, using model 1 Vs30 model. 


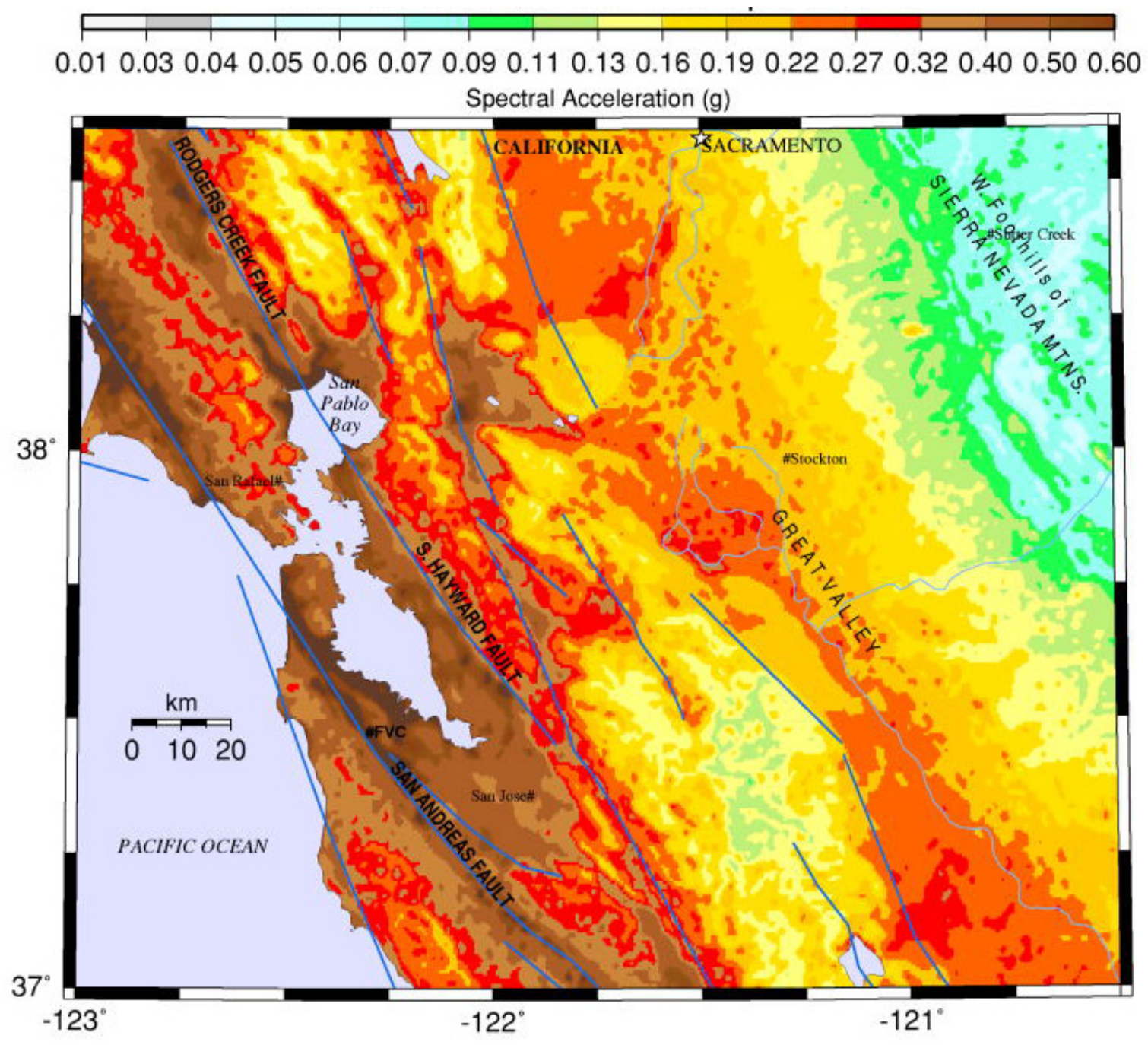

Figure 5. Regional scale site-specific hazard maps for central California, 3-second spectral acceleration (SA). (km, kilometers; g, acceleration of gravity, $9.8 \mathrm{~m} / \mathrm{s}^{2}$; MTNS, Mountains; darkest browns, in excess of $0.6 \mathrm{~g}$ )-Continued

$B$, Site-specific 3-second SA map for central California, using model 2 Vs30 model. 


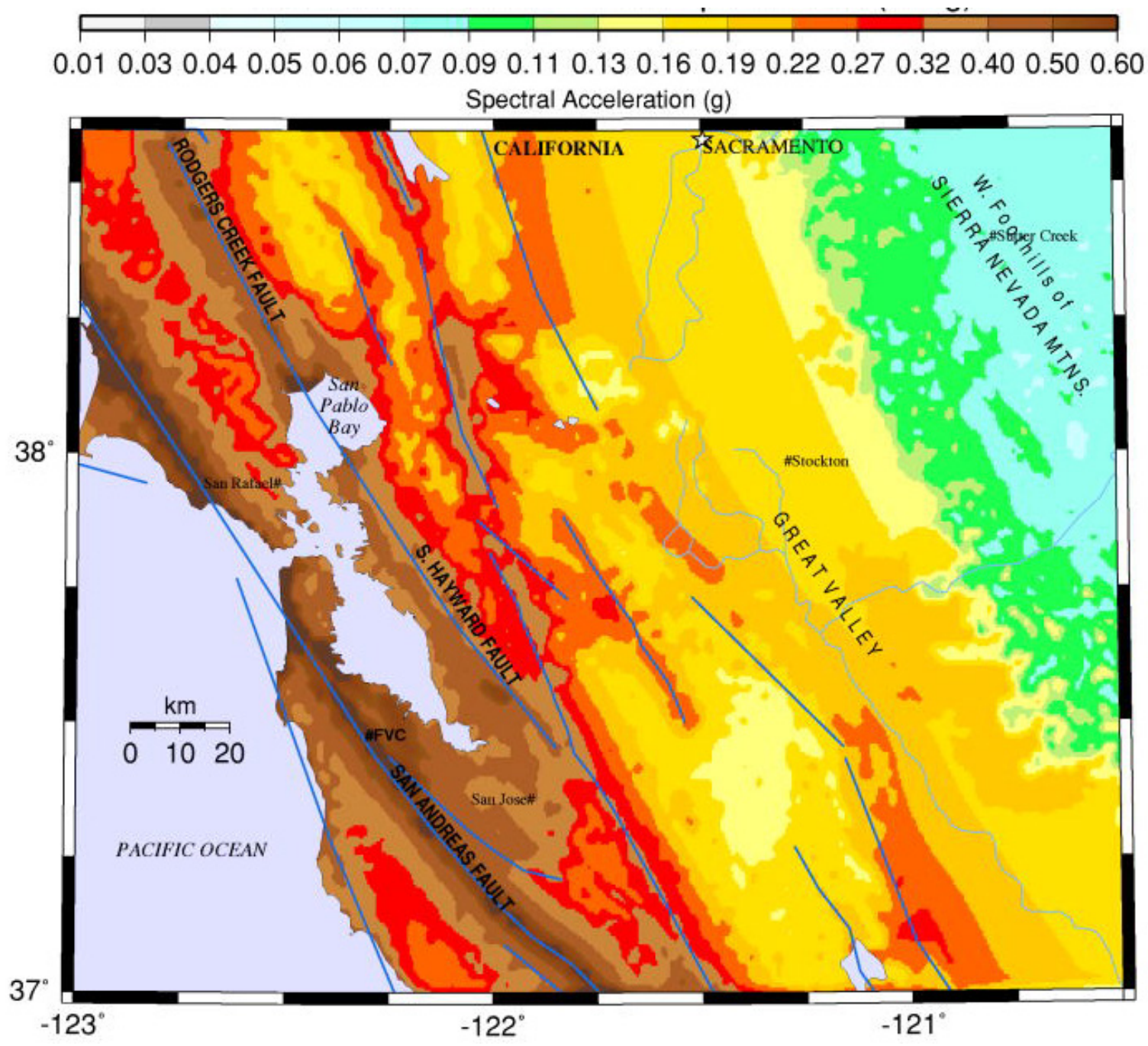

Figure 5. Regional scale site-specific hazard maps for central California, 3-second spectral acceleration (SA). (km, kilometers; $\mathrm{g}$, acceleration of gravity, $9.8 \mathrm{~m} / \mathrm{s}^{2}$; MTNS, Mountains; darkest browns, in excess of $0.6 \mathrm{~g}$ )-Continued

C, Site-specific 3-second SA map for central California, using model 3 Vs30 model. 
Figure $5 D$ shows the ratio of 2 percent in 50 -year PE ground motion at 3-s spectral period, where the numerator model uses the site specific Vs 30 model of figure $3 B$ and the denominator uses the Vs 30 model of figure $3 A$. The mean value of the ratio is 1.58 , indicating that the substantially lower Vs30 at several locations in the figure $3 B$ model is mapping into higher expected LP ground vibrations. Comparing figure $5 D$ and $4 D$ shows that the low-velocity sediments amplify the LP signal and deamplify the SP signal at many locations in the Sacramento River floodplain, SF Bay shoreline, and elsewhere, according to the NGA siteresponse models used in these calculations. Figure $5 E$ uses the Yong and others (in press) model in the denominator instead of the Wills and others (2006) model. The mean value of the Wald/Yong ratio is 1.18 .

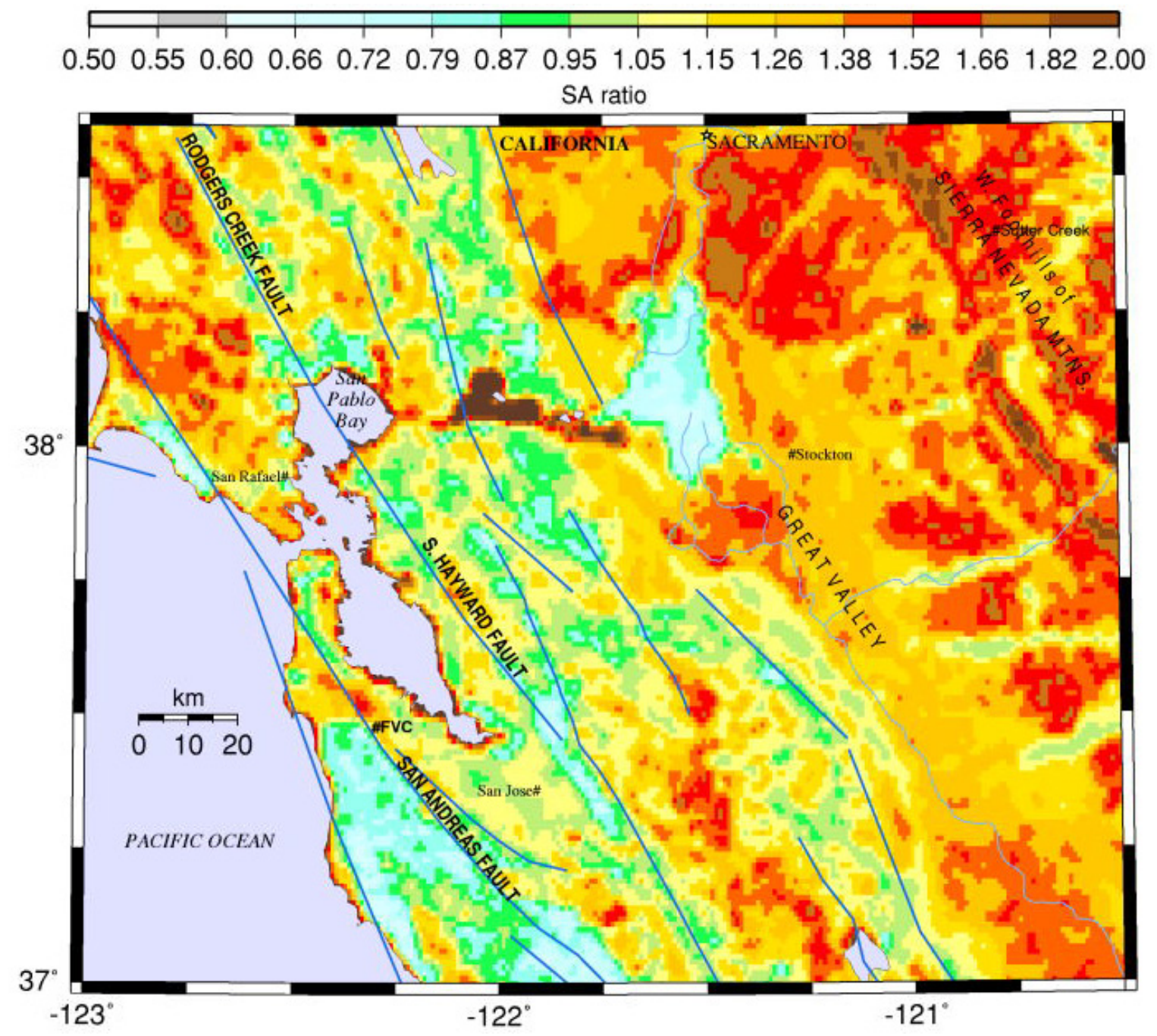

Figure 5. Regional scale site-specific hazard maps for central California, 3-second (s) spectral acceleration (SA). (km, kilometers; MTNS, Mountains)—Continued

$D$, Ratio of 3-s probabilistic motion in central California, where numerator is calculated using model 2 Vs30 (fig. $3 B$ ) and denominator is calculated using model $1 \mathrm{Vs} 30$. The average value of the ratio is 1.58 . 


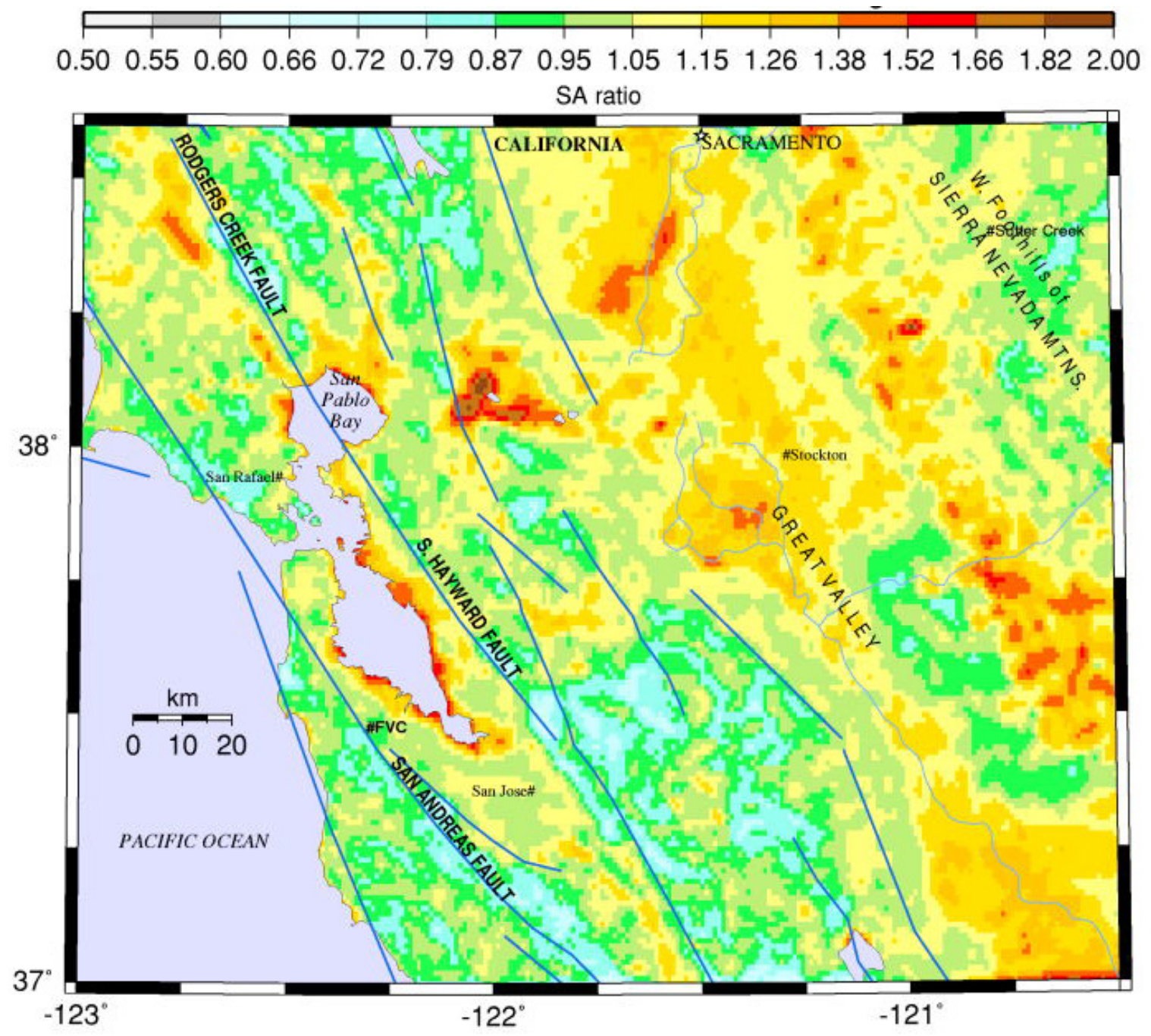

Figure 5. Regional scale site-specific hazard maps for central California, 3-second (s) spectral acceleration (SA). (km, kilometers; g, acceleration of gravity, $9.8 \mathrm{~m} / \mathrm{s}^{2}$; MTNS, Mountains)—Continued

$E$, Ratio of 3-s probabilistic motion in central California, where numerator is calculated using method 2 Vs30 (fig. 3B) and denominator is calculated using method 3 Vs30 (fig. 3C). The average value of the ratio is 1.18 . 


\section{Regional Scale Site-Specific Vs30 Maps for Southern California}

Patterns of correlation of ground motion with Vs30 that are illustrated above are equally evident in southern California hazard maps. Figure $6 A$ shows Vs30 for a region in southern California from method 1, figure $6 B$ shows Vs30 from method 2, and figure $6 C$ shows Vs30 from method 3. Some of the lowest-velocity sediments in this mapped region are found in the eastern Coachella Valley northwest of the Salton Sea and southwest of the SAF. These low seismic velocities are associated with the low-lying Salton Trough, which extends to the Mexico border. From a risk perspective, some of the most important low-Vs30 areas of figure 6 include the Los Angeles and San Bernardino basins, each with Vs30 of about 220 to $300 \mathrm{~m} / \mathrm{s}$. Method 2 predicts greater Vs30 than method 1 in the San Bernardino basin and predicts more rock at or near the $\mathrm{B} / \mathrm{C}$ boundary in the southern part of the map region. 


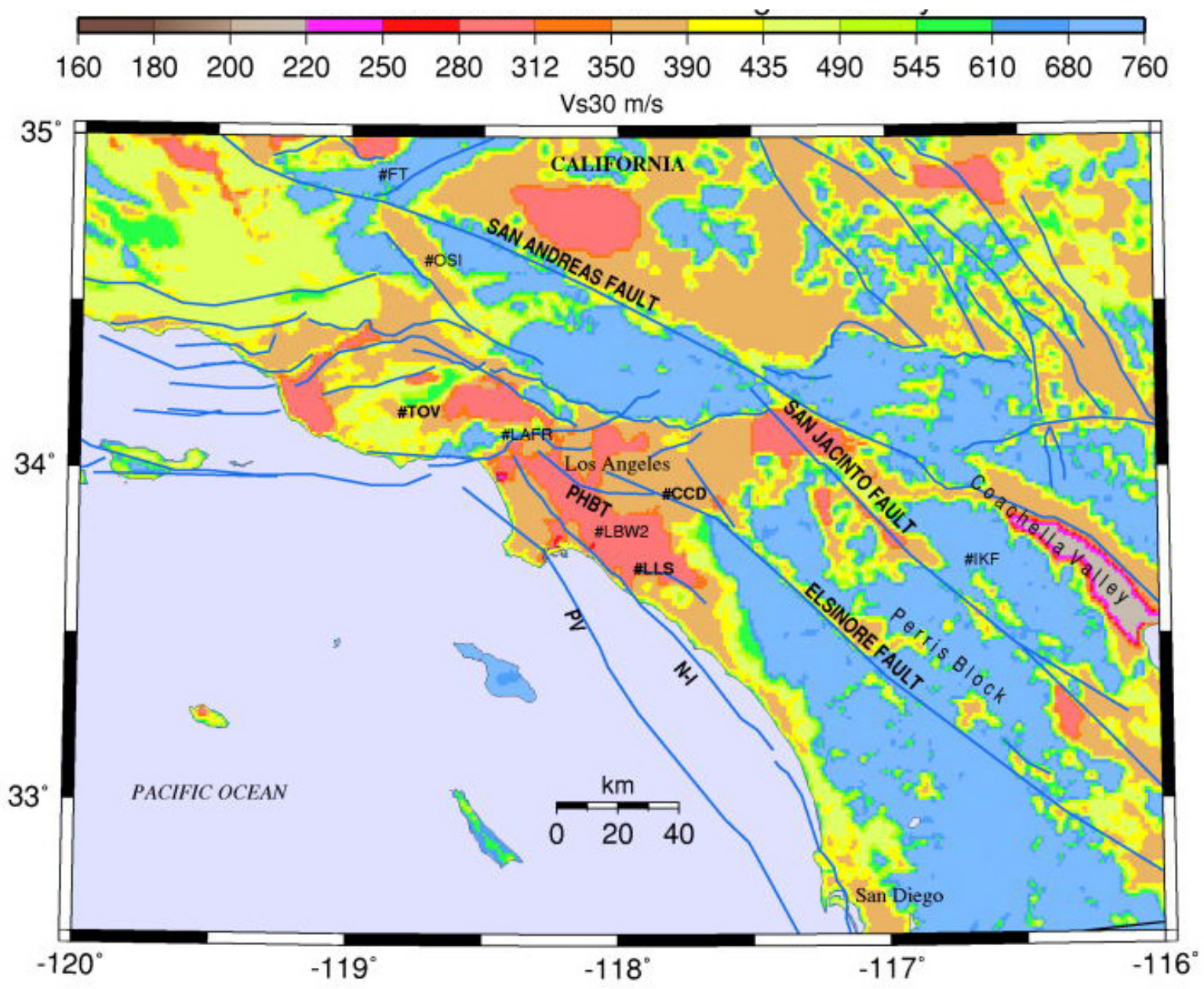

Figure 6. Regional scale site-specific Vs30 maps for southern California. ( $\mathrm{km}$, kilometers; $\mathrm{m} / \mathrm{s}$, meters per second; \#LA, Los Angeles site [discussed below]; CCD, Carbon Canyon Dam; COE, Colton Interchange E.; FT, Fort Tejon site; IKF, Idyllwild Keenwild Fire Station; LAFR, Los Angeles-N. Faring St.; LBW2, Long Beach; LLS, Fountain Valley [next to Santa Ana River]; N-I, Newport-Inglewood strikeslip fault system; OSI, Osito Audit-Castaic Lake Dam; PHBT, Puente Hills blind thrust fault system; PV, Palos Verdes strike-slip fault; TAR, Tarzana; TOV, Thousand Oaks [discussed below])

$A$, Vs30 map for a region in southern California, using method 1. 


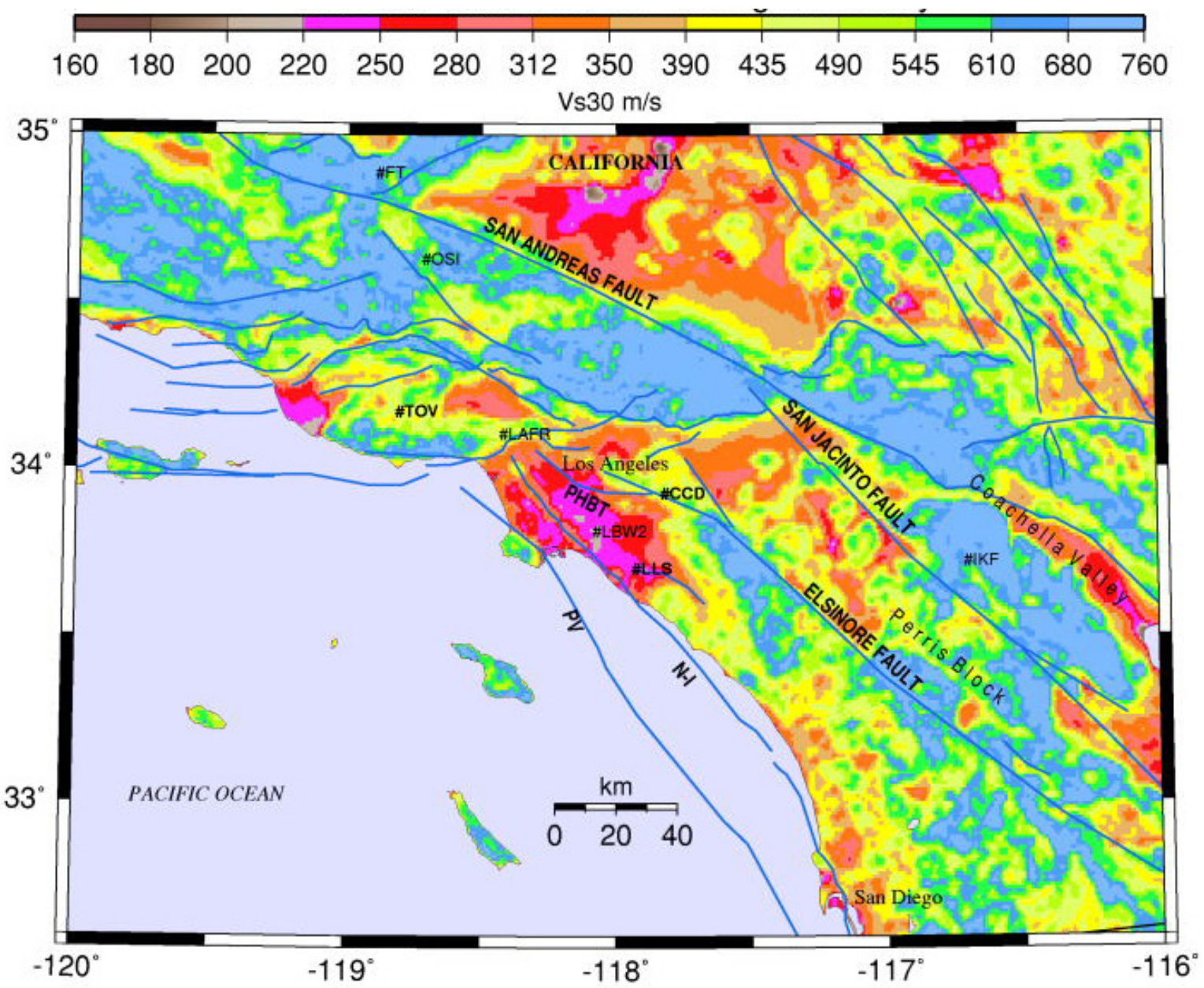

Figure 6. Regional scale site-specific Vs30 maps for southern California. (km, kilometers; $\mathrm{m} / \mathrm{s}$, meters per second; \#LA, Los Angeles site [discussed below]; CCD, Carbon Canyon Dam; COE, Colton Interchange E.; FT, Fort Tejon site; IKF, Idyllwild Keenwild Fire Station; LAFR, Los Angeles-N. Faring St.; LBW2, Long Beach; LLS, Fountain Valley [next to Santa Ana River]; N-I, Newport-Inglewood strikeslip fault system; OSI, Osito Audit-Castaic Lake Dam; PHBT, Puente Hills blind thrust fault system; PV, Palos Verdes strike-slip fault; TAR, Tarzana; TOV, Thousand Oaks [discussed below])—Continued

$B$, Vs30 map for a part of southern California, from the topographic slope method 2. 


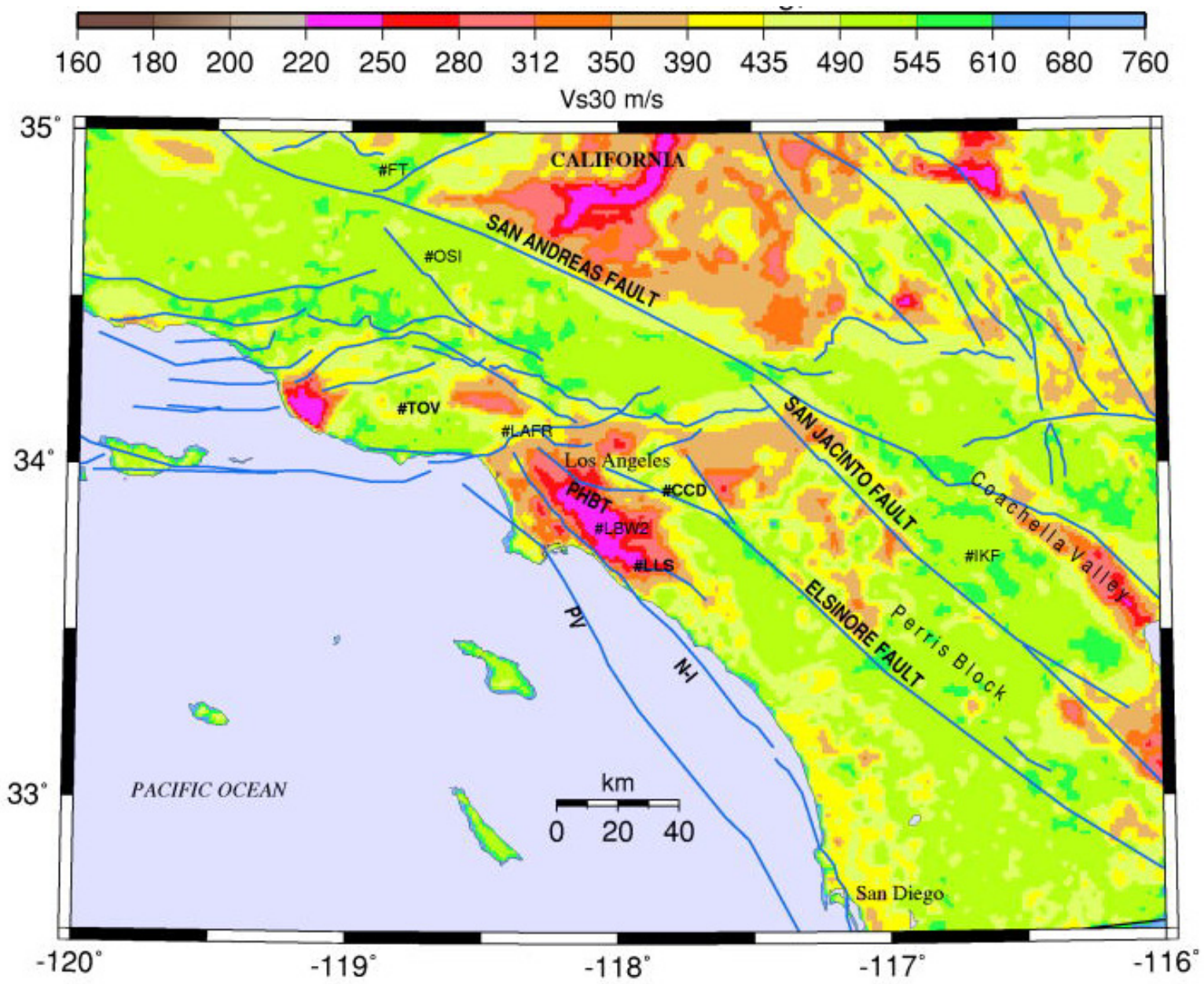

Figure 6. Regional scale site-specific Vs30 maps for southern California. ( $\mathrm{km}$, kilometers; $\mathrm{m} / \mathrm{s}$, meters per second; \#LA, Los Angeles site [discussed below]; CCD, Carbon Canyon Dam; COE, Colton Interchange E.; FT, Fort Tejon site; IKF, Idyllwild Keenwild Fire Station; LAFR, Los Angeles-N. Faring St.; LBW2, Long Beach; LLS, Fountain Valley [next to Santa Ana River]; N-I, Newport-Inglewood strikeslip fault system; OSI, Osito Audit-Castaic Lake Dam; PHBT, Puente Hills blind thrust fault system; PV, Palos Verdes strike-slip fault; TAR, Tarzana; TOV, Thousand Oaks [discussed below])—Continued C, Vs30 for southern California when using method 3. 


\section{Regional Scale Site-Specific Hazard Maps for Southern California}

Figures $7 A-C$, below, exhibit the site-specific 5-Hz SA with 2 percent in 50-year PE for the same region as figure 6 . As in central California, the 5-Hz probabilistic motion is reasonably symmetric around the San Andreas fault, even though media on the two sides of the fault may be firm rock versus relatively soft soil. Significant deamplification of the 5-Hz motion is evident in the eastern Coachella Valley on the southwest side of the SAF, where sediment Vs30 is less than $220 \mathrm{~m} / \mathrm{s}$. Probabilistic motion at $5 \mathrm{~Hz}$ is relatively symmetric on the two sides of the much less active Elsinore fault, even though at several locations the shallow portions of the respective blocks are rock and soil. The probabilistic 5-Hz motion is not amplified in the Los Angeles basin compared to neighboring regions with higher Vs30 values, in spite of the relatively low shallow shear-wave velocity in the LA basin. Figure $7 D$ shows the ratio of $5-\mathrm{Hz}$ SA using the data of figure $7 B$ divided by the data of figure $7 A$ to define the ratio. There are few locations where figures $7 A$ and $7 B$ differ significantly, even though there are many places where the corresponding Vs30 values differ significantly. It is not surprising that where one method predicts rock and the other predicts soil, differences can be significant. Rock at the B/C boundary has little nonlinear SP attenuation, whereas most soils have substantial SP attenuation of strong ground motion. Damping mechanisms in soil counter the amplification associated with lower rigidity and lower Vs30, yielding a reasonably stable SP motion estimate $(0.9<$ ratio $<1.1)$ in figure $7 D$. Figure $7 E$ also compares $5-\mathrm{Hz} \mathrm{SA}$, where the numerator again uses the method 2 Vs30 and denominator uses the method 3 Vs30. 


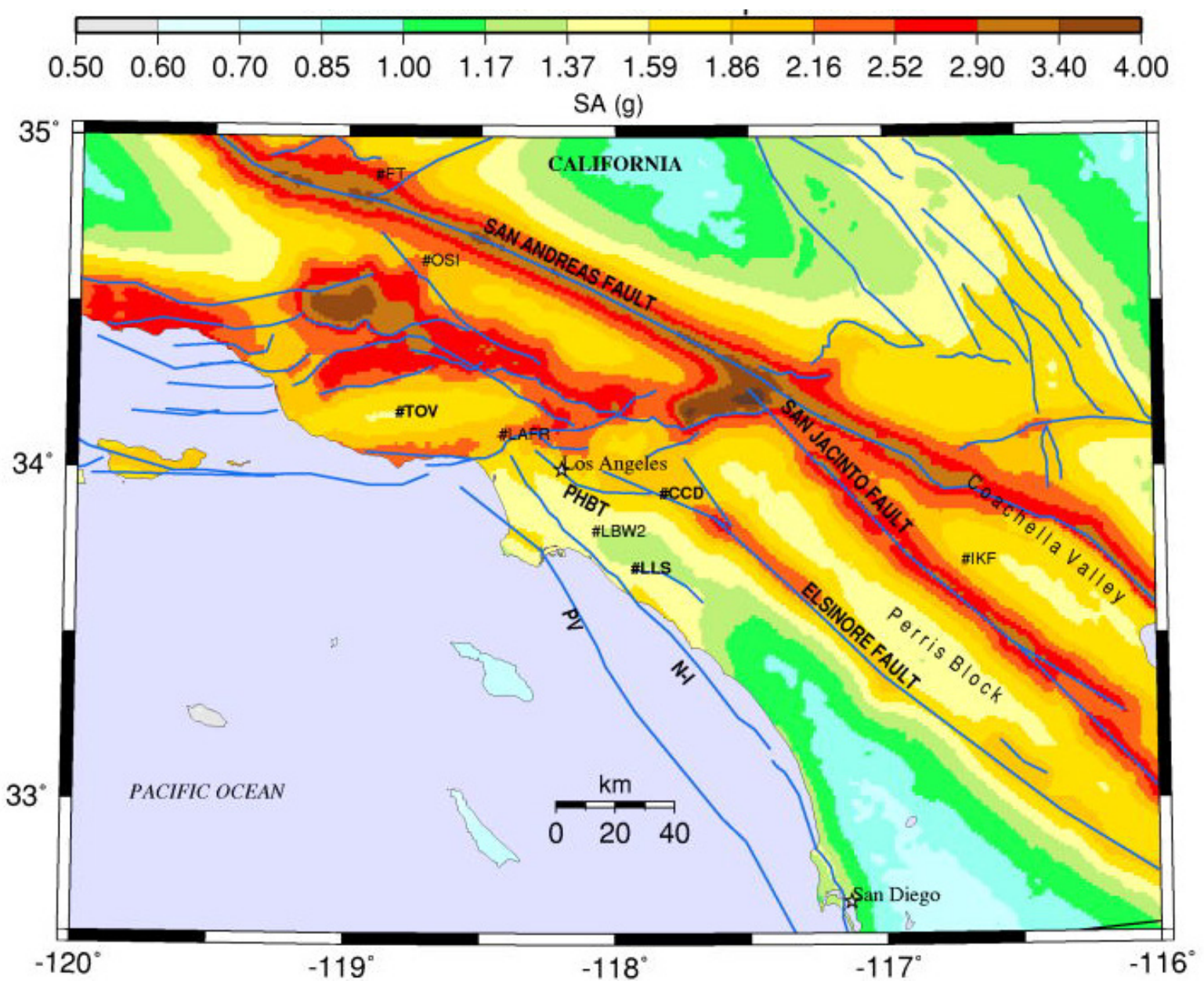

Figure 7. Regional scale site-specific hazard maps for southern California, 5-hertz $(\mathrm{Hz})$ spectral acceleration (SA). (km, kilometers; g, acceleration of gravity, $9.8 \mathrm{~m} / \mathrm{s}^{2} ; \mathrm{CCD}$, Carbon Canyon Dam; FT, Fort Tejon site; IKF, Idyllwild Keenwild Fire Station; LAFR, Los Angeles-N. Faring St.; LBW2, Long Beach; LLS, Fountain Valley [next to Santa Ana River]; OSI, Osito Audit-Castaic Lake Dam; PHBT, Puente Hills blind thrust fault system; TOV, Thousand Oaks)

$A$, Site-specific 5-hz SA in southern California corresponding to figure $6 A$ (method 1 Vs30 model). 


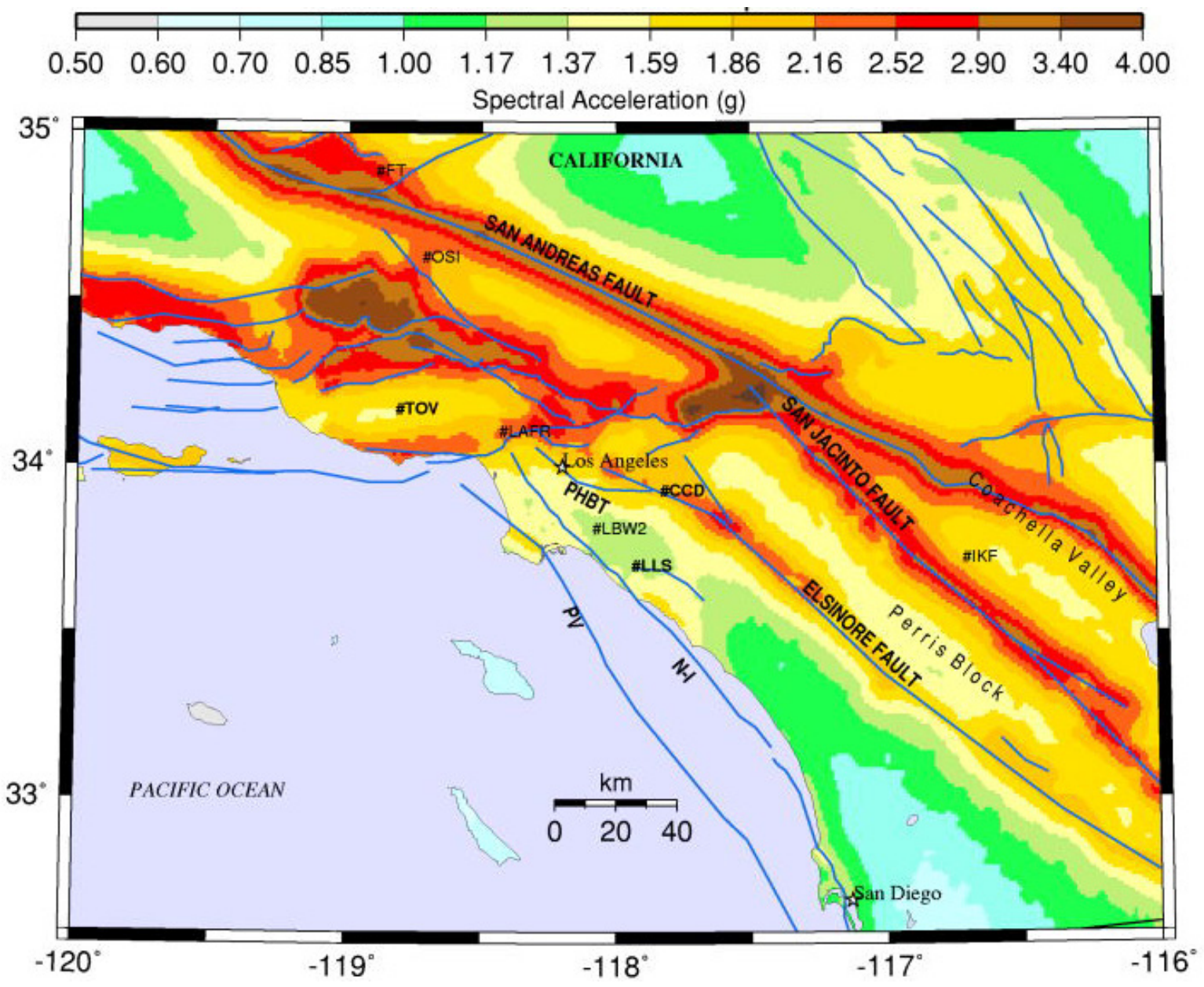

Figure 7. Regional scale site-specific hazard maps for central California, 5-Hertz (hz) spectral acceleration (SA). (km, kilometers; g, acceleration of gravity, $9.8 \mathrm{~m} / \mathrm{s}^{2}$; CCD, Carbon Canyon Dam; FT, Fort Tejon site; IKF, Idyllwild Keenwild Fire Station; LAFR, Los Angeles-N. Faring St.; LBW2, Long Beach; LLS, Fountain Valley [next to Santa Ana River]; N-I, Newport-Inglewood fault; OSI, Osito AuditCastaic Lake Dam; PHBT, Puente Hills blind thrust fault system; PV, Palos Verde fault; SAF, San Andreas fault; TOV, Thousand Oaks)-Continued

$B$, Site-specific 5-hz SA in southern California corresponding to figure $6 B$ (method 2 Vs30 model). 


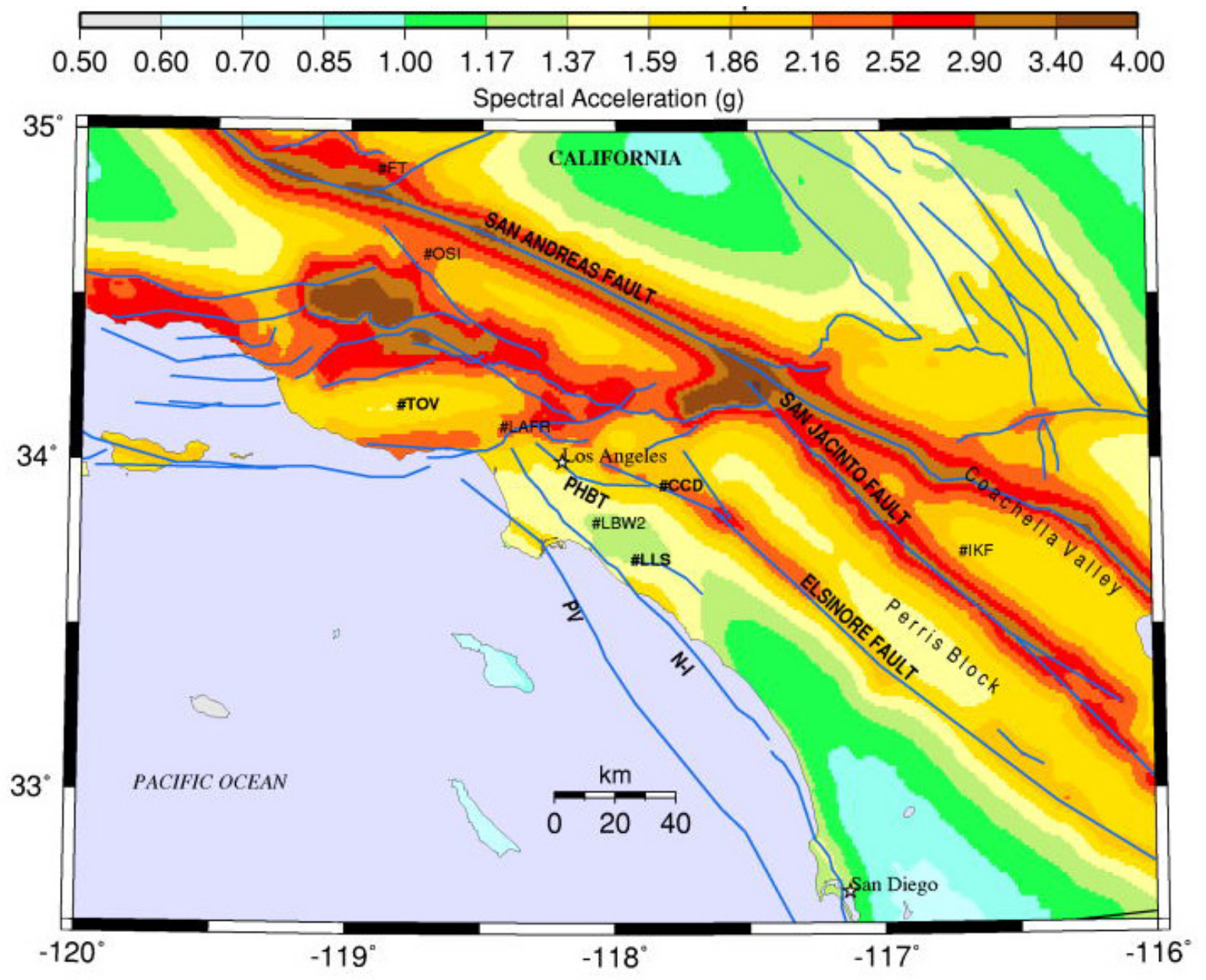

Figure 7. Regional scale site-specific hazard maps for central California, 5-Hertz (hz) spectral acceleration (SA). (km, kilometers; g, acceleration of gravity, $9.8 \mathrm{~m} / \mathrm{s}^{2} ; \mathrm{CCD}$, Carbon Canyon Dam; FT, Fort Tejon site; IKF, Idyllwild Keenwild Fire Station; LAFR, Los Angeles-N. Faring St.; LBW2, Long Beach; LLS, Fountain Valley [next to Santa Ana River]; N-I, Newport-Inglewood fault; OSI, Osito AuditCastaic Lake Dam; PHBT, Puente Hills blind thrust fault system; PV, Palos Verde fault; SAF, San Andreas fault; TOV, Thousand Oaks)—Continued

C, Site-specific 5-hz SA in southern California corresponding to figure 6C (method 3 Vs30 model). 


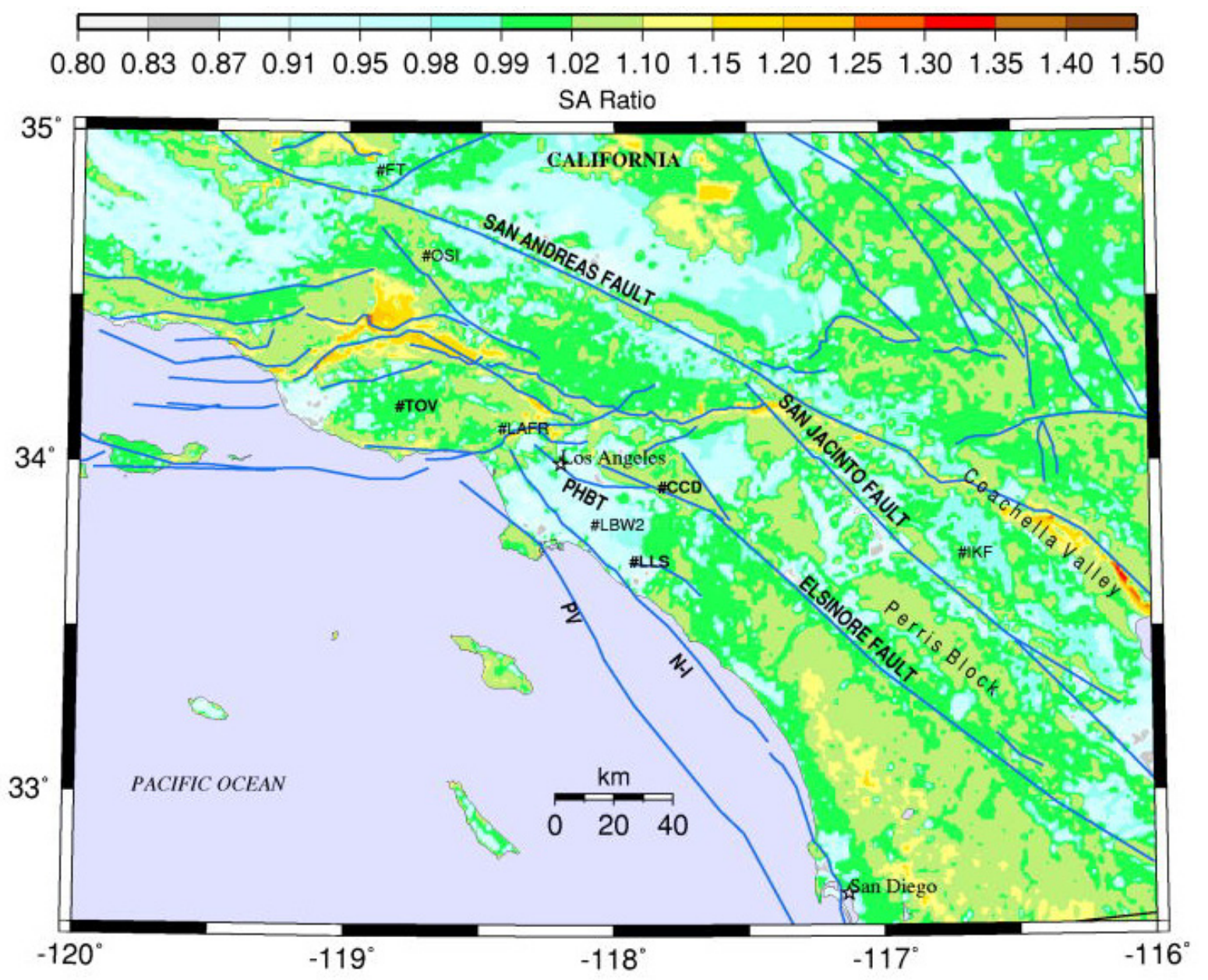

Figure 7. Regional scale site-specific hazard maps for central California, 5-Hertz (hz) spectral acceleration (SA). (km, kilometers; $\mathrm{g}$, acceleration of gravity, $9.8 \mathrm{~m} / \mathrm{s}^{2} ; \mathrm{CCD}$, Carbon Canyon Dam; FT, Fort Tejon site; IKF, Idyllwild Keenwild Fire Station; LAFR, Los Angeles-N. Faring St:; LBW2, Long Beach; LLS, Fountain Valley [next to Santa Ana River]; N-I, Newport-Inglewood fault; OSI, Osito AuditCastaic Lake Dam; PHBT, Puente Hills blind thrust fault system; PV, Palos Verde fault; SAF, San Andreas fault; TOV, Thousand Oaks)—Continued

$D$, Ratio of probabilistic site specific 5-hz SA, where numerator uses Vs30 from method 2 and denominator uses Vs30 from method 1. 


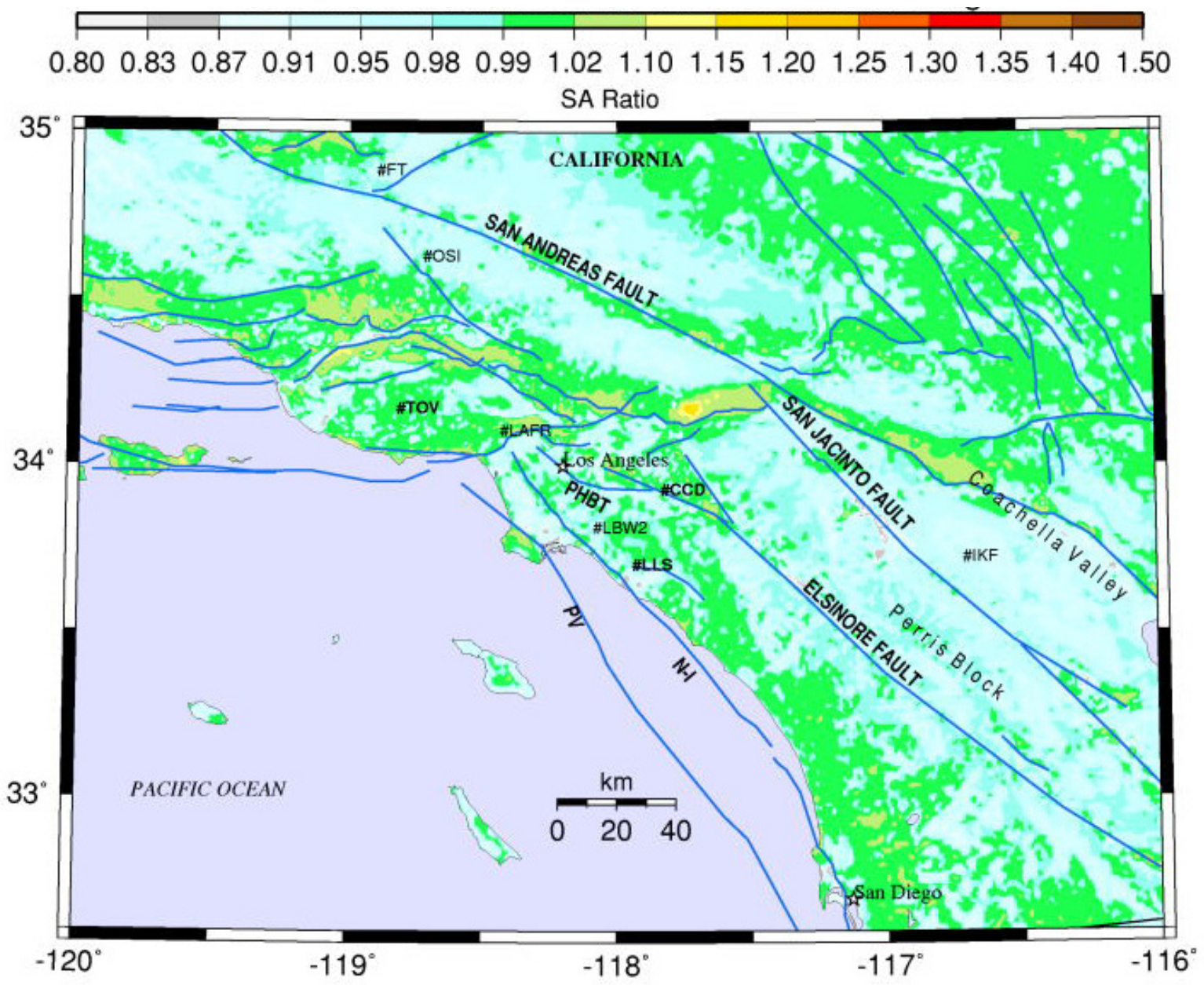

Figure 7. Regional scale site-specific hazard maps for central California, 5-Hertz (hz) spectral acceleration (SA). (km, kilometers; g, acceleration of gravity, $9.8 \mathrm{~m} / \mathrm{s}^{2} ; \mathrm{CCD}$, Carbon Canyon Dam; FT, Fort Tejon site; IKF, Idyllwild Keenwild Fire Station; LAFR, Los Angeles-N. Faring St.; LBW2, Long Beach; LLS, Fountain Valley [next to Santa Ana River]; N-I, Newport-Inglewood fault; OSI, Osito AuditCastaic Lake Dam; PHBT, Puente Hills blind thrust fault system; PV, Palos Verde fault; SAF, San Andreas fault; TOV, Thousand Oaks)_Continued

$E$, Ratio of probabilistic site specific 5-hz SA, where numerator uses Vs30 from method 2 and denominator uses Vs30 from method 3. 
Figures $8 A-C$ exhibit the site-specific 3-s SA for 2 percent in 50-year PE for a part of southern California. These figures, like the corresponding figures for central California, often show an asymmetric ground motion distribution around the major faults that is strongly correlated with Vs30. For example, the 3-s motion in the eastern Coachella Valley southwest of the SAF is significantly greater than at corresponding distances northeast of the SAF, at least in figures $8 A$ and $8 B$. The LP probabilistic motions at sites between the SAF and San Jacinto fault are some of the highest in the state, but the corresponding short-period motions are only high, not extremely high. The Coachella Valley is a region of special concern because the Coachella segment of the SAF is believed to be near the end of its seismic cycle, likely to rupture in the next few decades (Fialco, 2006; Weldon and others, 2008). Between the Elsinore and San Jacinto faults (the Perris block), various soil patches with an approximate 5-km radius are quite evident in the 3-s maps but are not apparent in the 5-Hz maps. In the vicinity of the San Andreas, San Jacinto, and Elsinore faults, Vs30 differences evident in figures $6 A$ and $6 B$ map into LP groundmotion differences in figures $8 A$ and $8 B$. Near Long Beach, Calif., figures $8 A$ and $8 B$ exhibit several locations with higher motion than figure $8 C$ because of the low-Vs sediments in figures $6 A$ and $6 B$, but not in $6 C$. 


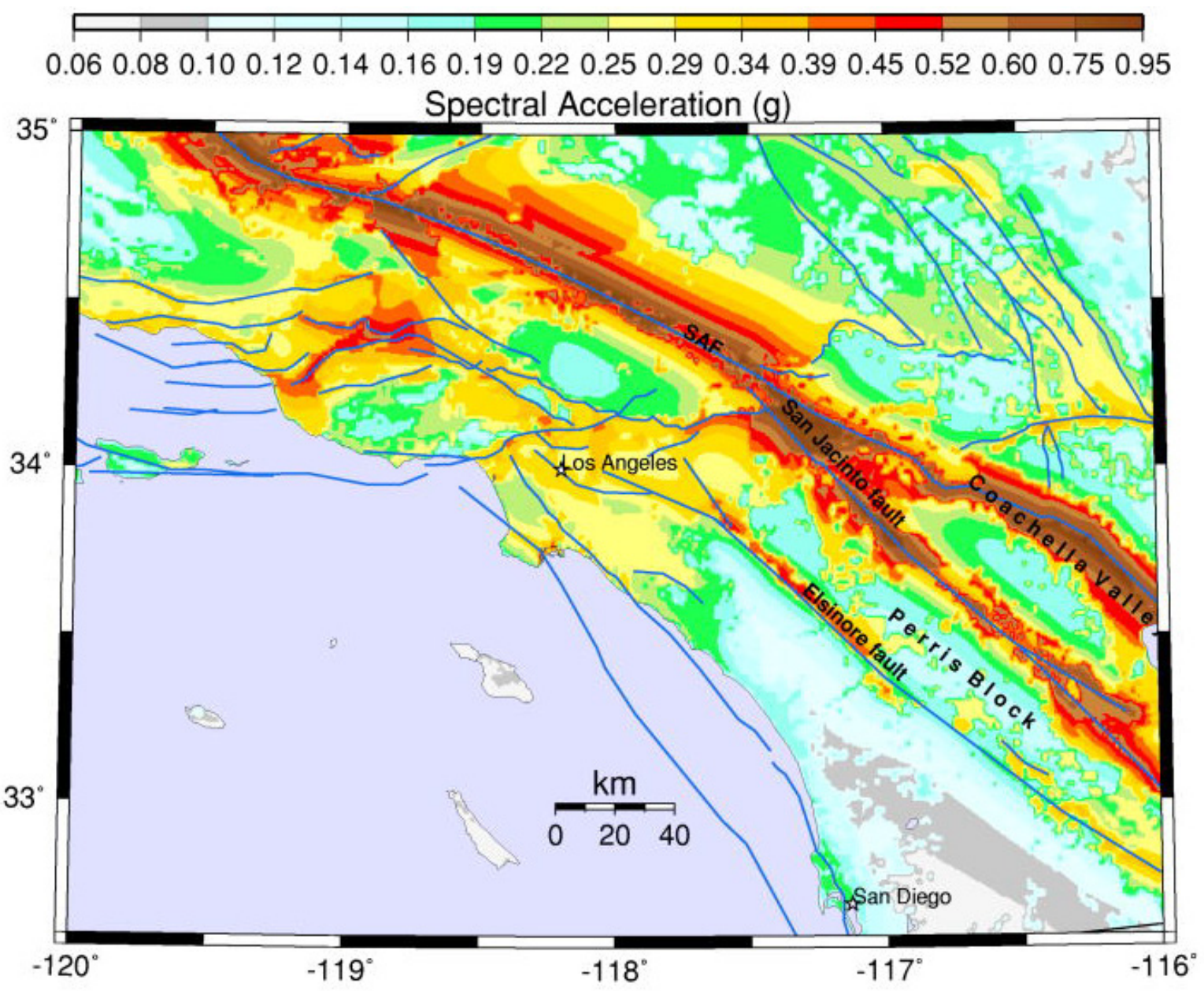

Figure 8. Regional scale site-specific hazard maps for central California, 3-second (s) spectral acceleration (SA). (km, kilometers; $\mathrm{g}$, acceleration of gravity, $9.8 \mathrm{~m} / \mathrm{s}^{2} ; \mathrm{CCD}$, Carbon Canyon Dam; FT, Fort Tejon site; IKF, Idyllwild Keenwild Fire Station; LAFR, Los Angeles-N. Faring St.; LBW2, Long Beach; LLS, Fountain Valley [next to Santa Ana River]; N-I, Newport-Inglewood fault; OSI, Osito AuditCastaic Lake Dam; PHBT, Puente Hills blind thrust fault system; PV, Palos Verde fault; SAF, San Andreas fault; TOV, Thousand Oaks)

A, Site-specific 3.0-s SA in southern California, using method 1 Vs30. 


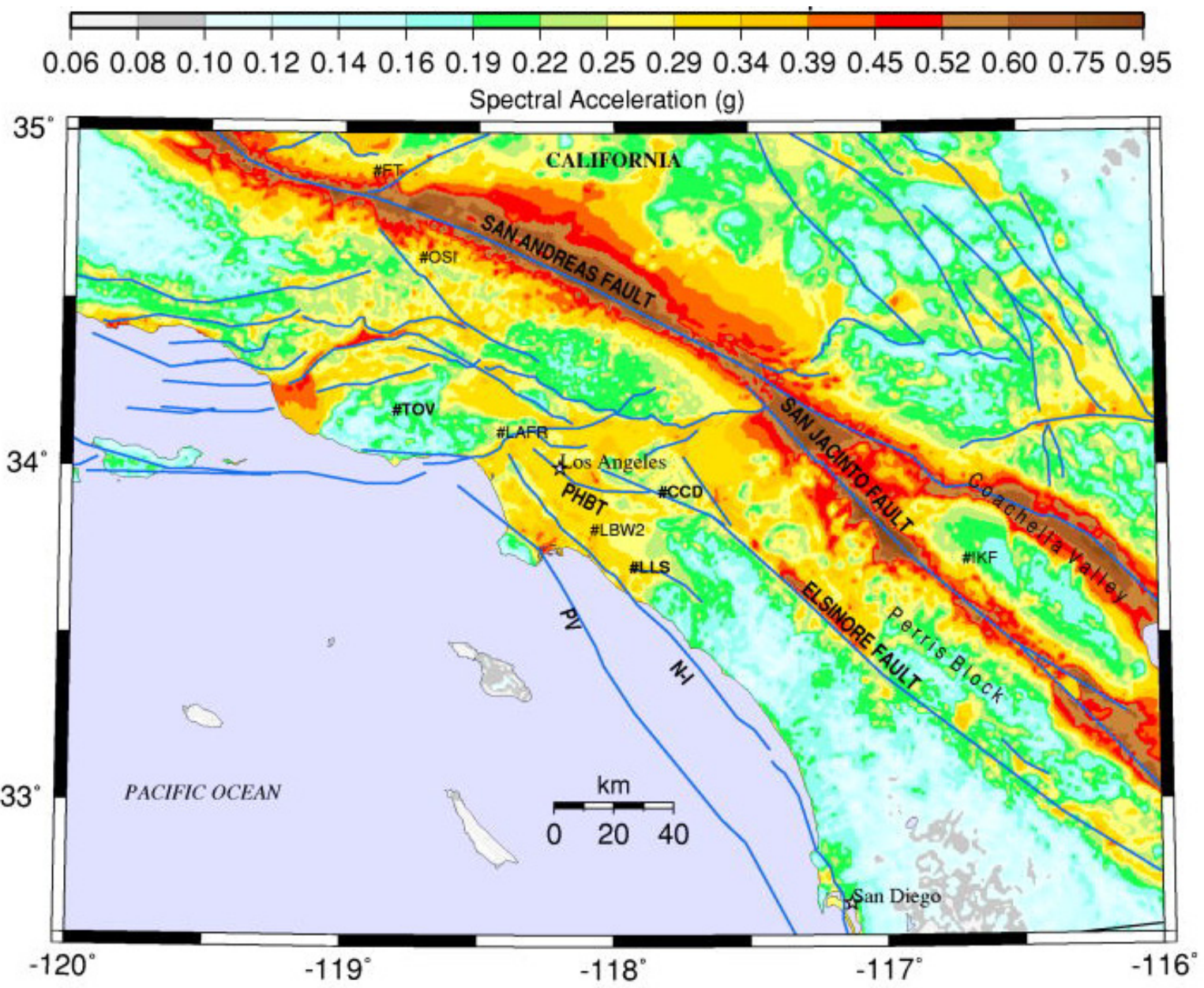

Figure 8. Regional scale site-specific hazard maps for central California, 3-second (s) spectral acceleration (SA). (km, kilometers; g, acceleration of gravity, $9.8 \mathrm{~m} / \mathrm{s}^{2} ; \mathrm{CCD}$, Carbon Canyon Dam; FT, Fort Tejon site; IKF, Idyllwild Keenwild Fire Station; LAFR, Los Angeles-N. Faring St.; LBW2, Long Beach; LLS, Fountain Valley [next to Santa Ana River]; N-I, Newport-Inglewood fault; OSI, Osito AuditCastaic Lake Dam; PHBT, Puente Hills blind thrust fault system; PV, Palos Verde fault; SAF, San Andreas fault; TOV, Thousand Oaks)_Continued

$B$, Site-specific 3.0-s SA in southern California, using method 2 Vs30. 


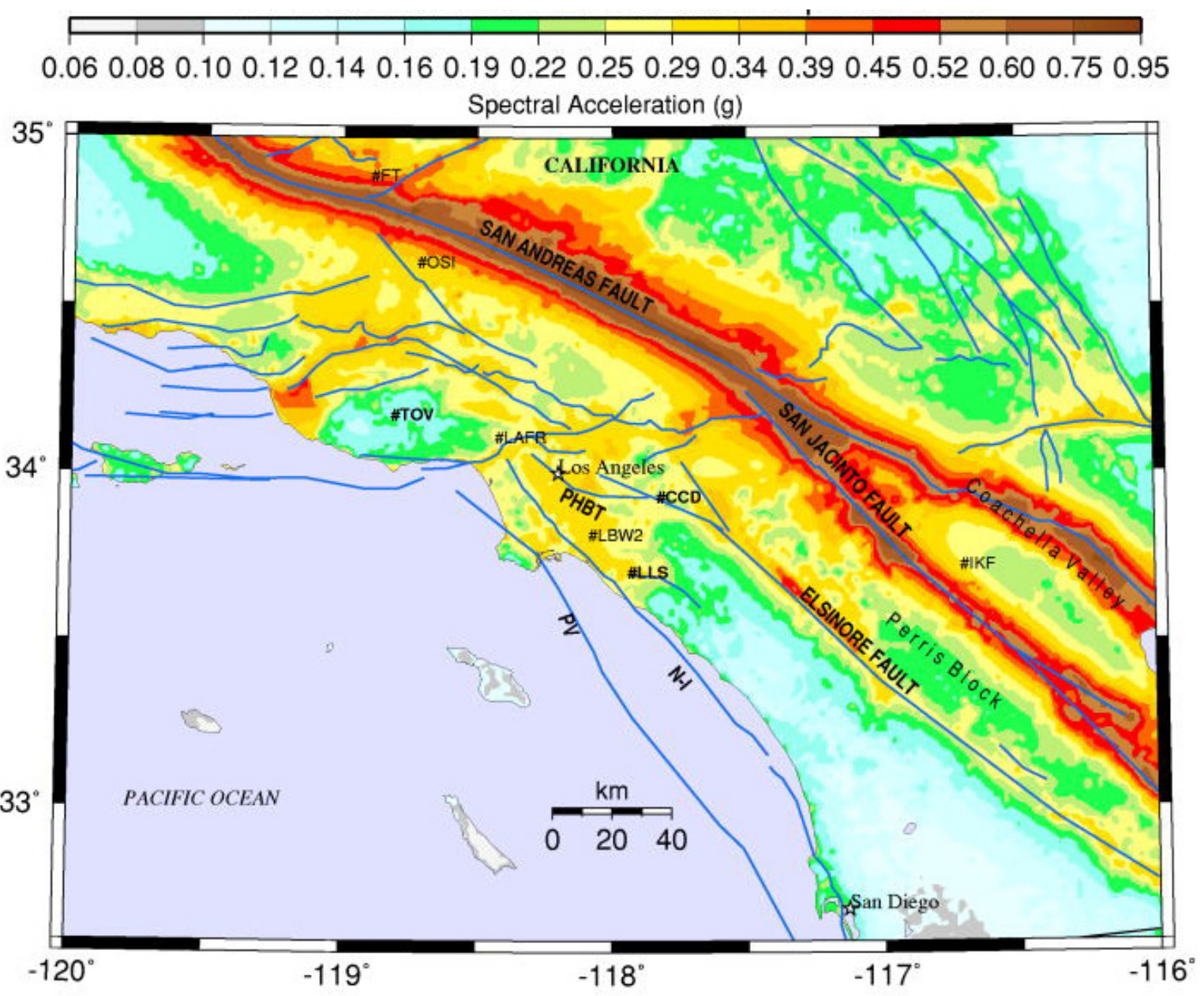

Figure 8. Regional scale site-specific hazard maps for central California, 3-second (s) spectral acceleration (SA). (km, kilometers; g, acceleration of gravity, $9.8 \mathrm{~m} / \mathrm{s}^{2} ; \mathrm{CCD}$, Carbon Canyon Dam; FT, Fort Tejon site; IKF, Idyllwild Keenwild Fire Station; LAFR, Los Angeles-N. Faring St:; LBW2, Long Beach; LLS, Fountain Valley [next to Santa Ana River]; N-I, Newport-Inglewood fault; OSI, Osito AuditCastaic Lake Dam; PHBT, Puente Hills blind thrust fault system; PV, Palos Verde fault; SAF, San Andreas fault; TOV, Thousand Oaks)—Continued

C, Site-specific 3.0-s SA in southern California, using method 3 Vs30. 
To further explore sensitivity of LP motion to differences in Vs30 estimates, figures $8 D$ and $8 E$ exhibit 3-s SA ratios for this southern California region. Figure $8 D$, SA from method 2 over SA from method 1, shows 5-40 percent larger LP SA in the greater Los Angeles urban region when using the Wald and Allen (2007) estimate of Vs30 versus using the hybrid Wills and Clahan (2006) estimate. The greatest differences in the greater LA region occur between the Newport-Inglewood and Palos Verdes faults. Strong LP SA differences, sometimes in excess of 100 percent (dark brown spots in figure $8 D$ ) are found in parts of the Perris block and elsewhere. Figure $8 E$, SA from method 2 over SA from method 3, shows less variability in much of the greater Los Angeles region between Wald and Allen (2007) and Yong and others (in press). Again, the Wald and Allen method predicts lower Vs30 and therefore greater 3-s SA than Yong and others between the Newport-Inglewood and Palos Verdes faults. 


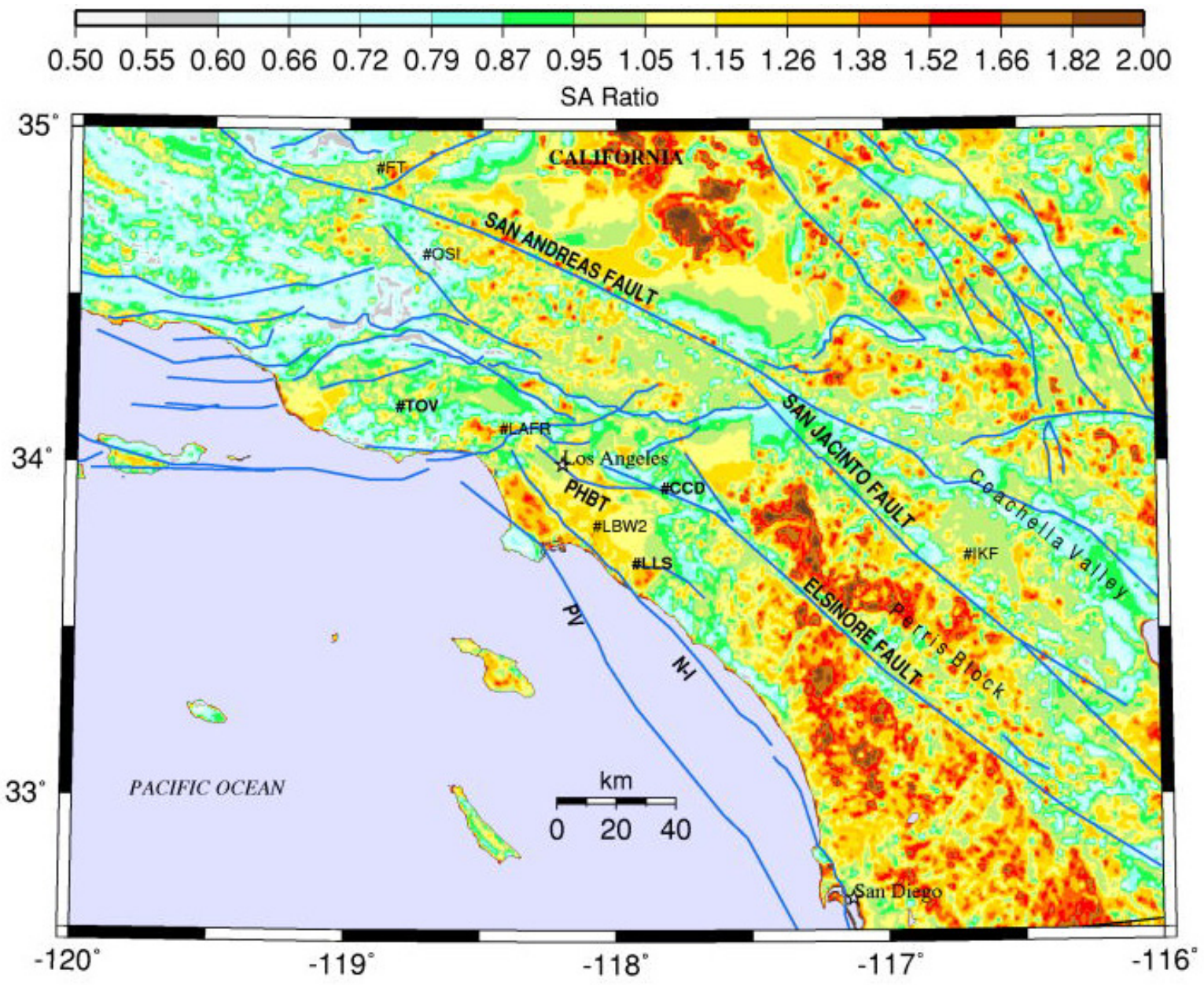

Figure 8. Regional scale site-specific hazard maps for central California, 3-second (s) spectral acceleration (SA). (km, kilometers; g, acceleration of gravity, $9.8 \mathrm{~m} / \mathrm{s}^{2} ; \mathrm{CCD}$, Carbon Canyon Dam; FT, Fort Tejon site; IKF, Idyllwild Keenwild Fire Station; LAFR, Los Angeles-N. Faring St.; LBW2, Long Beach; LLS, Fountain Valley [next to Santa Ana River]; N-I, Newport-Inglewood fault; OSI, Osito AuditCastaic Lake Dam; PHBT, Puente Hills blind thrust fault system; PV, Palos Verde fault; SAF, San Andreas fault; TOV, Thousand Oaks)-Continued

$D$, Ratio of site-specific 3.0-s SA, where numerator uses method 2 to estimate $\mathrm{Vs} 30$ and denominator uses method 1. 


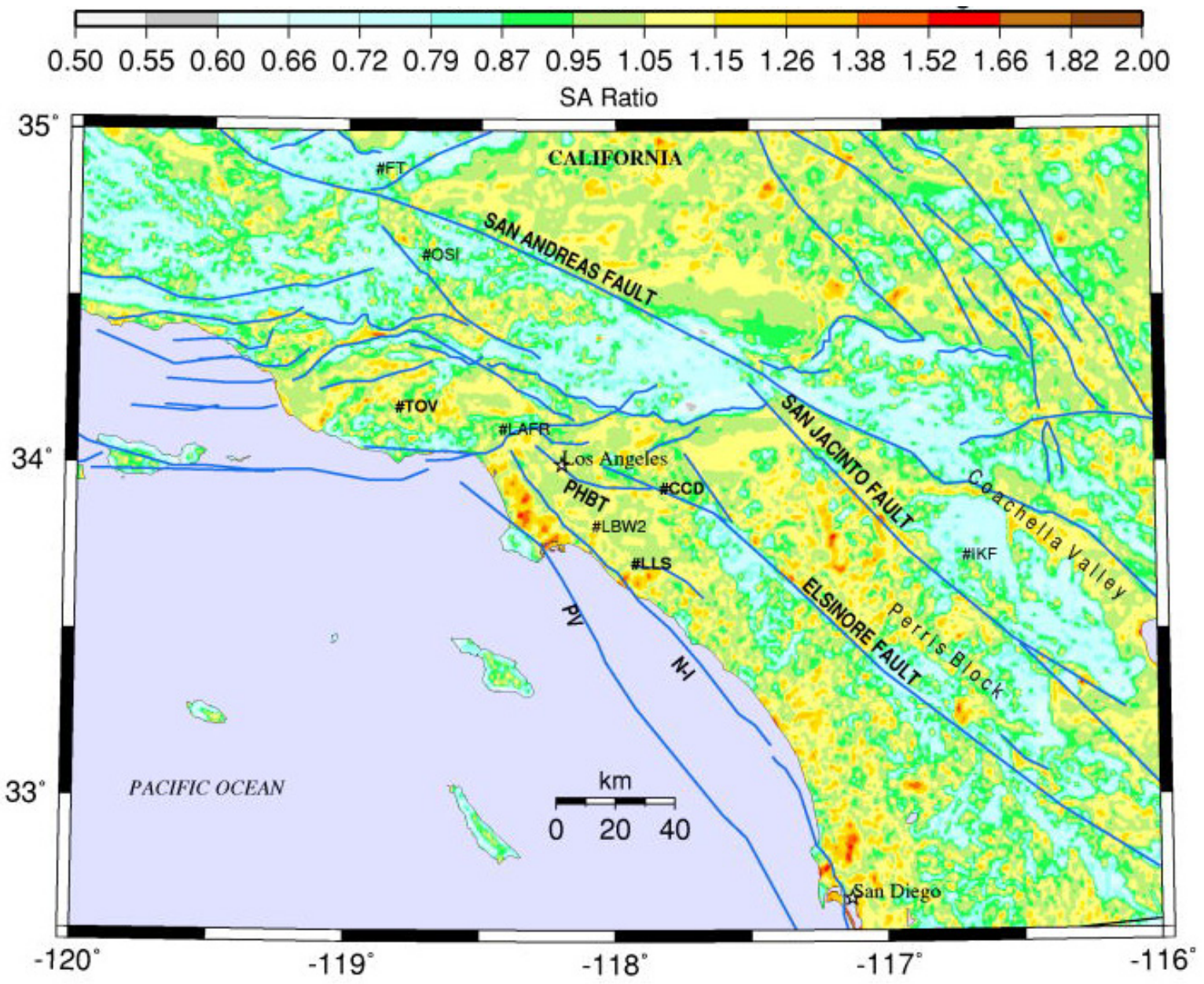

Figure 8. Regional scale site-specific hazard maps for central California, 3-second (s) spectral acceleration (SA). (km, kilometers; g, acceleration of gravity, $9.8 \mathrm{~m} / \mathrm{s}^{2} ; \mathrm{CCD}$, Carbon Canyon Dam; FT, Fort Tejon site; IKF, Idyllwild Keenwild Fire Station; LAFR, Los Angeles-N. Faring St.; LBW2, Long Beach; LLS, Fountain Valley [next to Santa Ana River]; N-I, Newport-Inglewood fault; OSI, Osito AuditCastaic Lake Dam; PHBT, Puente Hills blind thrust fault system; PV, Palos Verde fault; SAF, San Andreas fault; TOV, Thousand Oaks) - Continued

E, Ratio of site-specific 3.0-s SA, where numerator uses method 2 to estimate $V \mathrm{~s} 30$ and denominator uses method 3. 


\section{Deaggregation of Seismic Hazard at Specific Sites}

The strong effect that local site conditions have on probabilistic motion, generally for lower velocity sediments to amplify strong long-period motion and to deamplify strong shortperiod motion, suggests that the influence of different earthquake sources is highly dependent on the site condition and that this influence is also highly dependent on the spectral period or periods of interest. Thus, seismic hazard deaggregations should explicitly consider local shallowsoil effects (and deep basin effects as well) wherever possible. The USGS Geologic Hazards Science Center maintains an easy-to-use online seismic hazard deaggregation tool in which local Vs30 is one of the input parameters: https://geohazards.usgs.gov/deaggint/2008/. The source and GMPE models of the NSHMP model described in Petersen and others (2008) are built into this tool.

An early working hypothesis of engineers who required site-specific seismic hazard deaggregations is that the deaggregation for a soil site should be essentially the same as that for a rock site at the same location but with appropriately scaled ground motion, for example, using the NEHRP soil factors above. Implicit in this hypothesis is the assumption that nonlinear soil response should affect contributions from all sources in the model, if at all, to approximately the same degree. However, nonlinear soil damping is a far more important factor when predicting strong motion from the closer, larger source than weaker motion from the more distant or smaller source, as schematically shown in figure 1. In tectonically active regions with many well characterized faults, the nearest fault to the site is often the dominant source in seismic hazard deaggregations on rock. While explicit consideration of the soil column's effect does not tend to overturn this generalization, soil's nonlinear response often significantly modifies the relative contribution of this modal source. The ratio of the modal source rate to the total rate of exceedances is called the mode participation factor (MPF). In some instances, the modal (M,R) shifts from this nearest large source to a more distant source. This report examines some of these instances of reduced MPF and cases involving a significant shift in the modal (M,R).

As illustrated in figure 1, the probability of exceeding $\exp (0.0)=1.0 \mathrm{~g}$ (acceleration of gravity, $9.8 \mathrm{~m} / \mathrm{s}^{2}$ ) is considerably greater for the rock site (left; 0.5 versus 0.083 ), but it is considerably greater for the soil site (right; 0.023 versus 0.0024 ). The modal event is the source that produces the most ground-motion exceedances, which from equation 1 is a product of frequency of the event and probability of exceedance, given the occurrence of that event. Under the assumption that the frequency of the smaller, more distant source is greater than that of the larger source, the SA (and return time) where the modal event switches to the larger event is delayed when considering site-specific soil conditions because of SP vibration damping in the soil column. For the hypothetical data of figure 1, this switch may occur at about 1-g SA at a soil site if the smaller, more distant source has about 21 times the annual frequency of the larger, closer source. At a rock site, with all other things equal, this switch will occur at about $0.44 \mathrm{~g}$. If the mean return time of $0.44 \mathrm{~g}$ is 100 years at the rock site, the mean return time of $1 \mathrm{~g}$ at the soil site (given just these two sources) is 182 years, representing a significant delay in the modalevent switchover to the larger, closer source. In the NSHMP 2008 PSHA model, nonlinear effects are not quite as dramatic as those illustrated in figure 1, which uses round numbers to keep the discussion simple.

This section describes two general cases encountered in the deaggregation of the NSHMP 2008 SH model: (1) sites where the modal event for soil and rock site conditions are the same, but the relative contribution of the soil-site mode is less than the rock-site mode, and (2) sites 
where the modal event actually shifts to a more distant source when site condition is taken into account inside the integral (equation 1) instead of assuming the default rock site condition.

\section{Case I. Soil Mode Same as Rock Mode}

Current seismic-resistant design practice bases the design spectrum on a spectral amplitude at two periods, $\mathrm{T}=0.2 \mathrm{~s}(\mathrm{SP})$ and $\mathrm{T}=1.0 \mathrm{~s}$ (IP). In this article, we select these two periods to illustrate soil versus rock deaggregations. The online tool mentioned above allows users to specify $\mathrm{T}$, from 0.1 to $5.0 \mathrm{~s}$, and PGA.

The first example of soil versus rock probabilistic seismic hazard deaggregation corresponds to a site in the Los Angeles Basin. The California Geological Survey compiled several versions of Vs30 for the entire State; soil-site Vs30 estimates are taken from the latest of these models (Branum and others, 2008). The site is at $34.05^{\circ} \mathrm{N}, 118.25^{\circ} \mathrm{W}$, near the Disney Concert Hall. Vs30 is estimated to be $285 \mathrm{~m} / \mathrm{s}$ (NEHRP class D soil). The Vs30 estimate from figure $6 B$ is $360 \mathrm{~m} / \mathrm{s}$ (NEHRP class C/D). Borehole measurements at a nearby California Geological Survey strong-motion site, LA Temple and Hope at $34.059^{\circ} \mathrm{N}, 118.246^{\circ} \mathrm{W}$, yield Vs 30 of $376 \mathrm{~m} / \mathrm{s}$. Table 1 shows the spectral accelerations having 2 percent in 50-year PE and the principal fault sources contributing to SP and IP hazard at this site, given rock or soil site conditions. Also tabulated are the percentage of SA exceedances contributed by the principle sources conditioned on rock or soil site and the corresponding epsilon $\left(\varepsilon_{0}\right)$ values. Figure 9 shows the hazardous faults in the vicinity of the LA Temple and Hope site. The longest brown curve in figure 9 is the Puente Hills Connected fault.

Table 1. Important future earthquake sources in Los Angeles, California.

$[\mathrm{m} / \mathrm{s}$, meters per second; SA, spectral acceleration; s, second; $g$, acceleration of gravity; Char., characteristic rupture model; avg. $\left(\varepsilon_{0}\right)$, average epsilon; GMPE, ground-motion prediction equation]

\begin{tabular}{lcc}
\hline Site Vs30 (m/s) & 760 & 285 \\
SA at 0.2 s $(g)$ & 2.306 & 1.868 \\
Main source: Elysian Park Char. & $27.1 \%$ & $20.8 \%$ \\
Main source 2: Puente Hills 1\&2 Char.* & $17.3 \%$ & $12.6 \%$ \\
Avg $\left(\varepsilon_{0}\right)$ : all sources, all GMPEs & 1.03 & 1.36 \\
SA at 1.0 s $(g)$ & 0.673 & 1.188 \\
Main source: Elysian Park Char. & $27.1 \%$ & $29.7 \%$ \\
Main source 2: Puente Hills 1\&2 Char.* & $17.7 \%$ & $16.7 \%$ \\
Avg $\left(\varepsilon_{0}\right)$ : all sources, all GMPEs & 1.10 & 1.16 \\
\hline
\end{tabular}

*Puente Hills $1 \& 2$ is a pooled contribution from the Los Angeles segment and the all-segment Puente Hills characteristic rupture models. 


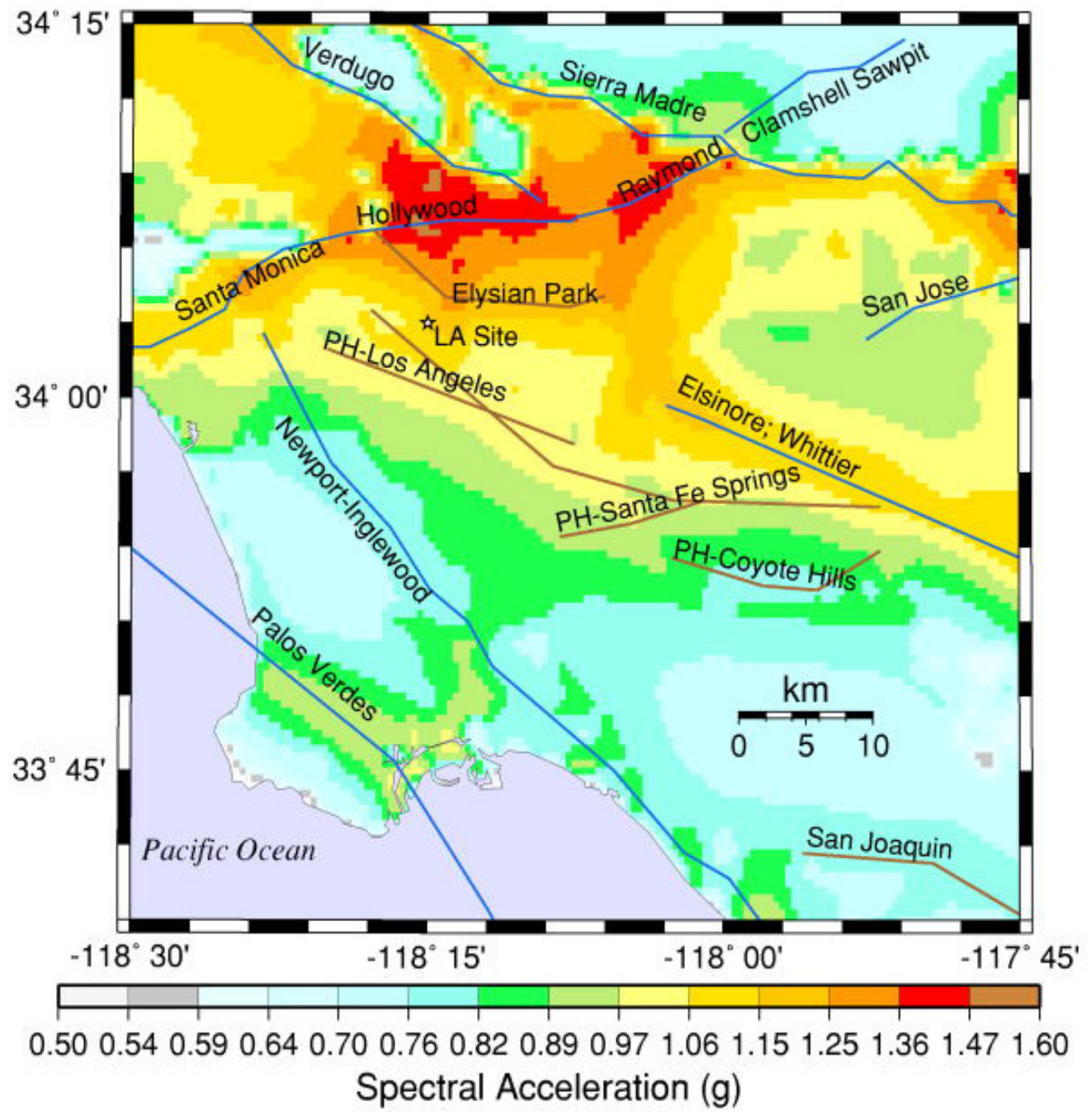

Figure 9. Map showing principal faults in the vicinity of the Los Angeles (LA) site. Traces of surface rupturing faults are depicted in blue; blind thrusts are brown. Base map shows the site-specific 1second spectral acceleration at 2 percent in 50 year probability of exceedance, using method 1 to estimate Vs30. (km, kilometer; g, acceleration of gravity, $9.8 \mathrm{~m} / \mathrm{s}^{2} ; \mathrm{PH}$, Puente Hills blind thrust fault system)

For SP hazard, table 1 shows that the biggest contributor (perhaps the modal source, depending on how the deaggregation is performed) and the second biggest contributor both have significantly reduced influence on the soil hazard compared to the rock hazard. The higher $\operatorname{avg}\left(\varepsilon_{0}\right)$ for soil versus rock motion with specified probability of exceedance is a manifestation of the reduction of importance of nearby sources on soil: more distant (higher $\varepsilon_{0}$ ) sources take up the slack. For the IP hazard, the biggest contributor's percentage actually increases, whereas the second biggest contributor's percentage decreases slightly. The reason for this unusual behavior is that the Elysian Park characteristic event has a magnitude (M) of 6.58 whereas the Puente Hills sources measure M6.87 and M7.05, respectively (averaged over logic tree branches). These larger-magnitude sources at about the same distance as the Elysian Park source produce reduced amplification in the soil column compared to more distant and (or) smaller sources for IP 
response as well as SP response. (The Whittier Narrows M5.9 mainshock of October 1987 ruptured part of the Elysian Park fault.) What takes up the slack as the main contributors decline in importance because of nonlinear damping of spectral response? At this site, more distant sources, such as the Raymond fault, the Puente Hills blind thrust-Santa Fe Springs segment, the Hollywood fault, and others become more important contributors when the soil response is included in the probability integral (equation 1). All of these neighboring faults have comparable activity rates, or recurrence intervals, as the ones listed. Smith and Harmsen (2010) present a new graphical tool that shows the changing relative influence of different sources with increasing ground motion, which at soil sites is caused in large part by nonlinear site response, at least for shorter-period hazard.

The second example of rock versus soil deaggregation corresponds to a site in San Jose, Calif., in the Santa Clara Valley. Like Los Angeles, San Jose has several active Quaternary faults in the immediate vicinity, though not as many as L.A. In contrast to L.A., where much of the hazard is from blind thrusts and other reverse faults, most of the hazard in San Jose is associated with right-lateral strike-slip faults. Less than 2 percent of the hazard comes from the Monte Vista/Shannon reverse fault system. The site is at $37.35^{\circ} \mathrm{N}, 121.9^{\circ} \mathrm{W}$. The Vs30 estimate is 285 $\mathrm{m} / \mathrm{s}$, as in L.A. The three main faults contributing to hazard at San Jose are (1) the HaywardRodgers Creek, (2) the northern San Andreas, and (3) the Calaveras. Figure 10 shows the site and the neighboring hazardous faults. For the purposes of discussion, the figure combines several rupture-model alternatives for each of these: Hayward N+Hayward S and Hayward S for the Hayward, all Calaveras ruptures containing the central segment for the Calaveras, and the most important a priori and moment-balanced models, respectively, for the northern San Andreas fault. These fault models are discussed further in Field and others (2009). Table 2 shows the contributions assuming the site is underlain by class BC rock or class D soil. 


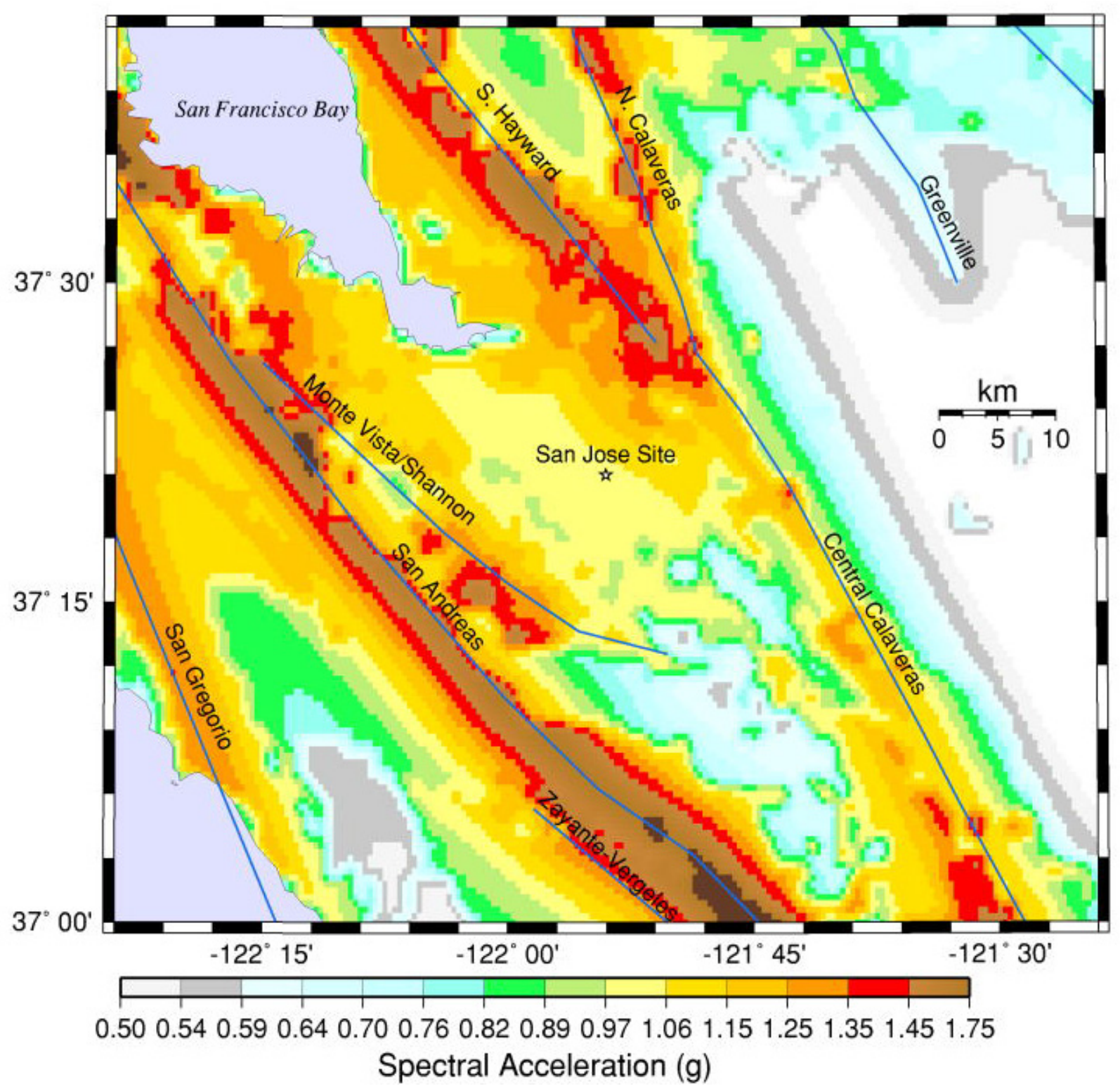

Figure 10. Map showing principal faults in the vicinity of a site in San Jose, California. The contour map shows site-specific 1 -second spectral acceleration (SA) with 2 percent in 50 years probability of exceedance using method 1 to estimate $\mathrm{Vs} 30$. ( $\mathrm{N}$, north; $\mathrm{S}$, south; $\mathrm{km}$, kilometer; $\mathrm{g}$, acceleration of gravity, $\left.9.8 \mathrm{~m} / \mathrm{s}^{2}\right)$ 
Table 2. Seismic hazard at San Jose, California.

$[\mathrm{m} / \mathrm{s}$, meters per second; SA, spectral acceleration; s, second; $g$, acceleration of gravity; SAF, San Andreas fault; avg. $\left(\varepsilon_{o}\right)$, average epsilon; GMPE, ground-motion prediction equation]

\begin{tabular}{lcc}
\hline Site Vs30 $(\mathrm{m} / \mathrm{s})$ & 760 & 285 \\
SA at $0.2 \mathrm{~s}(g)$ & 1.794 & 1.792 \\
Source 1: Hayward & $24.8 \%$ & $24.4 \%$ \\
Source 2: SAF & $9.1 \%$ & $9.0 \%$ \\
Source 3: Calaveras & $24.5 \%$ & $27.2 \%$ \\
Avg $\left(\varepsilon_{\mathrm{o}}\right)$ : all sources, all GMPEs & 1.90 & 1.98 \\
SA at 1.0 s $(g)$ & 0.550 & 1.023 \\
Source 1: Hayward & $24.9 \%$ & $24.7 \%$ \\
Source 2: SAF & $24.6 \%$ & $24.7 \%$ \\
Source 3: Calaveras & $16.1 \%$ & $16.2 \%$ \\
Avg $\left(\varepsilon_{\mathrm{o}}\right)$ : all sources, all GMPEs & 1.81 & 1.83 \\
\hline
\end{tabular}

Table 2 indicates remarkably little change in the primary three faults contributing to hazard at San Jose when explicitly including the local site condition versus using the firm-rock (default) site condition. The contrast with Los Angeles is due to fact that other sources with comparable recurrence intervals are relatively abundant in the vicinity of L.A., but such potential substitutes are uncommon around San Jose. The sameness of the 0.2-s SA for soil and rock at San Jose indicates that the 5-Hz GMPEs predict approximately unity soil amplification for most of the important sources. San Jose's deaggregations also exhibit very little change in the average $\varepsilon_{0}$ between rock and class D soil site condition.

\section{Case 2. Soil Mode Different from Rock Mode}

The degree of soil nonlinear damping is expected to increase as sites approach the rupture for a given Vs30 and other soil column properties presumed to be the same (and uniform source properties, which are not likely in nature). In practice soil properties vary, generally having the lowest Vs30 near estuaries, bays, lakes, rivers and reservoirs and also greatest propensity to liquefy in these low lying regions. The greater expected damping of the seismic signal on softer soils reduces the seismic hazard, but it is frequently associated with high risk from liquefaction, lateral spreading, and other ground damaging phenomena. Culturally speaking, one only needs to remember the extensive damage in the waterfront region of Oakland and San Francisco from the Loma Prieta earthquake - or more recently, damage in Port-au-Prince, Haiti, from the January 2010 mainshock and in Christchurch, South Island, New Zealand, from the September 2010 mainshock - to realize that damping of the high-frequency signal by soft soils such as unengineered fill is more likely to be an indication of troubles to come rather than a benefit to the urban built environment. Similar experience at soft-soil sites from the Northridge earthquake is documented in USGS Open-File Report 96-0263 (Updike, 1996), available on the Web at http://pubs.usgs.gov/of/1996/ofr-96-0263/. That said, this section examines sites where the modal source significantly shifts from one fault or source type to another when explicitly considering the soil column's influence on vibratory ground motion in the hazard integral (equation 1). 
The first example in this section is near San Rafael or Greenbrae, Calif., a site whose seismic hazard is primarily controlled by the San Andreas, Rodgers Creek, and north Hayward fault ruptures. The site is at $37.9375^{\circ} \mathrm{N}, 122.525^{\circ} \mathrm{W}$. The $\mathrm{Vs} 30$ for method 1 is $160 \mathrm{~m} / \mathrm{s}$ at this location. The site's 5-Hz seismic hazard deaggregation, assuming rock for local geology, is shown in figure 11.

In figure 11, the dominant hazard is associated with northern San Andreas fault multisegment ruptures, west of the site, M8.0 $\pm \Delta \mathrm{M}$, where $\Delta \mathrm{M}$ is uncertainty in characteristic-event magnitude. Secondary hazard is associated with Rodgers Creek and North Hayward fault segments, east of the site, M7.0 $\pm \Delta \mathrm{M}$. Because of the nearness of the north SAF to this site, relatively large nonlinear soil damping is expected in the soft soil column. Because of the greater distance and lower magnitude of the Rodgers Creek and North Hayward ruptures, less nonlinear signal damping is expected in the soft soil column from these sources. This result is confirmed in figure 12, which exhibits the SH deaggregation at the same site but assumes a $180-\mathrm{m} / \mathrm{s}$ Vs 30 , or soft soil site condition (Vs30 lower limit for the above-mentioned deaggregation online tool is $180 \mathrm{~m} / \mathrm{s}$, which is at the NEHRP class D/E boundary [soft soil]). 


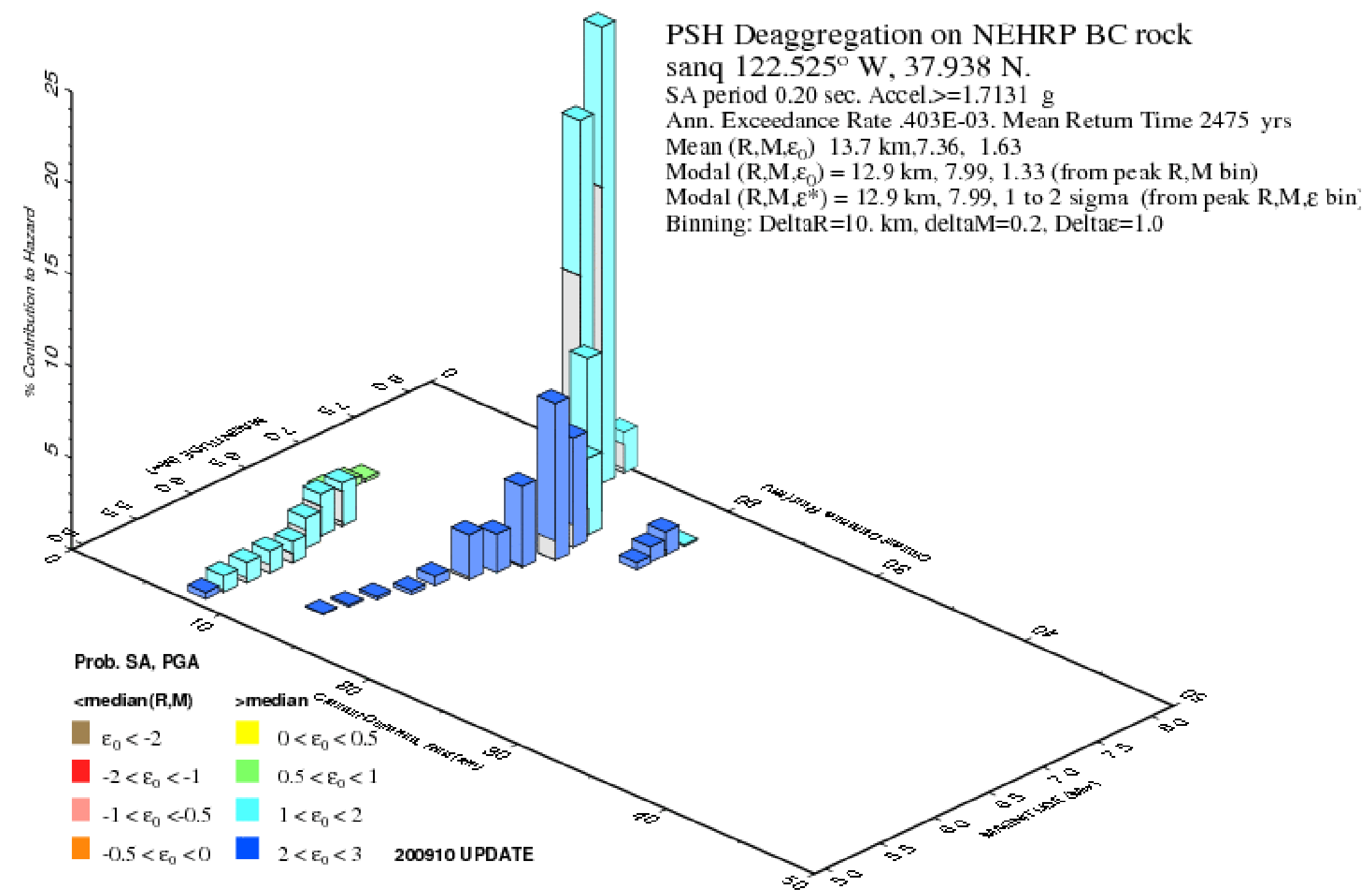

Figure 11. Rock-site hazard near San Rafael (and San Quentin prison): 5-hertz (Hz) spectral acceleration (SA) with 2 percent in 50 years probability of exceedance (PE) for a site with Vs30 of 760 meters per second $(\mathrm{m} / \mathrm{s})$. 


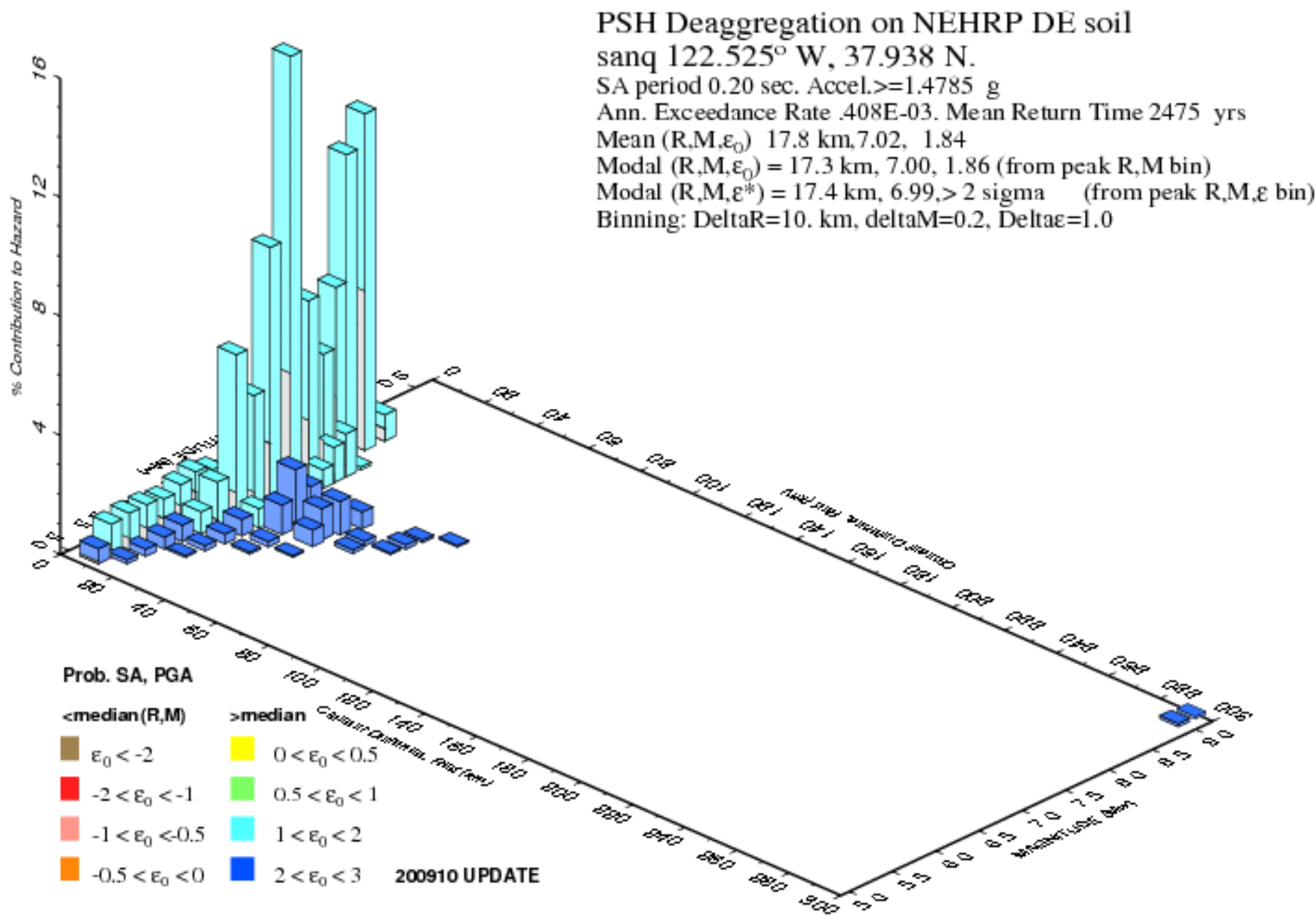

Figure 12. Soil-site hazard near San Rafael: 5 -hertz $(\mathrm{Hz})$ spectral acceleration $(\mathrm{SA})$ with 2 percent in 50 years probability of exceedance (PE) for a site with Vs30 of 180 meters per second $(\mathrm{m} / \mathrm{s})$. 
A comparison of figures 11 and 12 shows a clear shift in the tallest magnitude/distance bin from a northern San Andreas fault source of about M8.0 (rock-site modal-source) to a Rodgers Creek fault source of about M7.0 (soil-site modal-source). The very distant Cascadia subduction megathrust source is also visible in figure 12 but is comparatively unimportant at this site. When determining sources to use as inputs to software for seismic analysis of buildings and other structures, the initial reaction from examining figure 12 might be to select the M7.0 source. If soil liquefaction is a potential issue at this site, the San Andreas scenarios may be more likely to produce extensive liquefaction and lateral spreading than the Hayward/Rodgers Creek scenarios because of a longer duration of strong shaking. Thus, other criteria besides height of deaggregated-source columns may often provide important supplementary information in comprehensive hazard assessments at many soil sites. For intermediate- to long-period hazard, the soil deaggregation (M,R,percent) distribution is quite similar to the rock deaggregation, with the SAF clearly dominating the hazard in all such instances.

While several California cities are located between active Quaternary faults, few cities exhibit the balance-of-hazard shifts as dramatic as that illustrated in the above example near San Rafael. A more well-known city which exhibits a SP modal-source shift is Seattle, Wash. Downtown Seattle and South Seattle have many soft-sediment sites near the Puget Sound waterfront, at which infrastructure and commercial building damage was extensive in the Nisqually earthquake of 2002 and the Seattle earthquake of 1965. Many of these sites are near the en echelon Seattle faults, which are south dipping reverse faults. The relatively high annual frequency of the Puget Sound intraplate mainshocks suggests that they may be modal-event sources, but their uncertain locations (they are background sources, not associated with any known faults) and their relatively great depth (about $50 \mathrm{~km}$ ) suggest that they may not be important when stacked up against the Seattle fault. The next figures (figs. 13-14) show the 5-Hz hazard for a site on Harbor Island, a major port facility for Seattle and the Pacific Northwest. The $180-\mathrm{m} / \mathrm{s}$ Vs30 value (fig. 14) is for illustration only. In practice, the actual site Vs30 may be larger or smaller and will be affected by soil remediation efforts. 


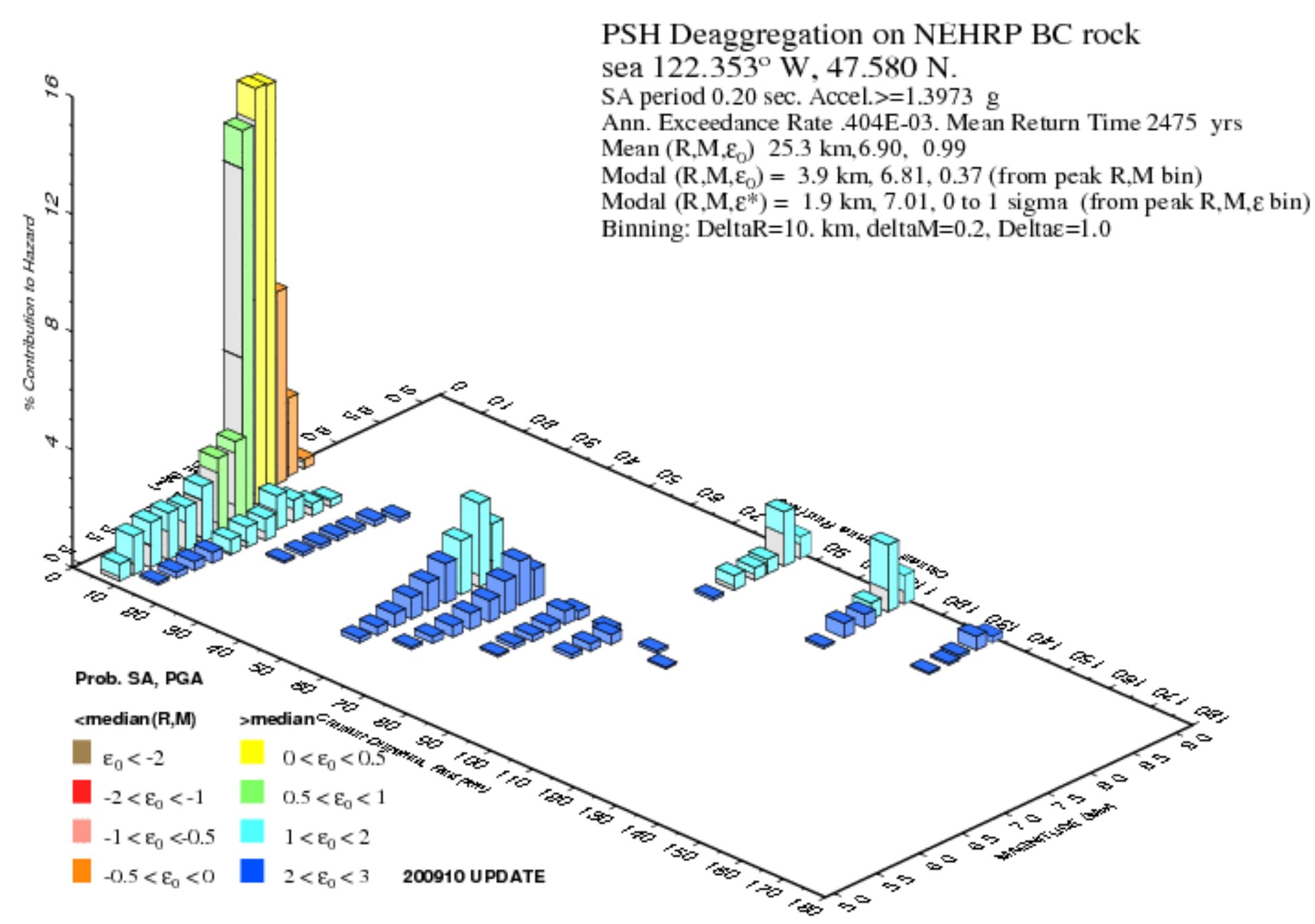

Figure 13. Harbor Island 5-hertz hazard deaggregation assuming rock site condition. 


\section{PSH Deaggregation on NEHRP DE soil}

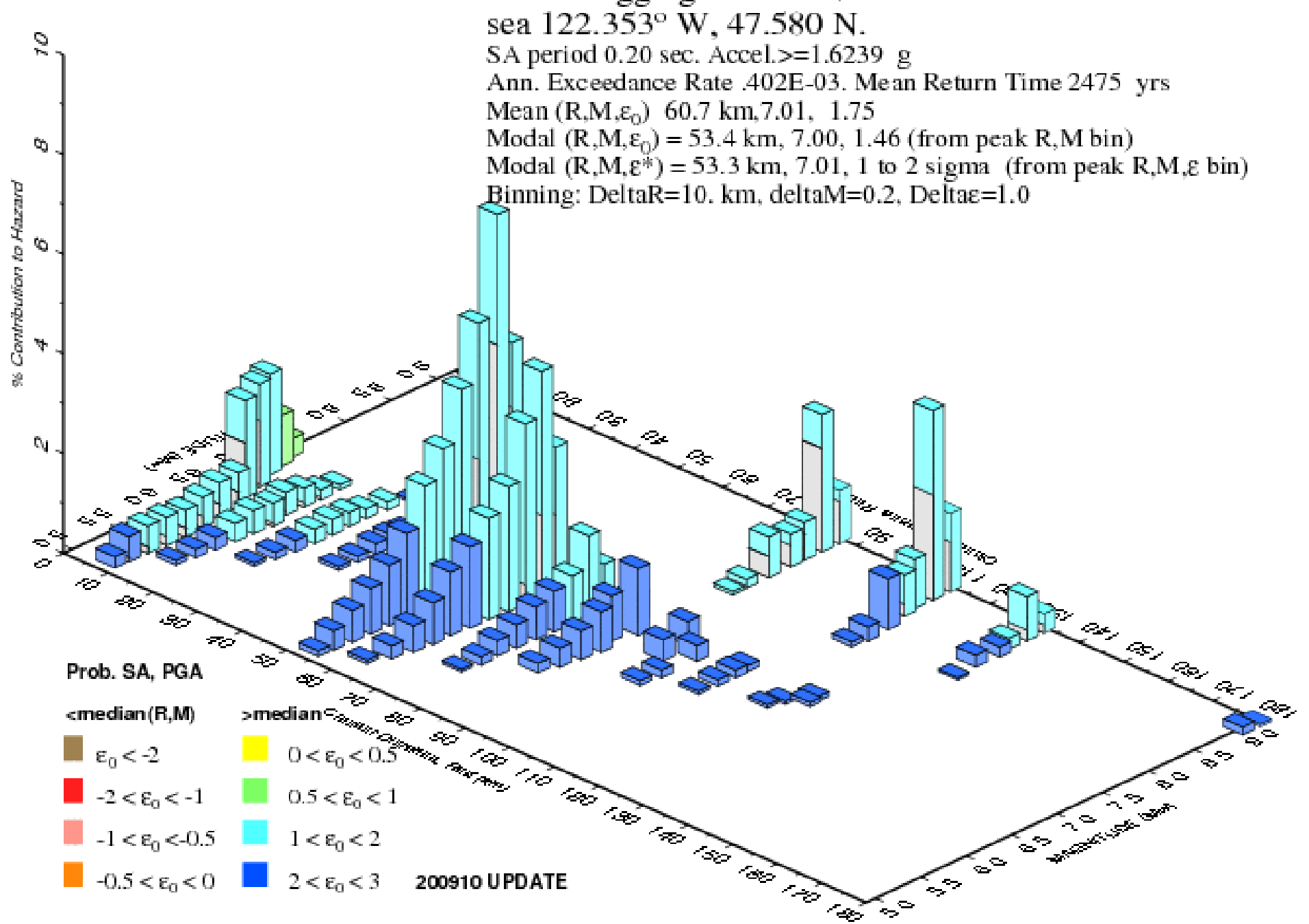

Figure 14. Harbor Island 5-hertz hazard deaggregation assuming 180 meters per second Vs30 (relatively soft) soil site condition. 
Figures 13 and 14 indicate a shift in modal-event distance from less than $5 \mathrm{~km}$ (Seattle fault) to more than $50 \mathrm{~km}$ (deep intraplate background seismicity) when explicitly considering the effect of the soil column on the 5-Hz vibratory intensity; also note the increasing contribution from Cascadia subduction in figure $14(\mathrm{M} 9$ at $\mathrm{R}>80 \mathrm{~km})$. The above example shows that the probabilistic 5-Hz SA on soil, $1.62 \mathrm{~g}$, is greater than the corresponding value on rock, $1.40 \mathrm{~g}$. The reduction of median motion from the very nearby Seattle fault compared to increases in the medians for the more distant deep and interplate sources and the reduction in aleatory $\sigma$ (on average) associated with Seattle fault motion as it might be recorded on soil versus rock are the driving causes of this large change in the distribution of SP hazard at Harbor Island. Groundmotion prediction equations associated with intraplate earthquakes do not have reduced soil $\sigma$, and this feature is a factor that may bias the probabilistic hazard towards intraplate and interface earthquakes.

Figures 15 and 16 show the corresponding rock and soil deaggregations at Harbor Island for the 1-s SA. The effect of less amplification of the IP signal from nearby relatively large sources in the soil column compared to that at rock outcrops means that for this site the Seattle fault will have a reduced hazard contribution (mode participation factor), while the soil condition at Harbor Island is explicitly included in the hazard integral (equation 1). Figure 16 shows two modal events, one for the tallest bin in R and $\mathrm{M}$ and the other for the tallest bin in $\mathrm{R}, \mathrm{M}$, and $\varepsilon$. The $\left(\mathrm{R}, \mathrm{M}, \varepsilon^{*}\right)$ mode corresponds to a Cascadia subduction event, whereas the $(\mathrm{R}, \mathrm{M})$ mode corresponds to a Seattle fault source. For the 1-s spectral period, the intraplate source is of reduced importance whether the Seattle site is rock or soil. While Seattle has been repeatedly subjected to strong ground motion from intraplate events, it has not experienced significant shaking from either Cascadia or Seattle fault sources; thus, the PSHA model and its deaggregation are based on heavily extrapolated information. 
PSH Deaggregation on NEHRP BC rock

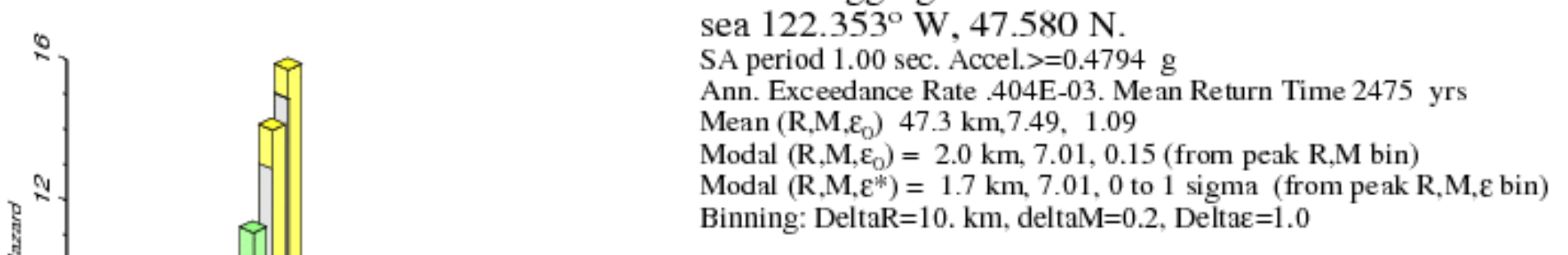

sea $122.353^{\circ} \mathrm{W}, 47.580 \mathrm{~N}$.

SA period $1.00 \mathrm{sec}$. Accel. $>=0.4794 \mathrm{~g}$

Modal $\left(\mathrm{R}, \mathrm{M}, \varepsilon_{0}\right)=2.0 \mathrm{~km}, 7.01,0.15$ (from peak R,M bin)

Binning: DeltaR $=10 . \mathrm{km}$, deltaM=0.2, Delta $\varepsilon=1.0$

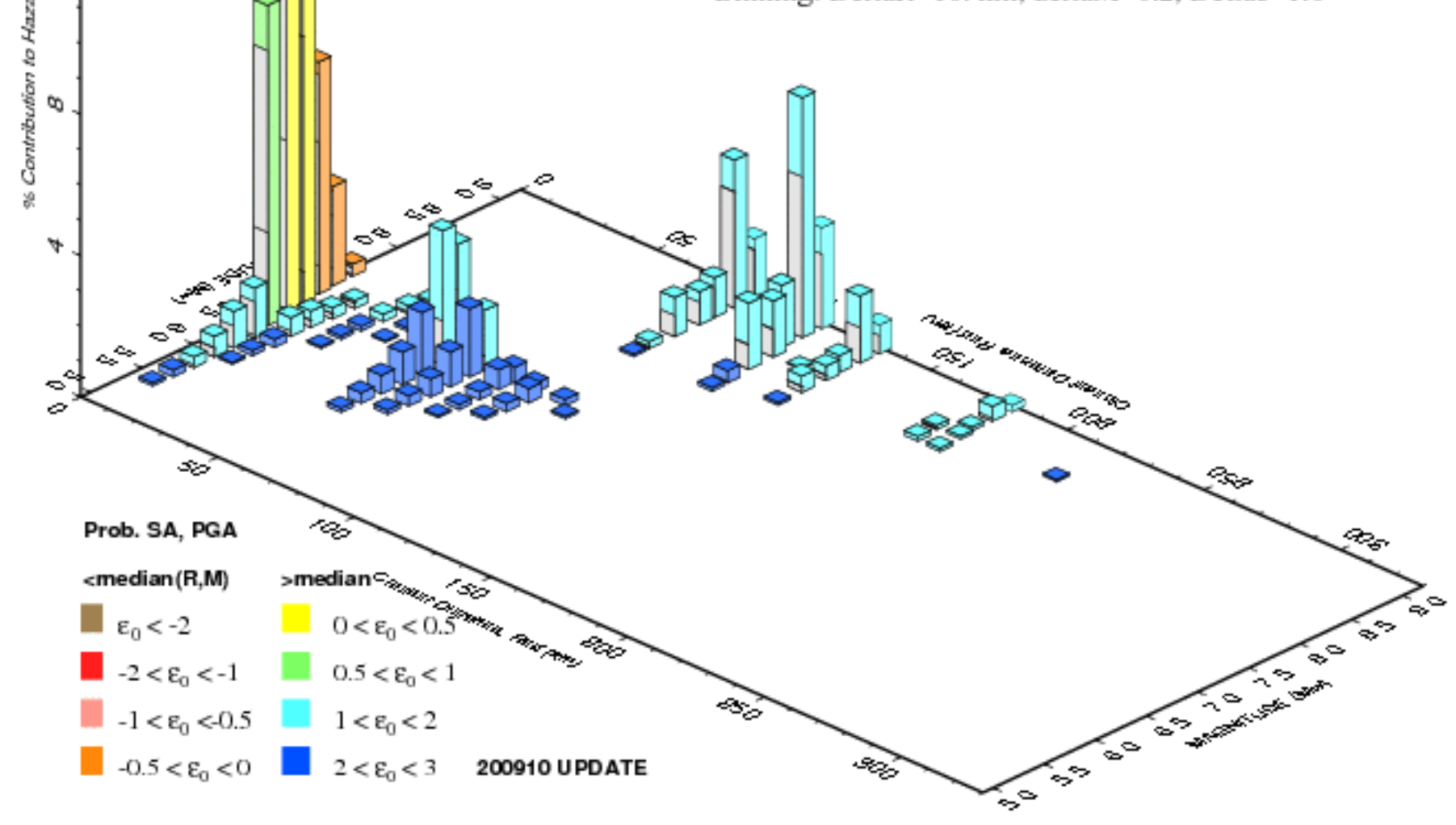

Figure 15. Harbor Island 1-second spectral acceleration assuming rock site condition. Seattle fault sources dominate the hazard. Cascadia sources are second in importance, deep intraplate are third. 


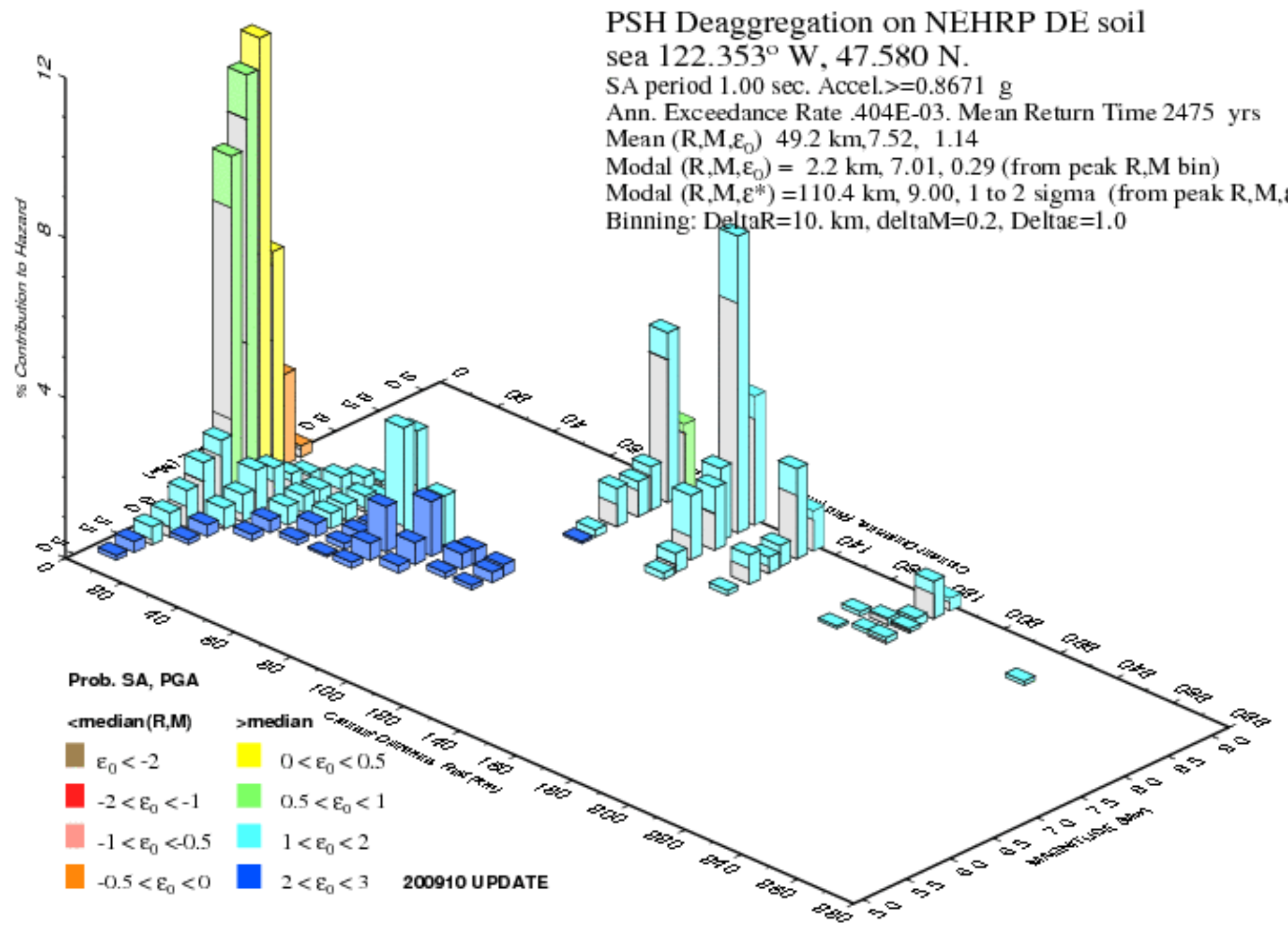

Figure 16. Harbor Island 1-second spectral acceleration assuming soil site condition. National Earthquake Hazards Reduction Program (NEHRP) DE soil is soil with Vs30 of $180 \mathrm{~m} / \mathrm{s}$, at the NEHRP boundary between D- and E- soils. Seattle fault sources dominate the hazard in distance and magnitude. Cascadia interface sources remain secondary but are closer in their total hazard contribution, and are dominant when considering distance, magnitude, and epsilon bins. 


\section{Caveats and Model Limits}

Regional mapping of Vs30 using various techniques can yield substantially different results, none of which are guaranteed to be close to the true site-specific Vs30. This section of the report compares estimates from the above three methods with measurements of Vs30 at several sites. Measured Vs30 data are from Gibbs and others (2000), Kayen and others (2005), and Louie (2005). The first uses borehole travel time measurements, the second uses spectral analysis of surface waves (SASW) methods (see http://walrus.wr.usgs.gov/geotech/methods.html), and the third uses refraction microtremor ("ReMi") methods. Table 3 presents results for more than a dozen sites shown in figures $3 B$ and $6 B$. These examples show that taking the median or average or any statistic from a set of biased estimates does not necessarily improve the estimate. The expectation is that Cretaceous granites (Kgr) and Franciscan mélange (KJf) will be relatively fast compared to most other geologic units in western California; however, reality may not always conform to expectation and, when it does, it is still unknown how much faster they are. The use of the real variable Vs30 in sitespecific PSHA rather than broad class variables such as NEHRP site class adds the responsibility to estimate Vs30 well. (However, how does one measure how well Vs30 is estimated? Within 10 percent? 20 percent?)

Table 3 shows some near blatant misses in Vs30 estimation. At almost co-located sites in Long Beach, both borehole and ReMi measurements were made, and the model Vs values are within the range of these measurements. In the case of a high Vs30 at Thousand Oaks (TOV), a thin layer of Quaternary alluvium, which seems to drive the model estimates, is underlain by fast Mesozoic rock. In the case of the a Vs30 at Fort Tejon, one might speculate that repeated major earthquakes such as the 1857 mainshock may have fractured the surficial rock significantly, lowering Vs30 from that which would be expected in a tectonically quieter environment. The same argument might be applied to the Filoli Visitor Center, very close to a part of the San Andreas fault that ruptured during the 1906 mainshock. A second speculation is that the Carbon Canyon Dam Vs30 estimates may be improved by sampling the topography and geology in the vicinity at a finer scale than that available when preparing this report (May 2010). Sampling Vs30 and other Earth-surface variables at $250 \mathrm{~m}$ instead of $1 \mathrm{~km}$ or $0.01^{\circ}$ has been suggested as a possible strategy to better capture small-scale site-response variability in urban environments. Except for the cost, this suggestion makes equal sense in rural environments. An added concern is that different field techniques for estimating Vs30 are known to yield sometimes substantially different results, for example, ReMi analysis compared to ROSRINE (Resolution of site response issues from the Northridge Earthquake) borehole analysis (Louie, 2007), although ReMi Vs30 generally is within 20 percent of the more expensive borehole value. In table 3, Vs30 estimates are sometimes interpolated from the nearest two samples. 
Table 3. Comparison of Vs30 values "measured" by one of three methods (borehole, spectral analysis of surface waves, or refraction microtremor) and Vs30 values from three regional model values (Wills and Clahan, 2006; Wald and Allen, 2007; Yong and others, in press), in meters per second.

[NEHRP, National Earthquake Hazard Reduction Program; OSI, Osito Audit-Castaic Lake Dam; LA, Los Angeles; E., east; LBW2, Long Beach Water Reclamation Plant 2; WTP, Long Beach Water Treatment Plant; LLS, Ellis; KJf, Franciscan mélange Cretaceous; Kgr, Cretaceous granite; Qal, Quaternary alluvium; Qoa, Older Quaternary alluvium; Qya, Younger Quaternary alluvium]

\begin{tabular}{lllllllll}
\hline \multicolumn{1}{c}{ Site } & Lat. & Long. & $\begin{array}{c}\text { Vs30 } \\
\text { measured }\end{array}$ & $\begin{array}{c}\text { Vs30 } \\
\text { Wills }\end{array}$ & $\begin{array}{c}\text { Vs30 } \\
\text { Wald }\end{array}$ & $\begin{array}{c}\text { Vs30 } \\
\text { Yong }\end{array}$ & $\begin{array}{c}\text { Geologic } \\
\text { unit }\end{array}$ & $\begin{array}{c}\text { NEHRP } \\
\text { site } \\
\text { class }\end{array}$ \\
\hline Filoli Visitor Center, & 37.468 & -122.308 & 240 & 470 & 470 & 490 & KJf & D- \\
Woodside & 34.87 & -118.90 & 314 & 760 & 727 & 532 & Kgr & D+ \\
Fort Tejon & 34.613 & -118.725 & 424 & 437 & 436 & 524 & & C- \\
OSI & 33.708 & -116.717 & 902 & 653 & 630 & 528 & Kgr & B- \\
Idyllwild & 34.157 & -118.821 & 884 & 397 & 470 & 455 & Qal, thin & B- \\
Thousand Oaks (TOV) & 33.912 & -117.838 & 235 & 457 & 457 & 424 & Qal, thin & D- \\
Carbon Canyon Dam & 34.089 & -118.435 & 255 & 354 & 520 & 464 & Qoa & D- \\
LA Faring Rd (LAFR) & 34.037 & -118.178 & 348 & 368 & 361 & 372 & & D+ \\
Obregon Park (OBG) & 34.160 & -118.533 & 256 & 399 & 416 & 437 & Qal, thin & D- \\
Tarzana (TAR) & 34.064 & -117.289 & 250 & 310 & 307 & 370 & Qya & D- \\
Colton Interchange E., (COE) & 33.799 & -118.088 & 279 & 241 & 246 & 246 & Qal & D \\
Long Beach LBW2 & 33.798 & -118.088 & 225 & 241 & 246 & 246 & Qal & D \\
Long Beach WTP & 33.687 & -117.943 & 220 & 262 & 261 & 275 & Qal & D- \\
Fountain Valley LLS & 33.872 & -117.923 & 306 & 323 & 324 & 327 & & D+ \\
Fullerton (FUL) & 35.042 & -118.377 & 320 & 530 & 607 & n/a & $?$ & D+ \\
Mojave Oak Creek Canyon & & & & & & & & \\
\hline
\end{tabular}


While Vs30 (or perhaps a finer grained category variable such as NEHRP site class with steps within class, as in the above table) is an important element in the characterization of the local site condition, knowledge of several other variables is required to perform a reasonably comprehensive site-specific hazard analysis. A second potentially important but here neglected consideration is layering in the sediment stack under the site, which produces shear-wave resonance at narrow bandwidth periods. For example, borehole analysis at the Tarzana (TAR) site in table 3 indicates a sharp S-velocity increase at $13 \mathrm{~m}$ depth. The average Vs in the top $13 \mathrm{~m}$ is about $180 \mathrm{~m} / \mathrm{s}$ (Gibbs and others, 2000), implying a wavelength of $54 \mathrm{~m}$ for 0.3 -s body waves. Quarter-wavelength theory predicts that $0.3 \mathrm{~s}$ may be a resonant period for $\mathrm{S}$ waves at the Tarzana site, and spectral analysis of strong-motion seismograms from the Northridge and Whittier Narrows mainshocks demonstrates that periods in the neighborhood of $0.3 \mathrm{~s}$ are strongly amplified at TAR. (Other factors have also been considered. Analyzing TAR's seismic behavior was a cottage industry following the Northridge mainshock.) When one or more soil-column resonant periods match structure resonant periods, the building must withstand an above-average shaking intensity.

A third important consideration is the effect of deep sedimentary basins on the seismic wave field. Basin fill, geometry, and relative location affects interaction with source properties such as focal depth, radiation pattern, and source directivity. Such effects are quantified in scenario studies, such as in southern California (Day and others, 2008) and in central California (Harmsen and others, 2008). Site-response models, such as those embedded in the NGA equations, frequently focus on the vertically propagating shear wave (one-dimensional analysis) and do not necessarily capture important basin-related amplification features that are observed in three-dimensional simulations and in many strong-motion records.

A fourth consideration is topographic amplification, which can increase risk to structures on ridges and hilltops in spite of relatively high Vs30 at many such sites. Topographic amplification of the seismic signal has been studied in several theoretical reports and in several empirical data reports, such as McCrink and others (2010). Procedures for inserting a defensible model of topographic amplification into NSHMP seismic-hazard codes probably could be developed by convening a workshop of experts.

Intermediate- to long-period site response may better correlate with Vs100 or Vs200 (the average shear-wave velocity in the top 100 to $200 \mathrm{~m}$ of the sedimentary basin, respectively) than with Vs30. As is frequently observed (for example, Louie and Scott, 2009), at intermediate to long periods, Vs30 works as well as it does as a predictor variable because of its correlation with Vs100 or Vs200. The correlation of Vs30 and Vs30 is not discussed, however, for the strongmotion data used in the NGA regressions (Chiou and others, 2008). Figure 17 illustrates the correlation of Vs100 with Vs30 at 50 sites in southern California, based on refraction microtremor data from Louie (2005). Places where the correlation may break down include alluvial valleys around intermittent streams that drain the Sierra Nevada Mountains, such as the ones visible in figures 3 and 5. Slow sediment thickness is expected to be quite limited in these high-erosion-rate environments. Here, the long-period signal is probably not much amplified by the shallow sediments around the streams. In figure 17, data labeled " $\mathrm{A}$ " are suggestive of sites where some short-period site amplification may not imply significant LP site amplification (Vs100 $>>$ Vs30). Whether there are at-risk long-period structures in such valleys needs to be determined before potential Vs30-model bias at those locations may be important from a risk perspective. 
The importance of deep-basin features to seismic hazard, such as depth of hard rock with $\mathrm{Vs}=2,500 \mathrm{~m} / \mathrm{s}$ or so and the nature of the sediment column above that depth, is generally underappreciated by the current generation of NGA and other GMPEs used in PSHA. One way in which apparent model sensitivity is in actuality absent is the depth to relatively hard rock with Vs of $1 \mathrm{~km} / \mathrm{s}$, or Z1, according to the Chiou and Youngs (2008) relation. Assuming that the site Vs30 is $200 \mathrm{~m} / \mathrm{s}$ (soft soil) and using the default depth of $Z 1=336.2 \mathrm{~m}$ that CY08 suggests instead of a much shallower $\mathrm{Z} 1$ of $50 \mathrm{~m}$, as might be more realistic in the western foothills of the Sierra Nevada Mountains, results in differences in estimated median 3-s ground motion from a M7 earthquake of less 0.1 percent, at all source-to-site distances. This miniscule difference in the CY08 model, versus what may be a first-order site-effect difference in reality, indicates that NGA models LP site-response features may benefit from further revision. The figures of this report would not be visibly altered if more realistic $\mathrm{Z1}$ values had been available and used in the two study regions

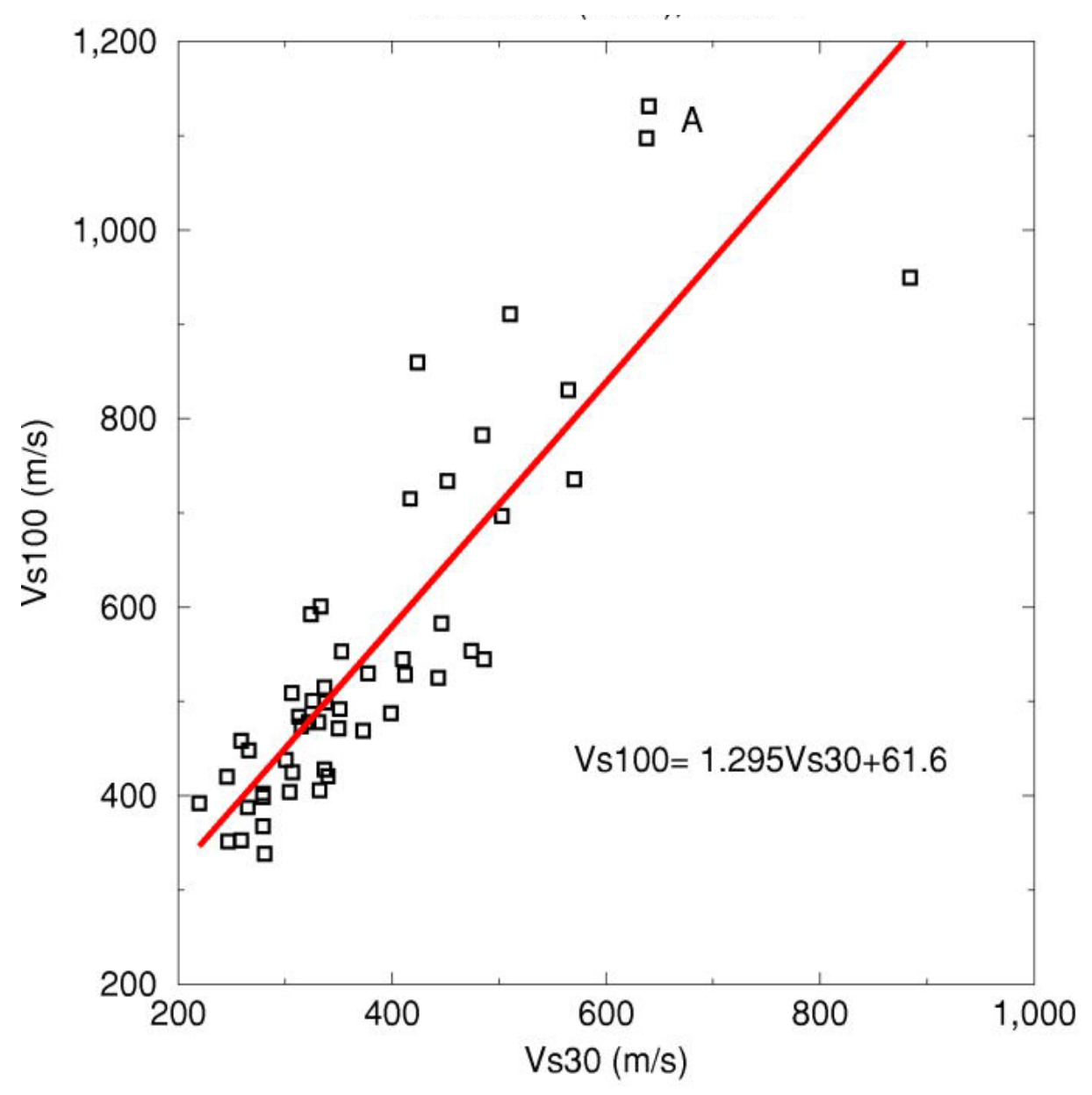

Figure 17. Scattergram of Vs100 versus Vs30 at or near 50 southern California strong-motion sites (from Louie, 2005, table 1). A standard linear regression is plotted in red $(\rho=0.859)$. Data labeled A probably correspond to thin layer of soil underlain by rock with relatively high shear-wave velocity. $(\mathrm{m} / \mathrm{s}$, meters per second; Vs30, average shear-wave velocity in top $30 \mathrm{~m}$; Vs100, average shear-wave velocity in top $100 \mathrm{~m})$ 
Site-response models contained in the NGA equations were developed mostly from data and simulations based on soil response in western California; they are average or generic models. Because of the many simplifications of the NGA GMPE site-response models, the "site-specific" label needs to be taken with a grain of salt. The minimum Vs30 where the NGA equations are believed to be valid is about $180 \mathrm{~m} / \mathrm{s}$, or soil at the NEHRP class D/E boundary. For the calculations presented in this report, sites with Vs30<180 m/s were revised to $180 \mathrm{~m} / \mathrm{s}$. Soil liquefaction and lateral spreading effects are not predicted by NGA site-response models.

True site-specific hazard analysis has other potentially important differences from regional hazard analysis such as is performed by NSHMP. Anderson and Brune (1999) point out that the uncertainty in ground motion at a single site is estimated from the scatter in data for a variety of sites having a range of Vs30 and other physical properties. Many of these data are likely to be unrepresentative of the motion that may be expected at a specific site, even when sites are restricted to a limited range of Vs30. For example, Tarzana's high recorded ground motion from several southern California mainshocks may be unrepresentative at other soil sites with different shallow Vs gradients. If and when better site- and path-specific data are available, the total aleatory sigma, $\sigma_{\mathrm{T}}$, associated with specific sites should decrease substantially, perhaps 20 to 25 percent, as suggested by John Anderson (Univ. of Nevada at Reno, 2010, written commun.). A reduction of 25 percent in $\sigma_{\mathrm{T}}$ can easily map into more than 15 percent reduction in probabilistic motion at the 2 percent in 50-year PE.

\section{Discussion and Conclusions}

Site-specific hazard mapping and deaggregation, using recently developed NGA equations for predicting ground motion, provide new perspective and potential realism to the assessment of seismic hazard compared to the ubiquitously available corresponding products for the bedrock site condition, that is, rock with Vs30=760 m/s (for example, Petersen and others, 2008). At short periods, and for relatively large probabilistic (or deterministic) ground motion, the soil column significantly deamplifies the expected ground motion, according to NGA models employed in the 2008 NSHMP hazard analysis. That probabilistic motion in many instances remains the same or goes down as NEHRP site class goes up $(B \rightarrow C \rightarrow D \rightarrow D E)$ is apparent in the $\mathrm{T}=0.2$-s results presented here and in other periods (see http://earthquake.usgs.gov/hazards/products/conterminous/2008/update_201001/). This result is at odds with portions of the BSSC site response tables (for example, Building Seismic Safety Council, 1997) and may be the most important finding of this investigation. (However, this conclusion is not new; see Trifunac and Todorovska, 1998). For LP response, the standard view that probabilistic motion increases inversely with Vs30 is of course upheld, but only under the assumption that shallow sediment properties such as low rigidity continue to much greater depth. At some locations, abrupt and sustained increases in rock rigidity with depth result in low LP site amplification, regardless of Vs30. Regional mapping of Vs100 or Vs200 is suggested to identify locations where LP response is not well predicted using Vs30.

The aleatory scatter associated with repeated occurrences is believed to be significantly less than the scatter at rock sites for a given PSHA source model (Abrahamson and Silva, 2007). At long periods, the expected amplification of spectral acceleration in the soil column is not much affected by strength of input motion, although the scatter may continue to be less than that at corresponding rock sites. In California and in some urban sedimentary basins elsewhere, several competing models of regional Vs30 are available; most are sampled at about $1 \mathrm{~km}^{2}$. They have significant differences. Where multiple regional estimates for Vs30 are available, it would 
be helpful to develop consensus Vs30 models. Increasing the spatial sampling in urban areas to about $250-\mathrm{m}$ squares also makes sense because $0.01^{\circ}$ squares are not adequate to capture important variations. Hazard mapping at the 250-m scale is currently being done in Japan's metropolitan areas (Wakamatsu and others, 2006). Even finer-scale geology is mapped in some urban areas, such as Oakland/Alameda Island, and some applications may require even finer sampling than $250 \mathrm{~m}$ to sample known soil hazards (Holzer and others, 2005).

As a general rule, the modal event, at least as determined in the deaggregation of 2 percent in 50-year ground motions, tends to be reasonably stable as a function of Vs30, although its contribution diminishes at sites over softer soils compared to firmer soils and bedrock. A few exceptional sites - where the modal event shifts from a nearby, relatively large earthquake to a more distant, perhaps smaller earthquake and when the local site condition is explicitly included in the hazard integral - are known, although many remain to be discovered. Site-specific case studies, such as those discussed in this report, may be important to consider as engineers design buildings and bridges to withstand scenario earthquakes.

The USGS and some State geological surveys are developing and improving State-wide Vs30 maps, or at least urban sedimentary basin Vs30 maps, and similar site-specific hazard products to allow computations of site-specific hazard maps and curves, such as is now routinely done in California. These site-specific probabilistic motions could ultimately replace the NEHRP soil amplification factors currently used in building design and retrofit codes. In California, continued interest in site amplification and its relation to Vs30 have resulted in additional studies, among them Wills and Gutierrez (2009), that find that small changes in sedimentary basin slope may be a helpful predictor of Quaternary alluvium Vs.

\section{Acknowledgments}

Rui Chen, of the California Geological Survey, provided the data file corresponding to the Wills version of Vs30 for the state of California. Alan Yong, of USGS Pasadena, provided his version of Vs30 for the two study regions. Maps were produced from the Generic Mapping Tools 3.4.3, Wessel and Smith (1991). Several NGA team members provided critical help implementing their models, with special thanks to Brian Chiou and Ken Campbell. Insightful reviews by Mark Petersen, Daniel Garcia, David Perkins, and David Wald (all with the USGS) improved the manuscript.

\section{References}

Abrahamson, Norman, and Silva, Walter, 2007, Abrahamson and Silva NGA ground motion relations for the geometric mean horizontal component of peak and spectral ground motion parameters: Pacific Earthquake Engineering Research Center, draft report.

Abrahamson, Norman, and Silva, Walter, 2008, Summary of the Abrahamson and Silva NGA ground-motion relations: Earthquake Spectra v. 24, p. 67-97.

Anderson, J.G., and Brune, J.N., 1999, Probabilistic seismic hazard analysis without the ergodic assumption: Seismological Research Letters, v. 70, p. 19-28.

Bazzurro, Paolo, and Cornell, C. Allin, 2004, Nonlinear soil-site effects in probabilistic seismichazard analysis: Bulletin of the Seismological Society of America, v. 94, p. 2110-2123.

Boore, D.M., and Atkinson, G.M., 2008, Ground-motion prediction equations for the average horizontal component of PGA, PGV, and 5\%-damped PSA at spectral periods between $0.01 \mathrm{~s}$ and 10.0 s: Earthquake Spectra, v. 24, p. 99-138. 
Boore, D.M., Joyner, W.B., and Fumal, T.E., 1997, Equations for estimating horizontal response spectra and peak acceleration from western North American earthquakes-A summary of recent work: Seismological Research Letters, v. 68, p. 128-153.

Branum, D., Harmsen, S., Kalkan, E., Petersen, M., and Wills, C., 2008, Earthquake shaking potential for California: California Geological Survey, Map Sheet 48 (revision).

Building Seismic Safety Council, 1997, NEHRP recommended provisions for seismic regulations for new buildings and other structures (1997 ed.)-Part 1. Provisions: Washington, D.C., Building Seismic Safety Council.

Campbell, K.W., and Bozorgnia, Yousef, 2008, NGA ground motion models for the geometric mean horizontal component of PGA, PGV, PGD, and 5\% damped linear elastic response spectra for perids ranging from $0.01 \mathrm{~s}$ to $10 \mathrm{~s}$ : Earthquake Spectra, v. 24, p. 139-171.

Chin, B.H., and Aki, K., 1991, Simultaneous study of the source, path, and site effects on strong ground motion during the 1989 Loma Prieta earthquake - A preliminary result on pervasive nonlinear site effects: Bulletin of the Seismological Society of America, v. 81, p. 1859-1884.

Chiou, Brian, Darragh, Robert, Gregor, Nick, and Silva, Walter, 2008, NGA project strongmotion database: Earthquake Spectra, v. 24, p. 23-44.

Chiou, B.S.-J., and Youngs, R.R., 2008, An NGA model for the average horizontal component of peak ground motion and response spectra: Earthquake Spectra, v. 24, p. 173-215.

Choi, Yoojoong, and Stuart, J.P., 2005, Nonlinear site amplification as function of $30 \mathrm{~m}$ shear wave velocity: Earthquake Spectra, v. 21, p. 1-30.

Darragh, R.B., and Idriss, I.M., 1997, A tale of two sites - Gilroy \#2 and Treasure Island. Site response using an equivalent-linear technique: Earthquake Engineering Research Institute, 1997 NEHRP Professional Fellowship Report.

Day, Steven, Graves, Robert, Bielak, Jacobo, Dreger, Douglas, Larsen, Shawn, Olsen, Kim, Pitarka, Arben, and Ramirez-Guzman, Leonardo, 2008, Model for basin effects on long-period response spectra in southern California: Earthquake Spectra, v. 24, p. 257-278.

Fialco, Yuri, 2006, Interseismic strain accumulation and the earthquake potential on the southern San Andreas fault system: Nature, v. 441, p. 968-971.

Field, E.H., Dawson, T.E., Felzer, K.R., Frankel, A.D., Gupta, V., Jordan, T.H., Parsons, T., Petersen, M.D., Stein, R.S., Weldon, R.J., II, and Wills, C.J., 2009, Uniform California Earthquake Rupture Forecast, version 2 (UCERF 2): Bulletin of the Seismological Society of America, v. 99, p. 2053-2107.

Gibbs, J.F., Tinsley, J.C., Boore, D.M., and Joyner, W.B., 2000, Borehole velocity measurements and geological conditions at thirteen sites in the Los Angeles, California region: U.S. Geological Survey Open-File Report 00-470, 118 p.

Hanks, T.C., and Brady, Gerald, 1991, The Loma Prieta earthquake, ground motion, and damage in Oakland, Treasure Island, and San Francisco: Bulletin of the Seismological Society of America, v. 81, p. 2019-2047.

Harmsen, Stephen, Hartzell, Stephen, and Liu, P.-C., 2008, Simulated ground motion in Santa Clara Valley, California, and vicinity from $M \geq 6.7$ scenario earthquakes: Bulletin of the Seismological Society of America, v. 98, p.1243-1271.

Holzer, Tom, Padovani, A., Bennett, M., Noce, T., and Tinsley, J., 2005, Mapping NEHRP Vs30 site classes: Earthquake Spectra, v. 21, p. 353-370.

Kalkan, Erol, Wills, C.J., and Branum, D.M., 2010, Seismic hazard mapping of California considering site effects: Earthquake Spectra, v. 26, p. 1039-1055. 
Kayen, Robert, Thompson, Eric, Minasian, Diane, and Carkin, Brad, 2005, Shear-wave velocity of the ground near sixty California strong-motion recording sites by the spectral analysis of surface waves (SASW) method and harmonic-wave sources: U.S. Geological Survey OpenFile Report 2005-1366, 132 p. (also available at http://pubs.usgs.gov/of/2005/1366/).

Louie, J.N., 2005, Improving next-generation attenuation models with shear-velocity measurements at all TriNet and Strong-Motion stations in LA: Final Technical Report to the Board of Regents of the Nevada System of Higher Education, USGS External Grant Award Number 05HQGR0078, 43 p.

Louie, J.N., 2007, Shear-wave velocity map for California-Collaborative research with CGS and UNR: Final Technical Report to the Board of Regents of the Nevada System of Higher Education, USGS External Grant Award Number 07HQGR0029, 98 p.

Louie, J.N., and Scott, J.B., 2009, Passive shallow seismic experiments using IRIS/PASSCAL facilities: Incorporated Research Institutions for Seismology, http://www.iris.edu/hq/gallery/photo/4804.

McCrink, T.P., Wills, C.J., Real, C.R., and Manson, M.W., 2010, Effects of topographic position and geology on shaking damage to residential wood-framed structures during the 2003 San Simeon earthquake, western San Luis Obispo County, California: Earthquake Spectra, v. 26, p. 779-802.

McGuire, Robin, 2004, Seismic hazard and risk analysis: Oakland, Calif., Earthquake Engineering Research Institute, $221 \mathrm{p}$.

Petersen, M.D., Frankel, A.D., Harmsen, S.C., Mueller, C.S., Haller, K.M., Wheeler, R.L., Wesson, R.L., Zeng, Yuehua, Boyd, O.S., Perkins, D.M., Luco, Nicolas, Field, E.H., Wills, C.J., and Rukstales, K.S., 2008, Documentation for the 2008 update of the United States National Seismic Hazard Maps: U.S. Geological Survey Open-File Report 2008-1128, 61 p. (also available at http://pubs.usgs.gov/of/2008/1128/).

Power, Maurice, Chiou, Brian, Abrahamson, Norman, Bozorgnia, Yousef, Shantz, Thomas, and Roblee, Clifford, 2008, An overview of the NGA project: Earthquake Spectra, v. 24, p. 3-22.

Sadigh, K. , Chang, C.-Y., Egan, J.A., Makdisi, F., and Youngs, R., 1997, Attenuation relationships for shallow crustal earthquakes based on California strong-motion data: Seismological Research Letters, v. 68, p. 180-189.

Smith, W.D., and Harmsen, S.C., 2010, Displaying seismic deaggregation-The importance of the various sources: Seismological Research Letters, v. 81, p. 488-497.

Trifunac, M.D., and Todorovska, M.I., 1998, Nonlinear soil response as a natural passive isolation mechanism-The 1994 Northridge, California, earthquake: Soil Dynamics and Earthquake Engineering, v. 17, p. 41-51.

Updike, R.G., 1996, USGS response to an urban earthquake-Northridge '94: U.S. Geological Survey Open-File Report 96-263 [variously paged] (available at http://pubs.usgs.gov/of/1996/ofr-96-0263/).

Wakamatsu, K., Matsuoka, M., and Hasegawa, K., 2006, GIS-based nationwide hazard zoning using the Japan engineering geomorphologic classification map, in U.S. National Conference on Earthquake Engineering, 8, San Francisco, Calif., April 18-22, 2006, Proceedings: Earthquake Engineering Research Institute, paper no. 849.

Wald, David, and Allen, Trevor, 2007, Topographic slope as a proxy for seismic site conditions and amplification: Bulletin of the Seismological Society of America, v. 97, p. 1379-1395.

Walling, Melanie, Silva, Walter, and Abrahamson, N.A., 2008, Non-linear site amplification factors for constraining the NGA models: Earthquake Spectra, v. 24, p. 243-255. 
Weldon, R.J., II, Biasi, G.P., Wills, C.J., and Dawson, T.E., 2008, Overview of the Southern San Andreas Fault Model, appendix E of 2007 Working Group on California Earthquake Probabilities, eds., The uniform California earthquake rupture forecast, version 2 (UCERF 2): U.S. Geological Survey Open-File Report 2007-1437E, California Geological Survey Special Report 203E, 85 p. (also available at http://pubs.usgs.gov/of/2007/1437/e/).

Wessel, Paul, and Smith, W.H.F., 1991, Free software helps map and display data: EOS, Transactions, American Geophysical Union, v. 72, p. 441.

Wills, C.J., and Clahan, L.B., 2006, Developing a map of geologically defined site-condition catagories for California: Bulletin of the Seismological Society of America, v. 96, no. 4A, p. $1483-1501$.

Wills, C.J., and Gutierrez, C., 2009, Investigation of geographic rules for improving siteconditions mapping: U.S. Geological Survey Open-File Report 2009-1298, 217 p. (also available at http://pubs.usgs.gov/of/2009/1298).

Yong, Alan, Hough, S.E., Iwahashi, J., and Braverman, A., in press, A terrain-based site characterization map of California with implications for the contiguous United States: Bulletin of the Seismological Society of America

Youngs, R.R., Chiou, S.-J., Silva, W.J., and Humphrey, J.R., 1997, Strong ground motion attenuation relationships for subduction zone earthquakes: Seismological Research Letters, v. 68 , p. 58-73. 